\title{
Synthetic, Non-Saccharide Glycosaminoglycan Mimetics Selectively Target Colon Cancer Stem Cells
}

Nirmita J. Patel ${ }^{\sharp, 1}$, Rajesh Karuturi ${ }^{\sharp, 2}$, Rami A. Al-Horani ${ }^{\sharp, 2}$, Somesh Baranwal ${ }^{1,3}$, Jagrut Patel1, Umesh R. Desai $i^{*}$ and Bhaumik B. Patel ${ }^{1,3^{*}}$

${ }^{1}$ Hunter Holmes McGuire VA Medical Center, Richmond, VA 23249, ${ }^{2}$ Department of Medicinal Chemistry and Institute for Structural Biology and Drug Discovery, Virginia Commonwealth University, Richmond, VA 23219, and ${ }^{3}$ Massey Cancer Center, Virginia Commonwealth University, Richmond, VA 23298

Correspondence: Dr. Bhaumik B. Patel, Hunter Holmes McGuire VA Medical Center, 1201 Broad Rock Blvd. 5A-124, Richmond, VA 23249. Phone (804) 675-5000 Ext. 4309; Email: bpatel2@mcvhvcu.edu. Dr. Umesh R. Desai, 800 East Leigh Street, Suite 212, Richmond, VA 23219. Phone (804) 828-7328; Email: urdesai@vcu.edu

\section{Supplementary Material}

Section

Page \#

Figure S1. Chemical structures of GAG mimetics G1-G9

Figure S2. Chemical structures of GAG mimetics G10-G12

Experimental methods: Synthetic chemistry

Scheme S1.Synthesis of sulfated 5,5-O-flavonoid dimers G2.1-G2.6

Scheme S2. Synthesis of sulfated 3', 3'-O-flavonoid dimers G3.1-G3.2

Scheme S3. Synthesis of sulfated 3', 5-O-flavonoid trimers G4.1-G4.2

Experimental procedures for Schemes S1, S2, and S3

Scheme S4. Structures and synthesis of side chains of G11 and G12

Scheme S5. Synthesis of penta-substituted glycosides

Scheme S6. Synthesis of tetra and tri-substituted glycosides

Scheme S7. Synthesis of di-substituted glycosides

Scheme S8. Structures and synthesis of sulfated inositols 
Figure S3. Flow cytometric analysis for LGR5 expression in HT-29 colon cancer cells grown as monolayer and spheroid.

Figure S4. Primary screening studies with 53 NSGMs belonging to 12 structurally distinct scaffolds.

Figure S5. Dose response profile of G2.2 treatment on the growth in spheroid and monolayer conditions.

Figure S6. Effect of $100 \mu \mathrm{M}$ G2.2 on primary spheroid growth in additional cancer cell lines. S30

Figure S7. Flow cytometric analysis of DCKL-1. 
$\underbrace{\mathrm{O}_{3} \mathrm{SO}}_{5}$

G1.1: 3, 5, 7, 3', 4' - pentasulfate G1.2: $3,5,7,2^{\prime}, 4^{\prime}$ - pentasulfate

G1.4: $5,7,3^{\prime}, 4^{\prime}$ - tetrasulfate

G1.5: $3,7,3^{\prime}$ - trisulfate

G1.7: $6,4^{\prime}$ - disulfate

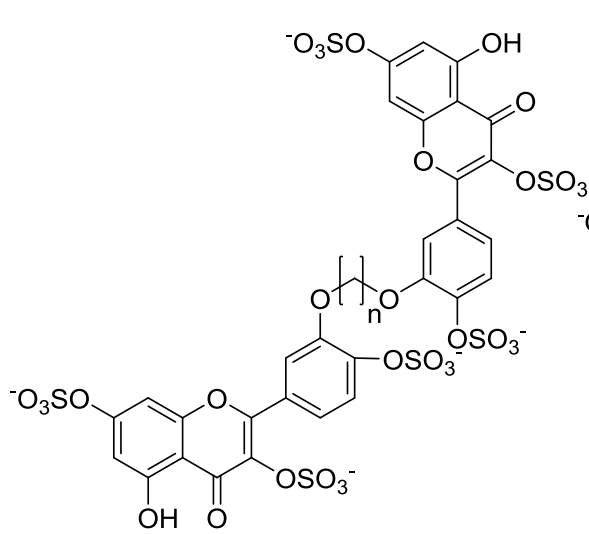

G3.1: $\mathrm{n}=3$

G3.2: trans 2 butene

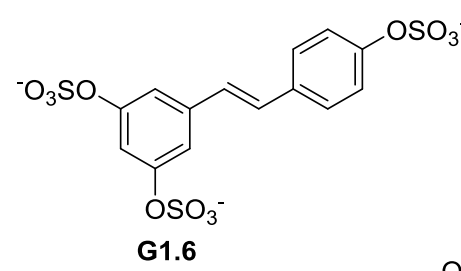

G1.6

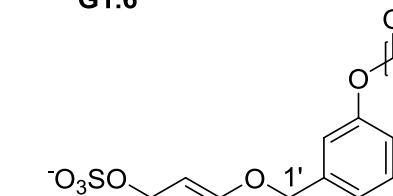

$-\mathrm{O}_{3} \mathrm{SO}$

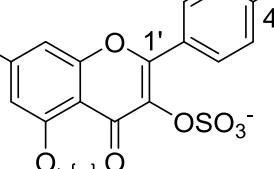

$\mathrm{SO}_{3}$<smiles>O=[W]</smiles>

$\mathrm{OSO}_{3}$

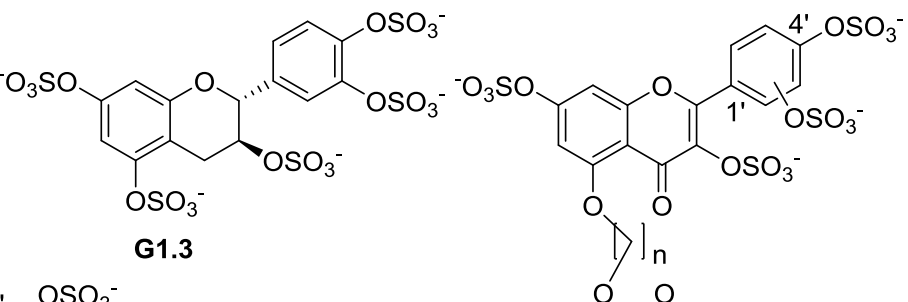

G1.3

$\mathrm{OSO}_{3}^{-}$ $4^{\prime} \mathrm{OSO}_{3}^{-}$

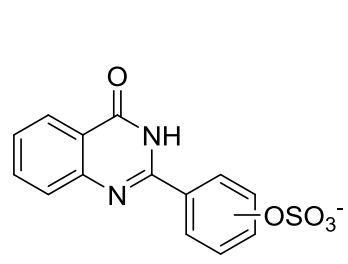

G5.1: 2, 4- $\mathrm{OSO}_{3}^{-}$ G5.2: $2,4,6-\mathrm{OSO}_{3}^{-}$

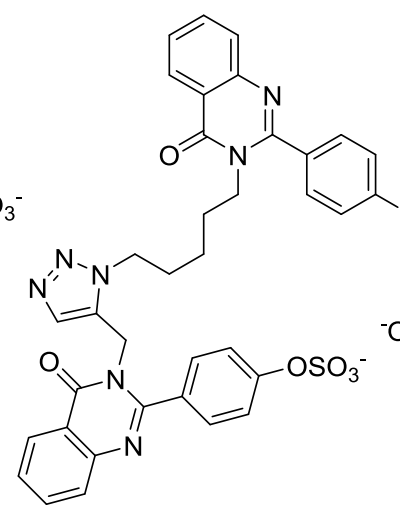

G8.1

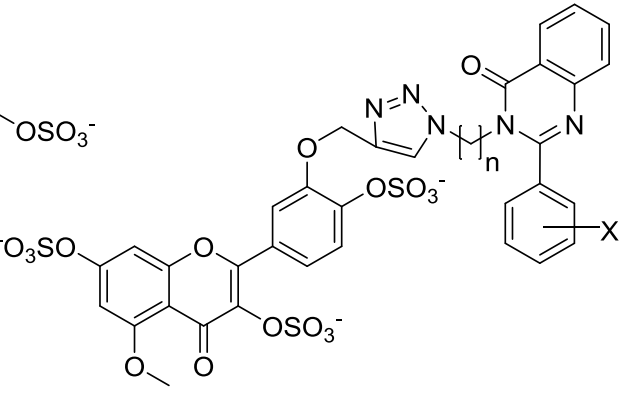

G9.1: $\mathrm{X}=3-\mathrm{OSO}_{3}^{-}, \mathrm{n}=4$

G9.2: $X=3-\mathrm{OAc}, 5-\mathrm{OSO}_{3}{ }^{-}, \mathrm{n}=4$

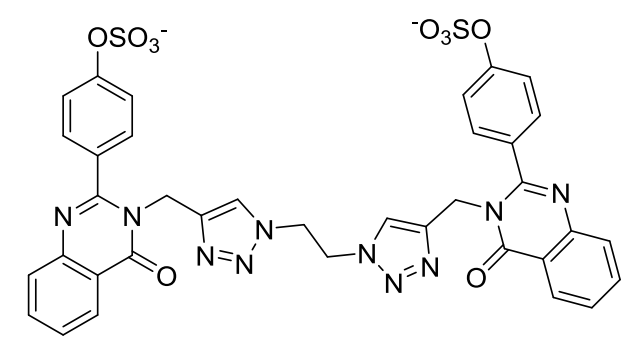

G7.1

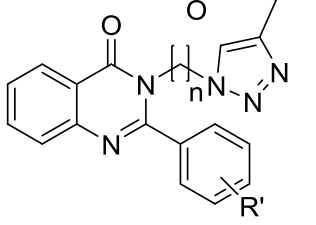

G6.1: $\mathrm{R}=3-\mathrm{OAc}, \mathrm{R}^{\prime}=3-\mathrm{OSO}_{3}^{-}, \mathrm{n}=4$

G6.2: $\mathrm{R}=3-\mathrm{OSO}_{3}{ }^{-}, \mathrm{R}^{\prime}=3-\mathrm{OSO}_{3}{ }^{-}, \mathrm{n}=3$

G6.3: R = 4- $-\mathrm{OSO}_{3}{ }^{-}, \mathrm{R}^{\prime}=3-\mathrm{OSO}_{3}{ }^{-}, \mathrm{n}=4$

G6.4: $\mathrm{R}=3-\mathrm{OSO}_{3}^{-}, \mathrm{R}^{\prime}=4-\mathrm{OSO}_{3}^{-}, \mathrm{n}=4$

G6.5: R $=3-\mathrm{OSO}_{3}{ }^{-}, \mathrm{R}^{\prime}=3-\mathrm{OSO}_{3}{ }^{-}, \mathrm{n}=4$

G6.6: $\mathrm{R}=4-\mathrm{OSO}_{3}^{-}, \mathrm{R}^{\prime}=4-\mathrm{OSO}_{3}^{-}, \mathrm{n}=5$

G6.7: $\mathrm{R}=4-\mathrm{OSO}_{3}{ }^{-}, \mathrm{R}^{\prime}=4-\mathrm{OSO}_{3}{ }^{-}, \mathrm{n}=6$

G6.8: $\mathrm{R}=3-\mathrm{OSO}_{3}^{-}, \mathrm{R}^{\prime}=3-\mathrm{OMe}^{-} 4-\mathrm{OSO}_{3}^{-}, \mathrm{n}=4$

G6.9 : R = 3-- $\mathrm{OSO}_{3}^{-}, 5-\mathrm{OSO}_{3}^{-}, \mathrm{R}^{\prime}=3-\mathrm{OSO}_{3}^{-}, \mathrm{n}=4$

G6.10: R = 3-OAc, 5- $-\mathrm{OSO}_{3}{ }^{-}, \mathrm{R}^{\prime}=3-\mathrm{OSO}_{3}{ }^{-}, \mathrm{n}=4$

G6.11: R = 3- $\mathrm{OSO}_{3}{ }^{-}, 5-\mathrm{OSO}_{3}{ }^{-}, \mathrm{R}^{\prime}=3-\mathrm{OSO}_{3}{ }^{-}, 5-\mathrm{OSO}_{3}{ }^{-} \mathrm{n}=4$

Figure S1. Structures of NSGMs belonging to the G1-G9 scaffolds. 


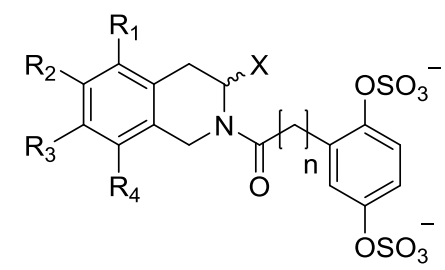

G10.1: $R_{1}=R_{4}=-H, R_{2}=R_{3}=-O_{3}{ }_{3}^{-}, n=1, X=-H$ G10.2: $R_{1}=R_{4}=-H, R_{2}=R_{3}=-O_{3}{ }^{-}, n=1, X=-C^{-}$ G10.3: $R_{1}=R_{4}=-H, R_{2}=R_{3}=-\mathrm{OSO}_{3}{ }^{-}, n=2, X=-\mathrm{COO}^{-}$ G10.4: $R_{1}=R_{4}=-H, R_{2}=R_{3}=-O_{3}{ }^{-}, n=3, X=-C^{-}$ G10.5: $\mathrm{R}_{1}=\mathrm{R}_{4}=-\mathrm{OSO}_{3}{ }^{-}, \mathrm{R}_{2}=\mathrm{R}_{3}=-\mathrm{H}, \mathrm{n}=1, \mathrm{X}=-\mathrm{COO}$ G10.6: $R_{1}=R_{4}=-\mathrm{OSO}_{3}^{-}, R_{2}=R_{3}=-H, n=2, X=-\mathrm{COO}^{-}$ G10.7: $R_{1}=R_{4}=-\mathrm{OSO}_{3}^{-}, R_{2}=R_{3}=-H, n=3, X=-C^{-}$ G10.8: $R_{1}=R_{2}=-O_{3} O_{3}^{-}, R_{3}=R_{4}=-H, n=3, X=-H$

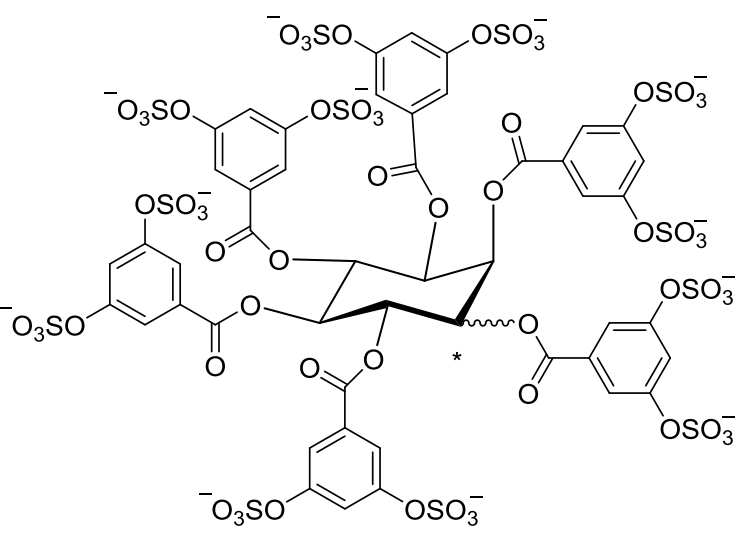

G12.1: *equatorial substituent

G12.2: *axial substituent

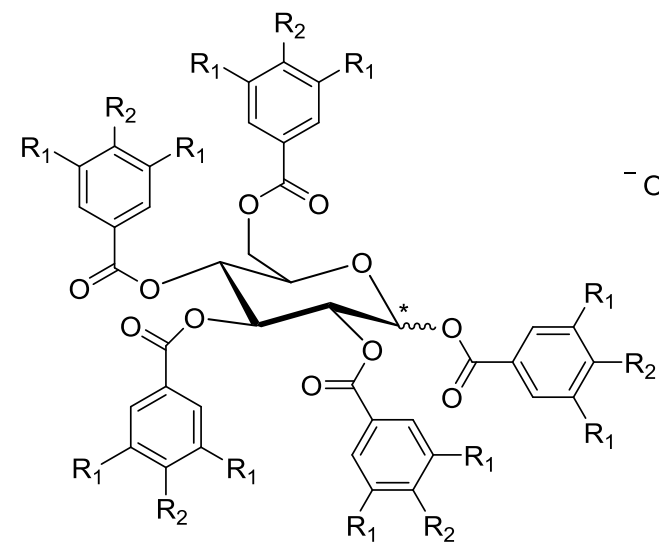

G11.1: $\mathrm{R}_{1}=-\mathrm{OSO}_{3}{ }^{-}, \mathrm{R}_{2}=-\mathrm{OSO}_{3}{ }^{-}$or $-\mathrm{H},{ }^{*}=$ beta isomer G11.2: $\mathrm{R} 1=-\mathrm{OSO}_{3}{ }^{-}, \mathrm{R}_{2}=-\mathrm{H},{ }^{*}=$ alpha \& beta isomers G11.3: $\mathrm{R} 1=-\mathrm{H}, \mathrm{R}_{2}=-\mathrm{OSO}_{3}{ }^{-},{ }^{*}=$ alpha \& beta isomers G11.4: R1 $=-\mathrm{H}, \mathrm{R}_{2}=-\mathrm{COO}^{-},{ }^{*}=$ alpha \& beta isomers

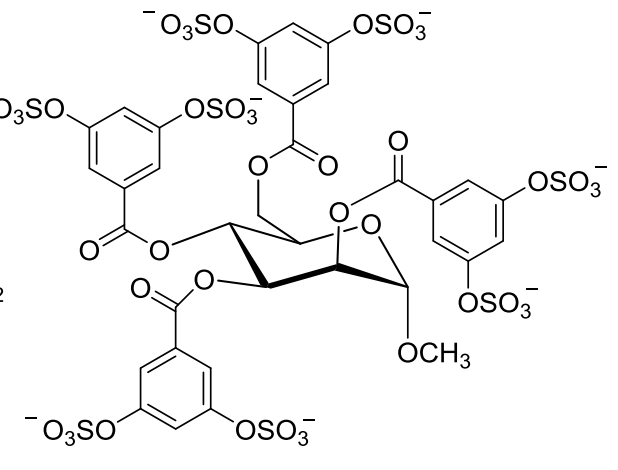

G11.5
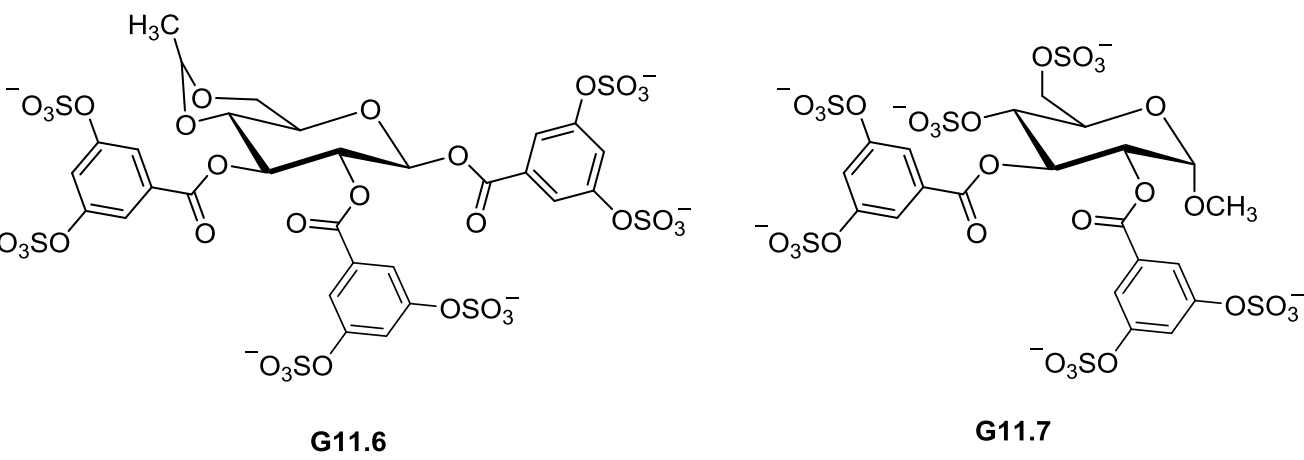

G11.7

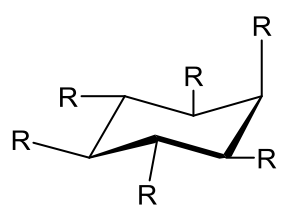

G12.3: $\mathrm{R}=-\mathrm{OSO}_{3}$

G12.4: $\mathrm{R}=-\mathrm{OPO}^{-2}$

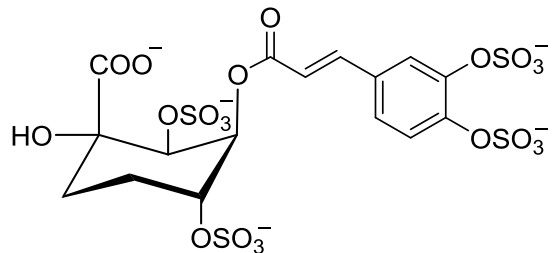

G12.5

Figure S2. Structures of NSGMs belonging to the G10-G12 scaffolds. 

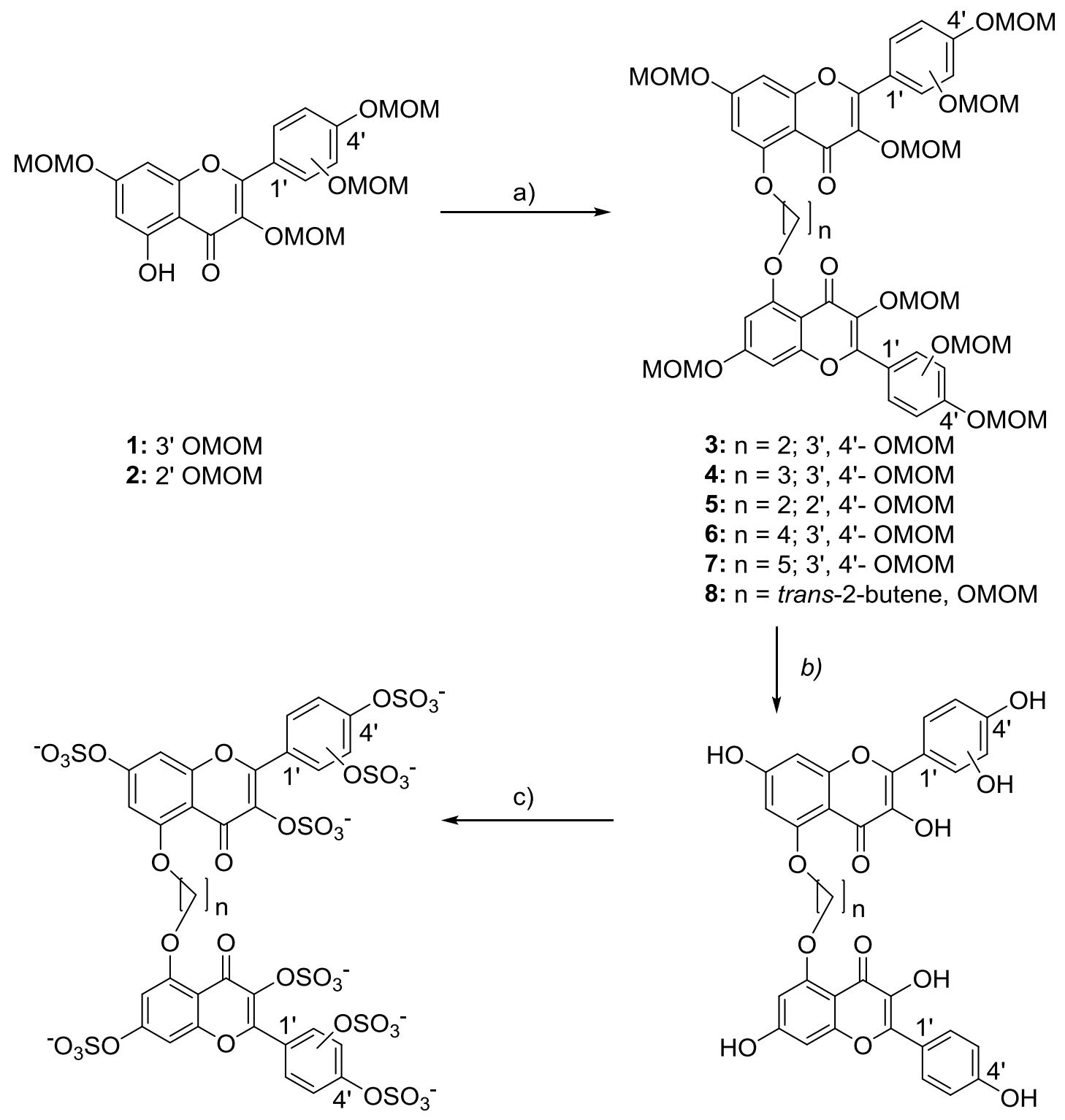

G2.1: $\mathrm{n}=2 ; 3^{\prime}-\mathrm{OSO}_{3}^{-}$

3a: $\mathrm{n}=2 ; 3^{\prime}-\mathrm{OH}$

G2.2: $\mathrm{n}=3 ; 3^{\prime}-\mathrm{OSO}_{3}^{-}$

4a: $n=3 ; 3 '-O H$

G2.3: $\mathrm{n}=2 ; 2^{\prime}-\mathrm{OSO}_{3}^{-}$

5a: $\mathrm{n}=2 ; 2 \mathrm{-OH}$

G2.4: $\mathrm{n}=4 ; 3^{\prime}-\mathrm{OSO}_{3}^{-}$

6a: $\mathrm{n}=4 ; 3$ '- OH

G2.5: $\mathrm{n}=5 ; 3^{\prime}-\mathrm{OSO}_{3}^{-}$

7a: $n=5 ; 3$ '- OH

G2.6: $\mathrm{n}=$ trans-2-butene, $3^{\prime}-\mathrm{OSO}_{3}^{-}$

8a: $n=$ trans-2-butene, $3^{\prime}-\mathrm{OH}$

Scheme S1. Synthesis of sulfated 5,5-O-flavonoid dimers G2.1-G2.6: a) $\mathrm{K}_{2} \mathrm{CO}_{3}$, dibromoalkane ( 0.5 equiv), DMF, $\mathrm{rt} / 6 \mathrm{~h}, 85-90 \%$, b) $p$-toluenesulfonic acid, $\mathrm{MeOH}$, reflux/48 h, 55-65\%, c) $\mathrm{SO}_{3}: \mathrm{Me}_{3} \mathrm{~N}, \mathrm{Et}_{3} \mathrm{~N}, \mathrm{CH}_{3} \mathrm{CN}$, microwave/6 h, 75$85 \%$. 
<smiles>COc1cc(O)c2c(=O)c(OC)c(-c3ccc(OC)c(O)c3)oc2c1</smiles>

9

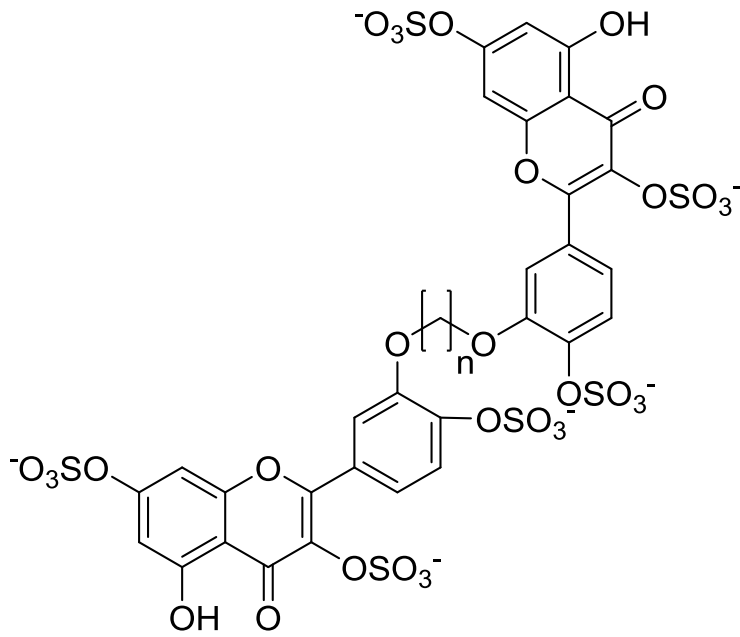

G3.1: $n=3$

G3.2: trans 2 butene

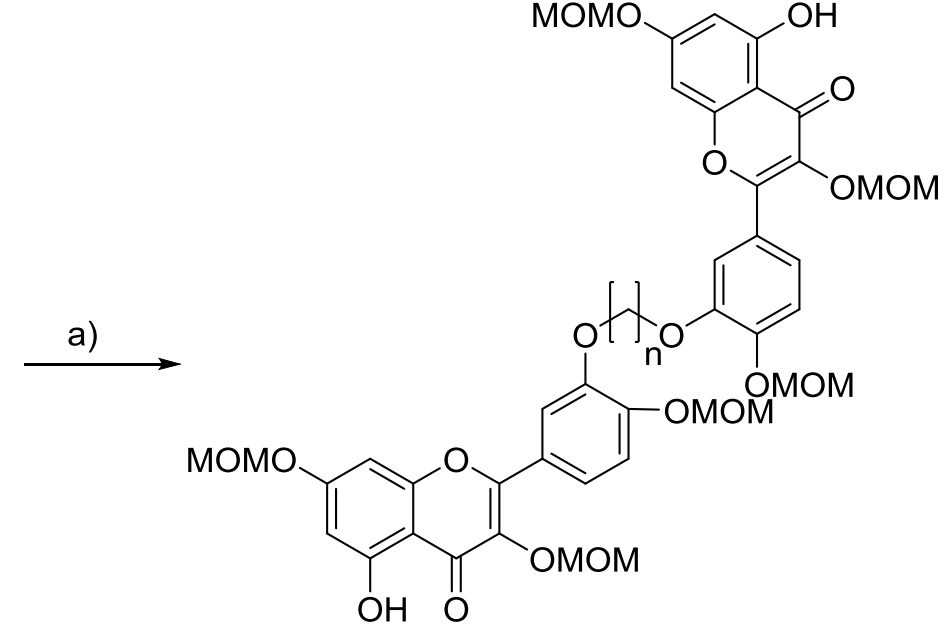

10: $\mathrm{n}=3$

11: trans 2 butene

b)<smiles>COc1cc(-c2oc3cc(O)cc(O)c3c(=O)c2O)ccc1OCC(C)Oc1cc(-c2oc3cc(O)cc(O)c3c(=O)c2O)ccc1O</smiles>

10a: $n=3$

11a: trans 2 butene

Scheme S2. Synthesis of sulfated 3', 3'-O-flavonoid dimers G3.1-G3.2: a) $\mathrm{K}_{2} \mathrm{CO}_{3}$, dibromoalkane ( 0.5 equiv), DMF, rt/3 h, 85-90\%, b) $p$-toluenesulfonic acid, $\mathrm{MeOH}$, reflux/48 h, 55-65\%, c) $\mathrm{SO}_{3}: \mathrm{Me}_{3} \mathrm{~N}, \mathrm{Et}_{3} \mathrm{~N}, \mathrm{CH}_{3} \mathrm{CN}$, microwave/6 h, 75$85 \%$. 
<smiles>COc1cc(O)c2c(=O)c(OC)c(-c3ccc(OC)c(OC)c3)oc2c1</smiles>

1

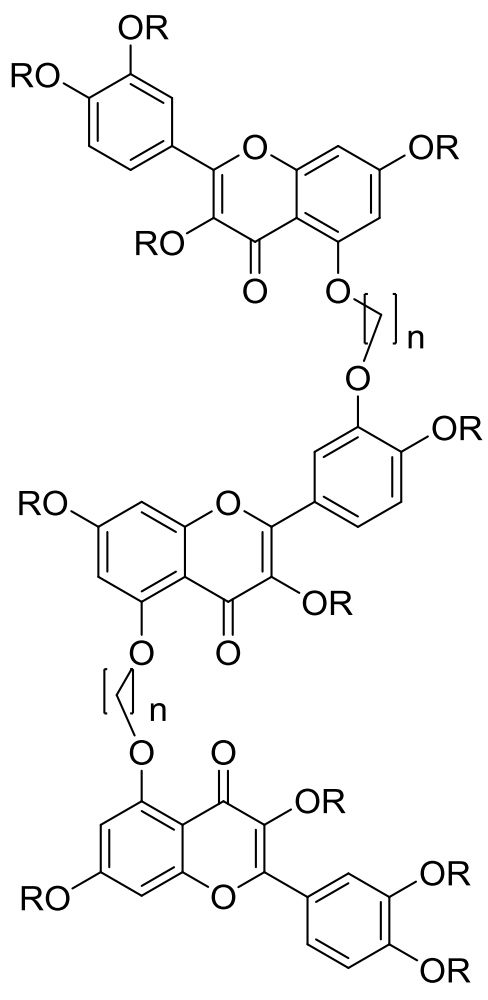

14: $\mathrm{n}=2, \mathrm{R}=\mathrm{OMOM}$ 15: $\mathrm{n}=3, \mathrm{R}=\mathrm{OMOM}$

14a: $\mathrm{n}=2, \mathrm{R}=\mathrm{OH}$ 15a: $n=3, R=O H$ a)<smiles>COc1cc(OC)c2c(=O)c(OC)c(-c3ccc(OC)c(OC)c3)oc2c1</smiles>

b), 13: $\mathrm{n}=3 ; 3^{\prime}, 4^{\prime}$ OMOM

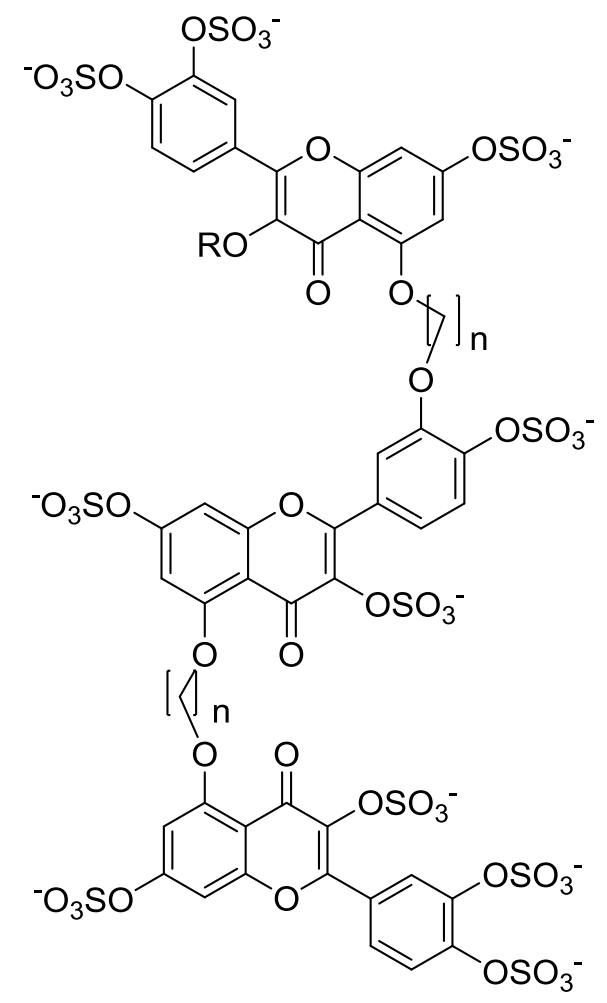

G4.1: $n=2$

G4.2: $n=3$

Scheme S3. Synthesis of sulfated 3', 5-O-flavonoid trimers G4.1-G4.2: a) $\mathrm{K}_{2} \mathrm{CO}_{3}$, dibromoalkane (1 equiv), DMF, rt/3 h, 85-90\%, b) 9, $\mathrm{K}_{2} \mathrm{CO}_{3}, \mathrm{DMF}, 60{ }^{\circ} \mathrm{C} / 4 \mathrm{~h}, 85-$ $90 \%$, c) $p$-toluenesulfonic acid, $\mathrm{MeOH}$, reflux/48 h, 55-65\%, d) $\mathrm{SO}_{3}: \mathrm{Me}_{3} \mathrm{~N}, \mathrm{Et}_{3} \mathrm{~N}$, $\mathrm{CH}_{3} \mathrm{CN}$, microwave/8 h, 75-85\%. 
Experimental Procedures and Spectral Characterization of Compounds of Schemes S1, S2, and S3.

General procedure for synthesis of methoxy methylated 5,5; 3',3' flavonoid dimers and 5,3 ' flavonoid trimers 3-8, 10, 11, 14, 15. To a solution of 1 or 2 (1.0 equiv) in $N, N$ dimethylformamide was added $\mathrm{K}_{2} \mathrm{CO}_{3}$ (2.5 equiv) and stirred for two minutes. This was followed by addition of di-bromo alkane ( 0.5 equiv) and stirred vigorously for 12 hours. After the reaction completed as indicated from TLC the reaction mixture was diluted with EtOAC (25 mL) and water $(25$ $\mathrm{mL})$. The organic layer was separated and the aqueous phase was extracted with EtOAc $(2 \times 25 \mathrm{~mL})$, organic layer was washed with saturated $\mathrm{NaCl}$ solution $(25 \mathrm{~mL})$. The combined organic layers were dried over anhydrous $\mathrm{Na}_{2} \mathrm{SO}_{4}$, evaporated under reduced pressure to afford crude compounds 3-8, 10, 11, 12, 14 and 15 which were further purified using flash chromatography on silica gel (70-85\% ethyl acetate in hexanes). Spectral characteristics of compounds are as follows:

5,5'-(ethane-1,2-diylbis(oxy))bis(2-(3,4-bis(methoxymethoxy)phenyl)-3,7-bis(methoxy-methoxy)4H-chromen-4-one) (3). ${ }^{1} \mathrm{H} \mathrm{NMR}\left(\mathrm{CDCl}_{3}, 400 \mathrm{MHz}\right): 7.93(\mathrm{~d}, J=2 \mathrm{~Hz}, 2 \mathrm{H}), 7.73(\mathrm{~d}, J=6.6 \mathrm{~Hz}, 2 \mathrm{H})$, 7.29- $7.26(\mathrm{~m}, 4 \mathrm{H}), 6.74(\mathrm{~d}, J=8.1 \mathrm{~Hz}, 2 \mathrm{H}), 5.33(\mathrm{~s}, 4 \mathrm{H}), 5.32(\mathrm{~s}, 4 \mathrm{H}), 5.28(\mathrm{~s}, 4 \mathrm{H}), 5.22(\mathrm{~s}, 4 \mathrm{H}), 4.64$ $(\mathrm{s}, 4 \mathrm{H}), 3.56(\mathrm{~s}, 6 \mathrm{H}), 3.56(\mathrm{~s}, 6 \mathrm{H}), 3.52(\mathrm{~s}, 6 \mathrm{H}), 3.25(\mathrm{~s}, 6 \mathrm{H}) .{ }^{13} \mathrm{C} \mathrm{NMR}\left(\mathrm{DMSO}_{6}, 400 \mathrm{MHz}\right)$ : 173.60, 161.42, 159.93, 158.41, 153.33, 149.20, 146.56, 137.87, 124.94, 123.69, 117.75, 115.74, 110.46, 99.44, 97.77, 96.36, 95.70, 95.17, 94.31, 68.18, 57.58, 56.44, 56.33. MS (ESI) calculated for $\mathrm{C}_{48} \mathrm{H}_{54} \mathrm{O}_{22},[(\mathrm{M}+\mathrm{H})]^{+}, m / z$ 983.31, found for $[(\mathrm{M}+\mathrm{H})]^{+}, m / z$ 983.251.

5,5'-(propane-1,3-diylbis(oxy))bis(2-(3,4-bis(methoxymethoxy)phenyl)-3,7-bis(methoxymethoxy)-4H-chromen-4-one) (4). ${ }^{1} \mathrm{H} \mathrm{NMR}\left(\mathrm{CDCl}_{3}, 400 \mathrm{MHz}\right): 7.88(\mathrm{~d}, J=2 \mathrm{~Hz}, 2 \mathrm{H}), 7.66(\mathrm{~d}, J=6.6$ $\mathrm{Hz}, 2 \mathrm{H}), 7.24(\mathrm{~d}, J=8.6 \mathrm{~Hz}, 4 \mathrm{H}), 6.63(\mathrm{~d}, J=2 \mathrm{~Hz}, 2 \mathrm{H}), 6.53(\mathrm{~d}, J=2 \mathrm{~Hz}, 2 \mathrm{H}), 5.29(\mathrm{~s}, 4 \mathrm{H}), 5.28(\mathrm{~s}$, $4 \mathrm{H}), 5.20(\mathrm{~s}, 4 \mathrm{H}), 5.17(\mathrm{~s}, 4 \mathrm{H}), 4.45(\mathrm{t}, J=5.4 \mathrm{~Hz}, 4 \mathrm{H}), 3.53(\mathrm{~s}, 6 \mathrm{H}), 3.52(\mathrm{~s}, 6 \mathrm{H}), 3.46(\mathrm{~s}, 6 \mathrm{H}), 3.19$ $(\mathrm{s}, 6 \mathrm{H}), 2.5(\mathrm{t}, J=5.4 \mathrm{~Hz}, 4 \mathrm{H}) .{ }^{13} \mathrm{C}$ NMR (DMSO-d $\left.6,400 \mathrm{MHz}\right): 173.63,161.43,160.48,158.43$, 153.18, 149.09, 146.51, 137.88, 125.03, 123.65, 117.72, 115.68, 110.09, 97.92, 97.81, 95.66, 95.18, 94.25, 94.31, 65.65, 57.54, 56.37, 56.33, 56.31, 21.5. MS (ESI) calculated for $\mathrm{C}_{49} \mathrm{H}_{56} \mathrm{O}_{22},[(\mathrm{M}+\mathrm{H})]^{+}, m / z$ 997.33, found for $[(\mathrm{M}+\mathrm{H})]^{+}, m / z 997.263$.

5,5'-(ethane-1,2-diylbis(oxy))bis(2-(2,4-bis(methoxymethoxy)phenyl)-3,7-bis(methoxymethoxy)-4H-chromen-4-one) (5). ${ }^{1} \mathrm{H} \mathrm{NMR}\left(\mathrm{CDCl}_{3}, 400 \mathrm{MHz}\right): 7.36(\mathrm{~d}, J=8.5 \mathrm{~Hz}, 2 \mathrm{H}), 6.84(\mathrm{~d}, J=$ $2.2 \mathrm{~Hz}, 2 \mathrm{H}), 6.72(\mathrm{~d}, J=6.3 \mathrm{~Hz}, 2 \mathrm{H}), 6.62(\mathrm{~d}, J=2.1 \mathrm{~Hz}, 2 \mathrm{H}), 6.58(\mathrm{~d}, J=2.2 \mathrm{~Hz}, 2 \mathrm{H}), 5.16(\mathrm{~s}, 2 \mathrm{H})$, $5.13(\mathrm{~s}, 2 \mathrm{H}), 5.10(\mathrm{~s}, 2 \mathrm{H}), 4.95(\mathrm{~s}, 2 \mathrm{H}), 4.53(\mathrm{~s}, 4 \mathrm{H}), 3.41(\mathrm{~s}, 6 \mathrm{H}), 3.40(\mathrm{~s}, 6 \mathrm{H}), 3.39(\mathrm{~s}, 6 \mathrm{H}), 2.86$ (s, $6 \mathrm{H}) .{ }^{13} \mathrm{C}$ NMR (DMSO-d 6 , $\left.400 \mathrm{MHz}\right): 173.53,161.36,160.11,159.99,159.01,156.58,154.32$, 138.86, 132.07, 114.98, 110.95, 108.75, 103.86, 99.36, 97.50, 96.61, 94.77, 94.45, 94.35, 68.23. MS (ESI) calculated for $\mathrm{C}_{48} \mathrm{H}_{54} \mathrm{O}_{22},[(\mathrm{M}+\mathrm{H})]^{+}, m / z$ 983.31, found for $[(\mathrm{M}+\mathrm{H})]^{+}, m / z$ 983.281.

5,5'-(butane-1,4-diylbis(oxy))bis(2-(3,4-bis(methoxymethoxy)phenyl)-3,7-bis(methoxy-methoxy)4H-chromen-4-one) (6). ${ }^{1} \mathrm{H} \mathrm{NMR}\left(\mathrm{CDCl}_{3}, 400 \mathrm{MHz}\right): 7.92(\mathrm{~d}, J=2.1 \mathrm{~Hz}, 2 \mathrm{H}), 7.69(\mathrm{~d}, J=6.6 \mathrm{~Hz}, 2$ H), $7.28(\mathrm{~d}, J=2.6 \mathrm{~Hz}, 2 \mathrm{H}), 6.58(\mathrm{~d}, J=2.1 \mathrm{~Hz}, 2 \mathrm{H}), 6.48(\mathrm{~d}, J=2.2 \mathrm{~Hz}, 2 \mathrm{H}), 5.32(\mathrm{~s}, 4 \mathrm{H}), 5.32(\mathrm{~s}, 4$ H), $5.31(\mathrm{~s}, 4 \mathrm{H}), 5.21(\mathrm{~s}, 4 \mathrm{H}), 4.29(\mathrm{~s}, 4 \mathrm{H}), 3.57(\mathrm{~s}, 6 \mathrm{H}), 3.56(\mathrm{~s}, 6 \mathrm{H}), 3.5(\mathrm{~s}, 6 \mathrm{H}), 3.22(\mathrm{~s}, 6 \mathrm{H}), 2.27$ $(\mathrm{s}, 4 \mathrm{H}) .{ }^{13} \mathrm{C}$ NMR (DMSO-d $\left.6,400 \mathrm{MHz}\right): 170.64,162.40,159.58,158.55,146.54,137.92,125.07$, 123.69, 117.78, 115.74, 105.17, 97.83, 97.59, 95.69, 95.26, 95.17, 94.29, 68.07, 57.55, 56.4, 25.32. MS (ESI) calculated for $\mathrm{C}_{50} \mathrm{H}_{58} \mathrm{O}_{22},[(\mathrm{M}+\mathrm{H})]^{+}, m / z, 1011.34$, found for $[(\mathrm{M}+\mathrm{H})]^{+}, m / z$ 1011.296.

5,5'-(pentane-1,5-diylbis(oxy))bis(2-(3,4-bis(methoxymethoxy)phenyl)-3,7-bis(methoxymethoxy)-4H-chromen-4-one) (7). ${ }^{1} \mathrm{H} \mathrm{NMR}\left(\mathrm{CDCl}_{3}, 400 \mathrm{MHz}\right): 7.91(\mathrm{~d}, J=2 \mathrm{~Hz}, 2 \mathrm{H}), 7.71(\mathrm{~d}, J=6.6$ $\mathrm{Hz}, 2 \mathrm{H}), 7.27$ (d, $J=3.7 \mathrm{~Hz}, 2 \mathrm{H}), 6.68(\mathrm{~d}, J=2.2 \mathrm{~Hz}, 2 \mathrm{H}), 6.46(\mathrm{~d}, J=2.1 \mathrm{~Hz}, 2 \mathrm{H}), 5.31(\mathrm{~s}, 4 \mathrm{H}), 5.31$ (s, $4 \mathrm{H}), 5.26(\mathrm{~s}, 4 \mathrm{H}), 5.21(\mathrm{~s}, 4 \mathrm{H}), 4.15(\mathrm{t}, J=6.5 \mathrm{~Hz}, 4 \mathrm{H}), 3.56(\mathrm{~s}, 6 \mathrm{H}), 3.55(\mathrm{~s}, 6 \mathrm{H}), 3.52(\mathrm{~s}, 6 \mathrm{H})$, 
3.23 (s, $6 \mathrm{H}), 2.09-2.03$ (m, $4 \mathrm{H}), 1 . .86-1.72(\mathrm{~m}, 2 \mathrm{H}) .{ }^{13} \mathrm{C}$ NMR (DMSO-d 6 , $\left.400 \mathrm{MHz}\right): 173.64$, $161.35,160.58,158.55,153.16,149.12,146.54,137.92,125.07,123.69,117.78,115.74,110.16,97.83$, 97.59, 95.69, 95.26, 95.17, 94.29, 69.34, 57.55, 56.4, 56.32, 28.4, 22.36. MS (ESI) calculated for $\mathrm{C}_{51} \mathrm{H}_{60} \mathrm{O}_{22},[(\mathrm{M}+\mathrm{H})]^{+}, m / z$ 1025.36, found for $[(\mathrm{M}+\mathrm{H})]^{+}, m / z, 1025.251$.

(E)-5,5'-(but-2-ene-1,4-diylbis(oxy))bis(2-(3,4-bis(methoxymethoxy)phenyl)-3,7-bis(methoxymethoxy)-4H-chromen-4-one) (8). ${ }^{1} \mathrm{H} \mathrm{NMR}\left(\mathrm{CDCl}_{3}, 400 \mathrm{MHz}\right): 8.02$ (s, $\left.2 \mathrm{H}\right), 7.92$ (d, J = $\left.2 \mathrm{~Hz}, 2 \mathrm{H}\right)$, $7.72(\mathrm{~d}, J=6.6 \mathrm{~Hz}, 2 \mathrm{H}), 7.27(\mathrm{~d}, J=8.7 \mathrm{~Hz}, 2 \mathrm{H}), 6.71(\mathrm{~d}, J=2.1 \mathrm{~Hz}, 2 \mathrm{H}), 6.47(\mathrm{~d}, J=2 \mathrm{~Hz}, 2 \mathrm{H}), 5.31$ (s, $4 \mathrm{H}), 5.31(\mathrm{~s}, 4 \mathrm{H}), 5.25(\mathrm{~s}, 4 \mathrm{H}), 5.23(\mathrm{~s}, 4 \mathrm{H}), 4.72(\mathrm{~d}, J=3.5 \mathrm{~Hz}, 4 \mathrm{H}), 3.29(\mathrm{~s}, 6 \mathrm{H}), 3.29(\mathrm{~s}, 6 \mathrm{H})$, 3.15 (s, $6 \mathrm{H}), 3.02$ (s, $6 \mathrm{H}) .{ }^{13} \mathrm{C}$ NMR (DMSO-d 6 , $\left.400 \mathrm{MHz}\right): 173.65,162.49,161.35,159.87,158.55$, 153.27, 149.17, 146.55, 137.92, 126.76, 124.97, 123.69, 117.76, 115.73, 110.21, 98.0, 97.78, 95.69, 95.59, 95.15, 94.37, 68.92, 57.58, 56.44, 56.32. MS (ESI) calculated for $\mathrm{C}_{50} \mathrm{H}_{56} \mathrm{O}_{22,}[(\mathrm{M}+\mathrm{H})]^{+}, m / z$ 1009.33 , found for $[(\mathrm{M}+\mathrm{H})]^{+}, m / z$ 1009.283.

2,2'-((propane-1,3-diylbis(oxy))bis(4-(methoxymethoxy)-3,1-phenylene))bis(5-hydroxy-3,7bis(methoxymethoxy)-4H-chromen-4-one) (10). ${ }^{1} \mathrm{H} \mathrm{NMR}\left(\mathrm{CDCl}_{3}, 400 \mathrm{MHz}\right): 12.32(\mathrm{~s}, 2 \mathrm{H}), 7.50$ (d, J= $1.8 \mathrm{~Hz}, 2 \mathrm{H}), 7.43(\mathrm{~d}, J=6.6 \mathrm{~Hz}, 2 \mathrm{H}), 7.03(\mathrm{~d}, J=8.3 \mathrm{~Hz}, 2 \mathrm{H}), 6.40(\mathrm{~d}, J=2.1 \mathrm{~Hz}, 2 \mathrm{H}), 6.26(\mathrm{~d}, J=2.2$ Hz, 2 H), 5.06 (s, 2 H), 5.03 (s, 2 H), 4.97 (s, 2 H), 4.15 (t, J=4.8 Hz, 4 H), 3.298 (s, 6 H), 3.294 (s, 6 $\mathrm{H}), 3.02(\mathrm{~s}, 6 \mathrm{H}), 2.25-2.22(\mathrm{~m}, 2 \mathrm{H}) .{ }^{13} \mathrm{C}$ NMR (DMSO-d $\left.6,400 \mathrm{MHz}\right): 178.56,162.98,161.92$, 156.67, 149.22, 148.71, 135.6, 128.08, 127.39, 124.46, 122.78, 116.1, 114.29, 106.61, 99.77, 97.89, 95.25, 94.21, 94.05, 65.83, 57.75, 56.41, 56.36. MS (ESI) calculated for $\mathrm{C}_{45} \mathrm{H}_{48} \mathrm{O}_{20},[(\mathrm{M}+\mathrm{H})]^{+}, m / z$ 909.27, found for $[(\mathrm{M}+\mathrm{H})]^{+}, m / z$ 909.231.

(E)-2,2'-((but-2-ene-1,4-diylbis(oxy))bis(4-(methoxymethoxy)-3,1-phenylene))bis(5-hydroxy-3,7bis(methoxymethoxy)-4H-chromen-4-one) (11). ${ }^{1} \mathrm{H} \mathrm{NMR}\left(\mathrm{CDCl}_{3}, 400 \mathrm{MHz}\right): 12.53(\mathrm{~s}, 2 \mathrm{H}), 7.71(\mathrm{~d}, J=$ $2 \mathrm{~Hz}, 2 \mathrm{H}), 7.63(\mathrm{~d}, J=6.6 \mathrm{~Hz}, 2 \mathrm{H}), 7.24(\mathrm{~d}, J=8.3 \mathrm{~Hz}, 2 \mathrm{H}), 6.62(\mathrm{~d}, J=2.2 \mathrm{~Hz}, 2 \mathrm{H}), 6.48(\mathrm{~d}, J=2.1$ Hz, 2 H), 6.23 (s, 2 H), 5.3 (s, 4 H), 5.25 (s, 4 H), 5.19 (s, 4 H), 4.77 (d, J=0.8 Hz, 4 H), 3.55 (s, $6 \mathrm{H})$, $3.51(\mathrm{~s}, 6 \mathrm{H}), 3.25$ (s, $6 \mathrm{H}) .{ }^{13} \mathrm{C}$ NMR (DMSO-d 6 , $\left.400 \mathrm{MHz}\right): 178.54,162.98,161.91,156.64,156.49$, 149.25, 148.15, 135.57, 128.76, 124.32, 122.73, 115.84, 114.48, 106.6, 99.77, 97.86, 95.26, 94.24, 94.06, 68.38, 57.75, 56.4. MS (ESI) calculated for $\mathrm{C}_{46} \mathrm{H}_{48} \mathrm{O}_{20},[(\mathrm{M}+\mathrm{H})]^{+}, m / z 921.27$, found for $[(\mathrm{M}+\mathrm{H})]^{+}, m / z$ 921.241.

2-(3,4-bis(methoxymethoxy)phenyl)-5-(2-(5-(5-(2-((2-(3,4-bis(methoxymethoxy)phenyl)-3,7bis(methoxymethoxy)-4-oxo-4H-chromen-5-yl)oxy)ethoxy)-3,7-bis(methoxymethoxy)-4-oxo-4Hchromen-2-yl)-2-(methoxymethoxy)phenoxy)ethoxy)-3,7-bis(methoxymethoxy)-4H-chromen-4-one (14). ${ }^{1} \mathrm{H} \mathrm{NMR}\left(\mathrm{CDCl}_{3}, 400 \mathrm{MHz}\right): 7.83-7.82(\mathrm{~m}, 2 \mathrm{H}), 7.71(\mathrm{~d}, J=2.0 \mathrm{~Hz}, 1 \mathrm{H}), 7.64-7.59(\mathrm{~m}, 3 \mathrm{H}), 7.19-7.14$ $(\mathrm{m}, 3 \mathrm{H}), 6.68-6.55(\mathrm{~m}, 6 \mathrm{H}), 5.22-5.20(\mathrm{~m}, 10 \mathrm{H}), 5.19(\mathrm{~s}, 4 \mathrm{H}), 5.13(\mathrm{~s}, 4 \mathrm{H}), 5.09$ (s, $4 \mathrm{H}), 4.54-4.46$ $(\mathrm{m}, 8 \mathrm{H}), 3.47-3.46(\mathrm{~m}, 18 \mathrm{H}), 3.43(\mathrm{~s}, 6 \mathrm{H}), 3.16(\mathrm{~s}, 3 \mathrm{H}), 3.15(\mathrm{~s}, 3 \mathrm{H}), 3.14(\mathrm{~s}, 3 \mathrm{H}) .{ }^{13} \mathrm{C} \mathrm{NMR}$ (DMSO-d 6 , 400 MHz): 173.57, 173.39, 161.45, 161.25, 160.10, 159.96, 158.46, 153.40, 153.30, 149.26, 149.0, 148.62, 146.65, 137.93, 125.20, 125.04, 124.99, 123.7, 123.09, 117.91, 116.69, 115.28, $110.72,110.54,99.59,97.90,97.82,97.72,96.47,95.77,95.63,95.24,94.37,68.29,67.89,57.61,57.54$, 56.40, 56.30. ESI-MS calculated for $\mathrm{C}_{71} \mathrm{H}_{78} \mathrm{O}_{32}[(\mathrm{M}+\mathrm{H})]^{+}, m / z$ 1443.36, found $[(\mathrm{M}+\mathrm{H})]^{+}, m / z$ 1443.187.

2-(3,4-bis(methoxymethoxy)phenyl)-5-(3-(5-(5-(3-((2-(3,4-bis(methoxymethoxy)phenyl)-3,7bis(methoxymethoxy)-4-oxo-4H-chromen-5-yl)oxy)propoxy)-3,7-bis(methoxymethoxy)-4-oxo-4Hchromen-2-yl)-2-(methoxymethoxy)phenoxy)propoxy)-3,7-bis(methoxymethoxy)-4H-chromen-4-one (15). ${ }^{1} \mathrm{H} \mathrm{NMR}\left(\mathrm{CDCl}_{3}, 400 \mathrm{MHz}\right):{ }^{1} \mathrm{H} \mathrm{NMR}\left(\mathrm{CDCl}_{3}, 400 \mathrm{MHz}\right): 7.62(\mathrm{~d}, J=1.0 \mathrm{~Hz}, 2 \mathrm{H}), 7.60-7.51(\mathrm{~m}$, $4 \mathrm{H})$, 7.19-7.09 (m, $3 \mathrm{H}), 6.6-6.47$ (m, $3 \mathrm{H}), 6.45-6.40$ (m, $3 \mathrm{H}), 5.22-5.21(\mathrm{~m}, 10 \mathrm{H}), 5.15$ (s, $4 \mathrm{H}), 5.13$ (s, 2 H), 5.10 (s, 2 H), 5.09 (s, 4 H), 4.38-4.23 (m, 8 H), 3.46-3.39 (m, 24 H), 3.12 (s, 6 H), 3.10 (s, 3 
H), 2.44-2.38 (m, $4 \mathrm{H}) .{ }^{13} \mathrm{C}$ NMR (DMSO-d 6 , $\left.400 \mathrm{MHz}\right): 173.37,172.89,162.45,161.9,160.25$, $159.98,158.48,154.09$, 153.25, 149.28, 148.98, 148.65, 146.86, 138.05, 125.27, 125.35, 124.28, 123.65, 123.09, 118.09, 116.89, 115.29, 110.93, 111.04, 99.78, 97.89, 97.86, 97.77, 96.57, 95.57, 95.86, 94.34, 94.38, 68.39, 67.75, 58.01, 57.58, 56.35, 56.29, 28.49. ESI-MS calculated for $\mathrm{C}_{73} \mathrm{H}_{82} \mathrm{O}_{32}[(\mathrm{M}+\mathrm{H})]^{+}$, $\mathrm{m} / z$ 1471.48, found $[(\mathrm{M}+\mathrm{H})]^{+}, \mathrm{m} / z$ 1471.162.

Synthesis of intermediates 12 and 13. To a solution of 1 (1.0 equiv) in $N, N$ dimethylformamide was added $\mathrm{K}_{2} \mathrm{CO}_{3}$ (2.5 equiv) and stirred for two minutes. This was followed by addition of di-bromo alkane (1.5 equiv) and stirred vigorously for 6 hours. After the reaction completed as indicated from TLC the reaction mixture was diluted with EtOAC (25 mL) and water $(25$ $\mathrm{mL})$. The organic layer was separated and the aqueous phase was extracted with EtOAc $(2 \times 25 \mathrm{~mL})$, organic layer was washed with saturated $\mathrm{NaCl}$ solution $(25 \mathrm{~mL})$. The combined organic layers were dried over anhydrous $\mathrm{Na}_{2} \mathrm{SO}_{4}$, evaporated under reduced pressure to afford crude $\mathbf{1 2}$ and 13, which were further purified using flash chromatography on silica gel (70-85\% ethyl acetate in hexanes). Spectral characteristics of compounds are as follows:

2-(3,4-bis(methoxymethoxy)phenyl)-5-(2-bromoethoxy)-3,7-bis(methoxymethoxy)-4Hchromen-4-one (12). ${ }^{1} \mathrm{H} \mathrm{NMR}\left(400 \mathrm{MHz}, \mathrm{CDCl}_{3}\right)$ : 7.69 (d, $\left.1 \mathrm{H}, J=2.0 \mathrm{~Hz}\right), 7.55-7.52$ (m, $\left.1 \mathrm{H}\right), 7.09$ $(\mathrm{d}, 1 \mathrm{H}, J=8.6 \mathrm{~Hz}), 6.54(\mathrm{~d}, 1 \mathrm{H}, J=2.1 \mathrm{~Hz}), 6.27(\mathrm{~d}, 1 \mathrm{H}, \mathrm{d}, J=2.1 \mathrm{~Hz}), 5.13(\mathrm{~s}, 2 \mathrm{H}), 5.09(\mathrm{~s}, 2 \mathrm{H})$, $5.05(\mathrm{~s}, 2 \mathrm{H}), 5.04(\mathrm{~s}, 2 \mathrm{H}), 4.37(\mathrm{t}, 2 \mathrm{H}, J=2.8 \mathrm{~Hz}), 3.51(\mathrm{t}, 2 \mathrm{H}, J=2.8 \mathrm{~Hz}), 3.39(\mathrm{~s}, 3 \mathrm{H}), 3.37(\mathrm{~s}, 3 \mathrm{H})$, 3.34 (s, $3 \mathrm{H}), 3.30$ (s, $3 \mathrm{H}) .{ }^{13} \mathrm{C} \mathrm{NMR}\left(100 \mathrm{MHz}, \mathrm{CDCl}_{3}\right): 173.80,161.47,161.08,158.57,153.19$, 149.03, 147.02, 137.75, 124.73, 123.28, 115.82, 115.48, 109.93, 97.58, 96.59, 95.33, 95.25, 94.36, 78.30, 76.04, 57.67, 57.10, 56.44, 56.41, 55.93. ESI-MS calculated for $\mathrm{C}_{25} \mathrm{H}_{29} \mathrm{BrO}_{11}[(\mathrm{M}+\mathrm{H})]^{+}, m / z, 585.07$ found $\mathrm{m} / \mathrm{z} 585.026$.

2-(3,4-bis(methoxymethoxy)phenyl)-5-(3-bromopropoxy)-3,7-bis(methoxymethoxy)-4Hchromen-4-one (13). ${ }^{1} \mathrm{H} \mathrm{NMR}\left(400 \mathrm{MHz}, \mathrm{CDCl}_{3}\right): 7.68$ (d, $\left.1 \mathrm{H}, \mathrm{J}=2.0 \mathrm{~Hz}\right), 7.55-7.52$ (m, $\left.1 \mathrm{H}\right), 7.07$ $(\mathrm{d}, 1 \mathrm{H}, J=8.6 \mathrm{~Hz}), 6.54(\mathrm{~d}, 1 \mathrm{H}, J=2.1 \mathrm{~Hz}), 6.28(\mathrm{~d}, 1 \mathrm{H}, \mathrm{d}, J=2.1 \mathrm{~Hz}), 5.13(\mathrm{~s}, 2 \mathrm{H}), 5.1(\mathrm{~s}, 2 \mathrm{H}), 5.08$ (s, 2 H), 5.05 (s, 2 H), 4.37 (t, $2 \mathrm{H}, J=2.9 \mathrm{~Hz}), 3.5$ (t, $2 \mathrm{H}, J=2.9 \mathrm{~Hz}), 3.39$ (s, $3 \mathrm{H}), 3.37$ (s, $3 \mathrm{H}), 3.34$ $(\mathrm{s}, 3 \mathrm{H}), 3.30(\mathrm{~s}, 3 \mathrm{H}), 2.02(2 \mathrm{H}, \mathrm{m}) .{ }^{13} \mathrm{C}$ NMR $\left(100 \mathrm{MHz}, \mathrm{CDCl}_{3}\right)$ : 173.65, 162.07, 161.08, 158.57, $153.19,149.03,146.92,137.75,124.73,123.28,114.92,115.48,109.93,97.58,96.59,95.33,95.25$, 94.36, 78.30, 76.04, 57.67, 57.10, 56.44, 56.41, 55.93, 38.25. MS (ESI) calculated for $\mathrm{C}_{26} \mathrm{H}_{31} \mathrm{BrO}_{11}$ $[(\mathrm{M}+\mathrm{H})]^{+}, m / z, 599.10$ found $m / z, 599.038$.

General procedure for synthesis of polyphenolic 5,5; 3',3' flavonoid dimers and 5,3' flavonoid trimers $3 a-8 a, 10 a, 11 a, 14 a$, and 15a. The methoxy methyl groups present in the compounds 3-8, 10, 11, 14, 15 were completely deprotected using fallowing procedure. To a solution of methoxy methylated compound in methanol was taken in a flask attached to a reflux condenser and $p$ Toluenesulfonic acid (catalytic) was added to it. The reaction mixture was stirred at reflux temperature, the extent of deprotection was monitored using UPLC-MS and continued until complete deprotection of all OMOM groups. After completion of the reaction EtOAC $(25 \mathrm{~mL})$ was added to precipitate the mixture. The precipitate was filtered, washed with excess EtOAC to remove $p$ toluenesulfonic acid and dried to obtain pure polyphenolic compounds 3a-8a, 10a, 11a, 14a, and $15 \mathbf{a}$. Spectral characteristics of compounds are as follows:

5,5'-(ethane-1,2-diylbis(oxy))bis(2-(3,4-dihydroxyphenyl)-3,7-dihydroxy-4H-chromen-4-one) (3a). ${ }^{1} \mathrm{H}$ NMR (DMSO-d 6 , $400 \mathrm{MHz}$ ): 10.64 (bs, $2 \mathrm{H}$ ), 9.7-8.2 (bs, $\left.5 \mathrm{H}\right), 7.57$ (d, J=2.2 Hz, $\left.2 \mathrm{H}\right), 7.41$ $(\mathrm{d}, J=6.2 \mathrm{~Hz}, 2 \mathrm{H}), 6.80(\mathrm{~d}, J=2.4 \mathrm{~Hz}, 2 \mathrm{H}), 6.44-6.40(\mathrm{~m}, 4 \mathrm{H}), 4.37(\mathrm{~s}, 4 \mathrm{H}) .{ }^{13} \mathrm{C} \mathrm{NMR}\left(\mathrm{DMSO}-\mathrm{d}_{6}\right.$, $100 \mathrm{MHz}$ ): 170.80, 162.33, 159.47, 157.86, 146.92, 145.03, 141.87, 137.11, 122.23, 119.08, 115.57, 
114.46, 105.46, 97.55, 95.12, 67.77. ESI-MS calculated for $\mathrm{C}_{32} \mathrm{H}_{22} \mathrm{O}_{14}[(\mathrm{M}+\mathrm{Na})]^{+}, m / z$ 653.52, found $[(\mathrm{M}+\mathrm{H})]^{+}, m / z 631.197$.

5,5'-(propane-1,3-diylbis(oxy))bis(2-(3,4-dihydroxyphenyl)-3,7-dihydroxy-4H-chromen-4-one) (4a). ${ }^{1} \mathrm{H}$ NMR (DMSO-d $\left.\mathrm{d}_{6}, 100 \mathrm{MHz}\right): 10.6$ (bs, 2H), 8.4-9.0 (bs, 3H), $7.55(\mathrm{~d}, J=2.1 \mathrm{~Hz}, 2 \mathrm{H}), 7.41$ (d, $J$ $=2.1 \mathrm{~Hz}, 2 \mathrm{H}), 6.80(\mathrm{~d}, J=8.4 \mathrm{~Hz}, 2 \mathrm{H}), 6.38(\mathrm{~d}, J=1.9 \mathrm{~Hz}, 2 \mathrm{H}), 6.30(\mathrm{~d}, J=2 \mathrm{~Hz}, 2 \mathrm{H}), 4.29(\mathrm{t}, J=5.8$ $\mathrm{Hz}, 4 \mathrm{H}$ ), 2.26-2.22 (m, 2H). ${ }^{13} \mathrm{C}$ NMR (DMSO-d 6 , $400 \mathrm{MHz}$ ): 171.04, 162.36, 159.74, 157.87, $146.90,145.01,141.88,137.15,122.28,119.09,115.56,114.48,105.21,96.32,94.54,64.82,28.54$. ESIMS calculated for $\mathrm{C}_{33} \mathrm{H}_{24} \mathrm{O}_{14}[(\mathrm{M}+\mathrm{Na})]^{+}, m / z 667.54$, found $[(\mathrm{M}+\mathrm{H})]^{+}, m / z$ 645.213.

\section{5,5'-(ethane-1,2-diylbis(oxy))bis(2-(2,4-dihydroxyphenyl)-3,7-dihydroxy-4H-chromen-4-one)}

(5a). ${ }^{1} \mathrm{H}$ NMR (DMSO-d 6 , $\left.400 \mathrm{MHz}\right):$ 9.1-10.5 (bs, $5 \mathrm{H}$ ), 7.14 (d, $\left.J=8.4 \mathrm{~Hz}, 2 \mathrm{H}\right), 6.40$ (d, $J=1.9 \mathrm{~Hz}, 2$ H), $6.31(\mathrm{~d}, J=1.9 \mathrm{~Hz}, 4 \mathrm{H}), 6.26(\mathrm{~d}, J=6.3 \mathrm{~Hz}, 2 \mathrm{H}), 4.36(\mathrm{~s}, 4 \mathrm{H}) .{ }^{13} \mathrm{C}$ NMR (DMSO-d 6 , $\left.400 \mathrm{MHz}\right)$ : 173.72, 160.81, 159.76, 156.47, 156.13, 155.68, 154.34, 137.46, 131.07, 116.34, 113.46, 112.04, $110.35,101.83,100.74,68.45$. ESI-MS calculated for $\mathrm{C}_{32} \mathrm{H}_{22} \mathrm{O}_{14}[(\mathrm{M}+\mathrm{Na})]^{+}, m / z$ 653.32, found $[(\mathrm{M}+\mathrm{H})]^{+}, m / z 631.197$.

5,5'-(butane-1,4-diylbis(oxy))bis(2-(3,4-dihydroxyphenyl)-3,7-dihydroxy-4H-chromen-4-one) (6a). ${ }^{1} \mathrm{H}$ NMR (DMSO-d 6 , $400 \mathrm{MHz}$ ): 10.58 (bs, $2 \mathrm{H}$ ), 9.34-8.64 (bs, $6 \mathrm{H}$ ), 7.57 (d, $J=2.2 \mathrm{~Hz}, 2 \mathrm{H}$ ), 7.42 $(\mathrm{d}, J=6.4 \mathrm{~Hz}, 2 \mathrm{H}), 6.80(\mathrm{~d}, J=8.5 \mathrm{~Hz}, 2 \mathrm{H}), 6.37-6.32(\mathrm{~m}, 4 \mathrm{H}), 4.06(\mathrm{~s}, 4 \mathrm{H}), 2.05(\mathrm{~s}, 4 \mathrm{H}) .{ }^{13} \mathrm{C} \mathrm{NMR}$ (DMSO-d $\mathrm{d}_{6}, 400 \mathrm{MHz}$ ): 170.96, 162.40, 159.90, 157.88, 146.88, 145.02, 141.72, 137.13, 122.30, $119.05,115.56,114.45,105.17,96.45,94.41,68.07,25.37$. ESI-MS calculated for $\mathrm{C}_{34} \mathrm{H}_{26} \mathrm{O}_{14}[(\mathrm{M}+\mathrm{Na})]^{+}$, $m / z 681.56$, found $[(\mathrm{M}+\mathrm{H})]^{+}, m / z 659.261$.

5,5'-(pentane-1,5-diylbis(oxy))bis(2-(3,4-dihydroxyphenyl)-3,7-dihydroxy-4H-chromen-4-one) (7a). ${ }^{1} \mathrm{H}$ NMR (DMSO-d $\left.6,400 \mathrm{MHz}\right): 7.64(\mathrm{~d}, J=2.1 \mathrm{~Hz}, 2 \mathrm{H}), 7.51-7.47(\mathrm{~m}, 2 \mathrm{H}), 7.13(\mathrm{~d}, J=7.9 \mathrm{~Hz}$, $1 \mathrm{H}), 6.88(\mathrm{~d}, J=8.1 \mathrm{~Hz}, 2 \mathrm{H}), 6.46-6.37(\mathrm{~m}, 3 \mathrm{H}), 4.05(\mathrm{t}, J=5.5 \mathrm{~Hz}, 4 \mathrm{H}), 2.05-2.01(\mathrm{~m}, 4 \mathrm{H}), 1.89-$ 1.85 (m, 2 H). ${ }^{13} \mathrm{C}$ NMR (DMSO-d 6 , $400 \mathrm{MHz}$ ): 170.78, 163.25, 158.89, 157.76, 146.97, 145.28, $141.82,136.95,122.48,119.35,115.86,113.98,105.16,98.35,94.35,68.37,25.38,22.24$. ESI-MS calculated for $\mathrm{C}_{35} \mathrm{H}_{28} \mathrm{O}_{14}[(\mathrm{M}+\mathrm{Na})]^{+}, m / z$ 695.59, found $[(\mathrm{M}+\mathrm{H})]^{+}, m / z$ 673.213.

(E)-5,5'-(but-2-ene-1,4-diylbis(oxy))bis(2-(3,4-dihydroxyphenyl)-3,7-dihydroxy-4H-chromen-4one) (8a). ${ }^{1} \mathrm{H}$ NMR (DMSO-d 6 , $\left.400 \mathrm{MHz}\right): 10.73$ ( $\left.\mathrm{s}, 1 \mathrm{H}\right), 9.45-8.6$ (bs, $\left.6 \mathrm{H}\right), 7.68(\mathrm{~d}, J=3.5 \mathrm{~Hz}, 2 \mathrm{H}$ ), 7.51-7.51 (m, $2 \mathrm{H}), 6.90-6.87(\mathrm{~m}, 3 \mathrm{H}), 6.62-6.43(\mathrm{~m}, 5 \mathrm{H}), 4.75(\mathrm{~d}, J=3.5 \mathrm{~Hz}, 4 \mathrm{H}) .{ }^{13} \mathrm{C}$ NMR (DMSO$\left.\mathrm{d}_{6}, 400 \mathrm{MHz}\right): 170.89,163.45,158.94,157.69,147.78,145.82,142.07,138.15,124.67,123.49$, $122.15,119.28,115.58,113.95,105.18,98.34,95.47,56.35$. ESI-MS calculated for $\mathrm{C}_{34} \mathrm{H}_{24} \mathrm{O}_{14}$ $[(\mathrm{M}+\mathrm{Na})]^{+}, m / z 679.55$, found $[(\mathrm{M}+\mathrm{H})]^{+}, m / z 657.181$.

2,2'-((propane-1,3-diylbis(oxy))bis(4-hydroxy-3,1-phenylene))bis(3,5,7-trihydroxy-4H-chromen4-one) (10a). ${ }^{1} \mathrm{H}$ NMR (DMSO-d $\left.{ }_{6}, 400 \mathrm{MHz}\right): 12.38$ (s, 2H), 10.82-10.42 (bs, 2H), 9.8-9.2 (bs, 4H), 7.73$7.61(\mathrm{~m}, 4 \mathrm{H}), 6.89(\mathrm{~d}, J=9.2 \mathrm{~Hz}, 2 \mathrm{H}), 6.39(\mathrm{~d}, J=2.1 \mathrm{~Hz}, 2 \mathrm{H}), 6.12(\mathrm{~d}, J=1.9 \mathrm{~Hz}, 2 \mathrm{H}), 4.20(\mathrm{t}, J=$ $5.4 \mathrm{~Hz}, 4 \mathrm{H}$ ), 2.23-2.20 (m, 2H). ${ }^{13} \mathrm{C}$ NMR (DMSO-d $6,400 \mathrm{MHz}$ ): 175.83, 163.88, 160.64, 156.13, $148.95,146.56,146.51,135.78,121.99,121.79,115.64,112.93,102.99,98.17,93.56,65.36,28.85$. ESIMS calculated for $\mathrm{C}_{33} \mathrm{H}_{24} \mathrm{O}_{14}[(\mathrm{M}+\mathrm{Na})]^{+}, m / z 667.54$, found $[(\mathrm{M}+\mathrm{H})]^{+}, m / z$ 645.149.

(E)-2,2'-((but-2-ene-1,4-diylbis(oxy))bis(4-hydroxy-3,1-phenylene))bis(3,5,7-trihydroxy-4Hchromen-4-one) (11a). ${ }^{1} \mathrm{H}$ NMR (DMSO- $\mathrm{d}_{6}, 400 \mathrm{MHz}$ ): 12.46 (bs, $2 \mathrm{H}$ ), 10.75 (s, $2 \mathrm{H}$ ), 9.77 (bs, $2 \mathrm{H}$ ), $9.33(\mathrm{bs}, 2 \mathrm{H}), 7.85(\mathrm{~d}, J=2 \mathrm{~Hz}, 2 \mathrm{H}), 7.68(\mathrm{~d}, J=6.3 \mathrm{~Hz}, 2 \mathrm{H}), 6.97$ (d, $J=8.7 \mathrm{~Hz}, 4 \mathrm{H}), 6.47$ (d, $J=2$ $\mathrm{Hz}, 2 \mathrm{H}), 6.25(\mathrm{~d}, J=2 \mathrm{~Hz}, 2 \mathrm{H}), 4.70(\mathrm{~s}, 4 \mathrm{H}) .{ }^{13} \mathrm{C}$ NMR (DMSO-d $\left.6,100 \mathrm{MHz}\right): 175.83,163.85$, 
160.64, 156.12, 149.07, 146.53, 146.18, 135.77, 128.58, 121.91, 115.76, 113.58, 103.0, 98.16, 93.57, 68.38. ESI-MS calculated for $\mathrm{C}_{34} \mathrm{H}_{24} \mathrm{O}_{14}[(\mathrm{M}+\mathrm{Na})]^{+}, m / z 679.55$, found $[(\mathrm{M}+\mathrm{H})]^{+}, m / z 657.124$.

14a. ${ }^{1} \mathrm{H}$ NMR (DMSO-d 6 , $400 \mathrm{MHz}$ ): 10.69 (bs, $\left.3 \mathrm{H}\right), 9.53-8.7$ (bs, $\left.6 \mathrm{H}\right), 7.83$ (d, $J=0.1 \mathrm{~Hz}, 1$ H), 7.70-7.64 (m, $3 \mathrm{H}), 7.49(\mathrm{~d}, J=9.0 \mathrm{~Hz}, 2 \mathrm{H}), 6.98(\mathrm{~d}, J=8.6 \mathrm{~Hz}, 1 \mathrm{H}), 6.87(\mathrm{~d}, J=8.5 \mathrm{~Hz}, 2 \mathrm{H}), 6.59$ $(\mathrm{d}, J=1.9 \mathrm{~Hz}, 1 \mathrm{H}), 6.51-6.44(\mathrm{~m}, 5 \mathrm{H}), 4.45-4.40(\mathrm{~m}, 8 \mathrm{H}) .{ }^{13} \mathrm{C}$ NMR (DMSO-d $\left.6,400 \mathrm{MHz}\right): 170.92$, 170.81, 162.38, 162.34, 159.47, 157.94, 157.89, 148.61, 146.95, 146.26, 145.04, 141.98, 141.92, 141.63, 137.24, 137.24, 137.12, 137.09, 127.99, 125.47, 122.42, 121.49, 119.11, 115.58, 114.51, 113.50, 105.52, 105.44, 97.71, 95.20, 95.10, 67.84, 67.72, 59.69. ESI-MS calculated for $\mathrm{C}_{49} \mathrm{H}_{34} \mathrm{O}_{21}[(\mathrm{M}+\mathrm{H})]^{+}, \mathrm{m} / z$ 958.16, found $[(\mathrm{M}+\mathrm{H})]^{+}, m / z$ 958.187.

15a. ${ }^{1} \mathrm{H}$ NMR (DMSO-d 6 , $400 \mathrm{MHz}$ ): 10.65 (bs, $\left.3 \mathrm{H}\right), 9.54-8.9$ (bs, $\left.6 \mathrm{H}\right), 7.75$ (d, $J=0.4 \mathrm{~Hz}, 1$ H), 7.72-7.66 (m, $3 \mathrm{H}), 7.5(\mathrm{~d}, J=8.9 \mathrm{~Hz}, 2 \mathrm{H}), 6.96(\mathrm{~d}, J=8.7 \mathrm{~Hz}, 1 \mathrm{H}), 6.88(\mathrm{~d}, J=8.6 \mathrm{~Hz}, 2 \mathrm{H}), 6.58$ $(\mathrm{d}, J=1.7 \mathrm{~Hz}, 1 \mathrm{H}), 6.52-6.43(\mathrm{~m}, 5 \mathrm{H}), 4.48-4.37(\mathrm{~m}, 8 \mathrm{H}), 2.39-2.27$ (m, $4 \mathrm{H}) .{ }^{13} \mathrm{C}$ NMR $\left(\mathrm{DMSO}-\mathrm{d}_{6}\right.$, $400 \mathrm{MHz}$ ): 171.92, 170.61, 162.37, 161.35, 158.47, 157.93, 157.85, 148.81, 147.85, 146.28, 144.04, $142.97,141.98,142.68,137.28,137.26,137.13,137.09,126.98,125.45,122.35,122.09,119.19,114.98$, 114.48, 113.25, 105.35, 105.09, 97.61, 95.52, 95.23, 67.74, 67.62, 59.80, 29.13. ESI-MS calculated for $\mathrm{C}_{51} \mathrm{H}_{38} \mathrm{O}_{21}[(\mathrm{M}+\mathrm{H})]^{+}, m / z$ 987.19, found $[(\mathrm{M}+\mathrm{H})]^{+}, m / z$ 987.462.

General Procedure for Synthesis of Sulfated Flavonoid Dimers and Trimers. Sulfation of phenolic precursors was achieved using microwave-assisted chemical sulfation as described earlier. Briefly, to a stirred solution of polyphenol in anhydrous $\mathrm{CH}_{3} \mathrm{CN}(1-5 \mathrm{~mL})$ at room temperature, $\mathrm{Et}_{3} \mathrm{~N}$ (10 equiv per $-\mathrm{OH}$ group) and $\mathrm{Me}_{3} \mathrm{~N} / \mathrm{SO}_{3}$ complex ( 6 equiv per $-\mathrm{OH}$ ) were added. The reaction vessel was sealed and microwaved (CEM Discover, Cary, NC) for 4 to $6 \mathrm{~h}$ at $90{ }^{\circ} \mathrm{C}$. The reaction mixture was cooled and transferred to a roundbottom flask, and the volume was reduced as much as possible under low pressure conditions at $25^{\circ} \mathrm{C}$. The reaction mixture was then directly loaded on to a flash chromatography column and purified using a dichloromethane and methanol solvent system (5-30\%) to obtain the sulfated flavonoid dimers and trimers. The samples were concentrated and reloaded onto a SP Sephadex C-25 column for sodium exchange. Appropriate fractions were pooled, concentrated in vacuo, and lyophilized to obtain a white powder. Spectral characteristics of all the sulfated compounds G-2.1-G-2.6, G-3.1, G-3.2, G-4.1 and G-4.2, are listed below.

G2.1. ${ }^{1} \mathrm{H}$ NMR (DMSO-d 6 , $\left.400 \mathrm{MHz}\right): 8.19-8.09$ (m, $\left.4 \mathrm{H}\right), 7.66(\mathrm{~d}, J=9 \mathrm{~Hz}, 2 \mathrm{H}), 7.1$ (d, $J=2$ $\mathrm{Hz}, 2 \mathrm{H}), 6.87$ (d, J=2.0 Hz, $2 \mathrm{H}), 4.55$ (s, $4 \mathrm{H}) .{ }^{13} \mathrm{C}$ NMR (DMSO-d $\left.6,100 \mathrm{MHz}\right): 174.14,158.66$, 156.91, 154.16, 146.72, 142.98, 135.13, 124.6, 123.27, 119.90, 118.83, 109.70, 99.78, 68.21. ESI-MS calculated for $\mathrm{C}_{32} \mathrm{H}_{14} \mathrm{Na}_{8} \mathrm{O}_{38} \mathrm{~S}_{8}[(\mathrm{M}+\mathrm{Na})]^{+}, m / z$ 1469.87, found $[(\mathrm{M}-8 \mathrm{Na}+8 \mathrm{HxA})+2 \mathrm{HxA}]^{2+}, m / z$ 1142.812 .

G2.2. ${ }^{1} \mathrm{H}$ NMR (DMSO-d 6 , $\left.400 \mathrm{MHz}\right): 8.07-7.99(\mathrm{~m}, 4 \mathrm{H}), 7.56(\mathrm{~d}, J=9 \mathrm{~Hz}, 2 \mathrm{H}), 6.98(\mathrm{~d}, \mathrm{~J}=$ $1.6 \mathrm{~Hz}, 2 \mathrm{H}), 6.66$ (s, $2 \mathrm{H}), 4.2$ (s, $4 \mathrm{H}), 2.28$ (s, $2 \mathrm{H}) .{ }^{13} \mathrm{C} \mathrm{NMR}\left(\mathrm{DMSO}-\mathrm{d}_{6}, 100 \mathrm{MHz}\right): 159.07$, 157.02, 146.44, 142.92, 135.31, 124.50, 123.56, 119.81, 109.56, 66.37, 42.41. ESI-MS calculated for $\mathrm{C}_{33} \mathrm{H}_{16} \mathrm{Na}_{8} \mathrm{O}_{38} \mathrm{~S}_{8}[(\mathrm{M}+\mathrm{Na})]^{+}, m / z$ 1483.90, found $[(\mathrm{M}-8 \mathrm{Na}+8 \mathrm{HxA})+2 \mathrm{HxA}]^{2+}, m / z$ 1149.085.

G2.3. ${ }^{1} \mathrm{H}$ NMR (DMSO- $\left.\mathrm{d}_{6}, 400 \mathrm{MHz}\right): 7.60$ (d, $\left.J=9 \mathrm{~Hz}, 2 \mathrm{H}\right), 7.35$ (d, $\left.J=2 \mathrm{~Hz}, 2 \mathrm{H}\right), 7.09-7.06$ $(\mathrm{m}, 4 \mathrm{H}), 6.97$ (d, $J=1.8 \mathrm{~Hz}, 2 \mathrm{H}), 4.55$ (s, $4 \mathrm{H}) .{ }^{13} \mathrm{C}$ NMR (DMSO-d $\left.6,100 \mathrm{MHz}\right): 174.62,158.61$, 158.46, 157.47, 156.13, 155.68, 152.14, 136.26, 131.07, 116.34, 113.46, 112.04, 110.35, 101.83, 100.74, 68.65. ESI-MS calculated for $\mathrm{C}_{32} \mathrm{H}_{14} \mathrm{Na}_{8} \mathrm{O}_{38} \mathrm{~S}_{8}[(\mathrm{M}+\mathrm{Na})]^{+}, m / z$ 1469.87, found [(M-8Na+8 $\mathrm{HxA}+2 \mathrm{HxA}]^{2+}, m / z 1142.588$. 
G2.4. ${ }^{1} \mathrm{H}$ NMR (DMSO- $\left.\mathrm{d}_{6}, 400 \mathrm{MHz}\right)$ : 8.15-8.07 (m, $\left.4 \mathrm{H}\right), 7.64(\mathrm{~d}, J=9 \mathrm{~Hz}, 2 \mathrm{H}), 7.04(\mathrm{~d}, J=$ $1.8 \mathrm{~Hz}, 2 \mathrm{H}), 6.72(\mathrm{~s}, 2 \mathrm{H}), 4.15$ (s, $4 \mathrm{H}), 2.11(\mathrm{~s}, 4 \mathrm{H}) .{ }^{13} \mathrm{C}$ NMR (DMSO-d $\left.6,100 \mathrm{MHz}\right): 173.0,159.41$, 158.31, 157.01, 153.27, 146.41, 142.92, 135.30, 124.50, 123.59, 119.80, 118.77, 109.42, 100.02, 98.85, 68.81, 25.5. ESI-MS calculated for $\mathrm{C}_{34} \mathrm{H}_{18} \mathrm{Na}_{8} \mathrm{O}_{38} \mathrm{~S}_{8}[(\mathrm{M}+\mathrm{Na})]^{+}, \mathrm{m} / z$ 1497.95, found $[(\mathrm{M}-8 \mathrm{Na}+8$ $\mathrm{HxA})+2 \mathrm{HxA}]^{2+}, m / z 1156.367$.

G2.5. ${ }^{1} \mathrm{H}$ NMR (DMSO-d 6 , $\left.400 \mathrm{MHz}\right)$ : 8.14-8.05 (m, $\left.4 \mathrm{H}\right), 7.63(\mathrm{~d}, J=9 \mathrm{~Hz}, 2 \mathrm{H}), 7.03(\mathrm{~d}, J=$ $1.8 \mathrm{~Hz}, 2 \mathrm{H}), 6.72(\mathrm{~s}, 2 \mathrm{H}), 4.1(\mathrm{~s}, 4 \mathrm{H}), 1.94(\mathrm{~s}, 4 \mathrm{H}), 1.74(\mathrm{~s}, 2 \mathrm{H}) .{ }^{13} \mathrm{C}$ NMR (DMSO-d $\left.6,100 \mathrm{MHz}\right)$ : 173.6, 159.21, 158.21, 157.01, 153.17, 146.21, 142.52, 135.30, 124.4, 123.95, 119.79, 118.76, 109.45, 100.32, 98.65, 67.81, 25.5, 23.8. ESI-MS calculated for $\mathrm{C}_{35} \mathrm{H}_{20} \mathrm{Na}_{8} \mathrm{O}_{38} \mathrm{~S}_{8}[(\mathrm{M}+\mathrm{Na})]^{+}, m / z$ 1511.95, found $[(\mathrm{M}-8 \mathrm{Na}+8 \mathrm{HxA})+2 \mathrm{HxA}]^{2+}, m / z$ 1163.163.

G2.6. ${ }^{1} \mathrm{H}$ NMR (DMSO- $\left.\mathrm{d}_{6}, 400 \mathrm{MHz}\right): 8.07(\mathrm{~d}, J=2.2 \mathrm{~Hz}, 2 \mathrm{H}), 8.0(\mathrm{~d}, J=6.7 \mathrm{~Hz}, 2 \mathrm{H}), 6.98(\mathrm{~d}$, $J=1.9 \mathrm{~Hz}, 2 \mathrm{H}), 6.63(\mathrm{~d}, J=1.9 \mathrm{~Hz}, 2 \mathrm{H}), 6.39(\mathrm{~s}, 2 \mathrm{H}), 4.64(\mathrm{~s}, 4 \mathrm{H}) .{ }^{13} \mathrm{C}$ NMR (DMSO-d, $\left.100 \mathrm{MHz}\right)$ : 173.24, 158.43, 158.25, 157.08, 154.28, 148.43, 143.82, 134.31, 123.50, 123.28, 119.84, 118.78, $108.45,100.05,98.87,75.81$. ESI-MS calculated for $\mathrm{C}_{34} \mathrm{H}_{16} \mathrm{Na}_{8} \mathrm{O}_{38} \mathrm{~S}_{8}[(\mathrm{M}+\mathrm{Na})]^{+}, m / z$ 1495.91, found $[(\mathrm{M}-8 \mathrm{Na}+8 \mathrm{HxA})+2 \mathrm{HxA}]^{2+}, m / z, 1155.620$.

G3.1. ${ }^{1} \mathrm{H}$ NMR (DMSO-d $\left.\mathrm{D}_{6}, 400 \mathrm{MHz}\right): 12.33$ (s, $\left.2 \mathrm{H}\right), 8.01$ (s, $\left.2 \mathrm{H}\right), 7.64-7.56(\mathrm{~m}, 4 \mathrm{H}), 6.95$ (d, $J=1.9 \mathrm{~Hz}, 2 \mathrm{H}), 6.58(\mathrm{~d}, J=2.0 \mathrm{~Hz}, 2 \mathrm{H}), 4.17(\mathrm{t}, J=2.0 \mathrm{~Hz}, 4 \mathrm{H}), 2.13-2.11(\mathrm{~m}, 2 \mathrm{H}) .{ }^{13} \mathrm{C} \mathrm{NMR}$ (DMSO-d 6 , $100 \mathrm{MHz}$ ): 177.97, 160.11, 159.60, 155.32, 148.52, 145.74, 133.29, 124.47, 121.16, 119.64, 115.11, 106.08, 101.93, 97.75, 65.50, 52.77. ESI-MS calculated for $\mathrm{C}_{33} \mathrm{H}_{18} \mathrm{Na}_{6} \mathrm{O}_{32} \mathrm{~S}_{6}[(\mathrm{M}+\mathrm{Na})]^{+}$, $m / z$ 1279.81, found [(M-6Na+6 HxA)+HxA $]^{+}, m / z 1833.882$.

G3.2. ${ }^{1} \mathrm{H}$ NMR (DMSO- $\left.\mathrm{d}_{6}, 400 \mathrm{MHz}\right): 12.34(\mathrm{~s}, 2 \mathrm{H}), 8.03(\mathrm{~d}, J=2 \mathrm{~Hz}, 2 \mathrm{H}), 7.64-7.58(\mathrm{~m}, 4 \mathrm{H})$, $6.92(\mathrm{~d}, J=1.8 \mathrm{~Hz}, 2 \mathrm{H}), 6.57(\mathrm{~d}, J=1.8 \mathrm{~Hz}, 2 \mathrm{H}), 6.10(\mathrm{~s}, 2 \mathrm{H}), 4.61(\mathrm{~s}, 4 \mathrm{H}) .{ }^{13} \mathrm{C}$ NMR $\left(\mathrm{DMSO}-\mathrm{d}_{6}\right.$, $100 \mathrm{MHz}$ ): 177.97, 160.14, 159.60, 156.40, 155.30, 148.29, 145.65, 133.35, 128.69, 124.35, 119.46, 114.92, 106.10, 101.96, 97.75, 68.41, 52.78. ESI-MS calculated for $\mathrm{C}_{34} \mathrm{H}_{18} \mathrm{Na}_{6} \mathrm{O}_{32} \mathrm{~S}_{6}[(\mathrm{M}+\mathrm{Na})]^{+}, m / z$ 1291.82, found $[(\mathrm{M}-6 \mathrm{Na}+6 \mathrm{HxA})+\mathrm{HxA}]^{+}, m / z 1845.498$.

G4.1. ${ }^{1} \mathrm{H}$ NMR (DMSO- $\left.\mathrm{d}_{6}, 400 \mathrm{MHz}\right)$ : 8.18-8.06 (m, $\left.5 \mathrm{H}\right), 7.79-7.63$ (m, $\left.4 \mathrm{H}\right), 7.31-7.14$ (m, 3 $\mathrm{H}), 6.92-6.74(\mathrm{~m}, 3 \mathrm{H}), 4.52(\mathrm{~s}, 6 \mathrm{H}), 4.42(\mathrm{~s}, 2 \mathrm{H}) .{ }^{13} \mathrm{C}$ NMR (DMSO-d $\left.6,100 \mathrm{MHz}\right): 170.92,170.81$, 162.38 , 162.34, 159.47, 157.94, 157.89, 148.61, 146.95, 146.26, 145.04, 141.98, 141.92, 141.63, 137.24, 137.12, 137.09, 127.99, 125.47, 122.42, 122.26, 121.49, 119.11, 115.84, 115.58, 114.51, 113.50, 105.52, 105.44, 97.71, 95.20, 95.10, 67.84, 67.72, 59.69. ESI-MS calculated for $\mathrm{C}_{49} \mathrm{H}_{23} \mathrm{Na}_{11} \mathrm{O}_{54} \mathrm{~S}_{11}$ $[(\mathrm{M}+\mathrm{Na})]^{+}, m / z, 2104.28$, found $[(\mathrm{M}-11 \mathrm{Na}+11 \mathrm{HxA})+2 \mathrm{HxA}]^{2+}, m / z$ 1578.349.

G4.2. ${ }^{1} \mathrm{H}$ NMR (DMSO-d 6 , 400 MHz): 8.14-8.06 (m, 5 H), 7.68-7.62 (m, 4 H), 7.16-7.05 (m, 3 $\mathrm{H}), 6.79-6.63(\mathrm{~m}, 3 \mathrm{H}), 4.32(\mathrm{~s}, 6 \mathrm{H}), 4.24(\mathrm{~s}, 2 \mathrm{H}), 2.35-2.27(\mathrm{~m}, 4 \mathrm{H}) .{ }^{13} \mathrm{C}$ NMR (DMSO-d 6,100 MHz): 171.92, 170.29, 162.48, 162.64, 159.67, 157.85, 157.19, 149.81, 145.85, 146.86, 144.04, $140.68,141.82,140.73,137.64,137.32,137.19,127.88,124.48,123.41,122.26,121.49,119.11$, $115.84,115.58,114.51,113.50,105.52,105.44,97.71,95.20,95.10,66.94,66.68$. ESI-MS calculated for $\mathrm{C}_{49} \mathrm{H}_{23} \mathrm{Na}_{11} \mathrm{O}_{54} \mathrm{~S}_{11}[(\mathrm{M}+\mathrm{Na})]^{+}, m / z$ 2132.33, found $[(\mathrm{M}-11 \mathrm{Na}+11 \mathrm{HxA})+2 \mathrm{HxA}]^{2+}, m / z 1592.727$. 


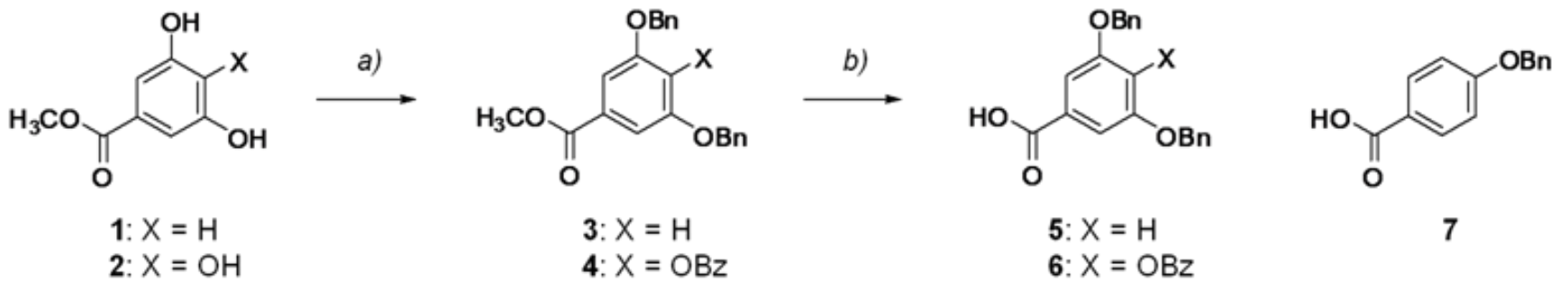<smiles>O=Cc1ccc(C(=O)O)cc1</smiles><smiles>O=Cc1ccc(C(=O)OCc2ccccc2)cc1</smiles><smiles>O=C(O)c1ccc(C(=O)OCc2ccccc2)cc1</smiles>

Scheme S4. Structures and synthesis of side chains. a) $\mathrm{BnBr}$ (3-4 eq.) $\mathrm{K}_{2} \mathrm{CO}_{3}$ (3-4 eq.), DMAP (Cat.), $\mathrm{CH}_{2} \mathrm{Cl}_{2}$, rt, 24 hrs, 87\%. b) LiOH.H $\mathrm{H}_{2} \mathrm{O}$ (5 eq.), $\mathrm{CH}_{3} \mathrm{OH}, \mathrm{H}_{2} \mathrm{O}, \mathrm{rt}, 8$ hrs, $71 \%$. c) $\mathrm{BnBr}$ (1.5 eq.), $\mathrm{K}_{2} \mathrm{CO}_{3}$ (1.5 eq.), DMAP (Cat.), $\mathrm{CH}_{2} \mathrm{Cl}_{2}, \mathrm{rt}, 4$ hrs, $92 \%$. d) Oxone ${ }^{\circledR}$ (2 eq.), DMF, rt, 24 hrs, $78 \%$.<smiles>OC1COC(O)C(O)C(O)C1O</smiles>

11<smiles>[CH]=C</smiles>

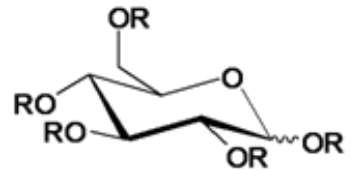<smiles>[R]C(=O)c1cc([Y])c([Y2])c([Y])c1</smiles>

12

12a: $Y_{1}=Y_{2}=Y_{3}=O B n$ 12b: $Y_{1}=Y_{3}=O B n, Y_{2}=H$

b) 12c: $Y_{1}=Y_{3}=H, Y_{2}=O B n$ 12d: $Y_{1}=Y_{3}=H, Y_{2}=C O O B n$

G11.1: $Y_{1}=Y_{2}=Y_{3}=O H$ and/or $\mathrm{OSO}_{3}{ }^{-}$

G11.2: $Y_{1}=Y_{3}=\mathrm{OSO}_{3}^{-}, Y_{2}=\mathrm{H}$

G11.3: $Y_{1}=Y_{3}=H, Y_{2}=\mathrm{OSO}_{3}^{-}$

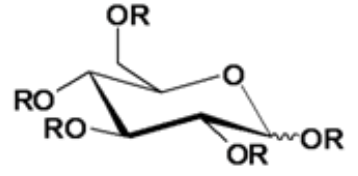<smiles>[Y]c1cc(C(C)=O)cc([Y])c1[Y]</smiles>

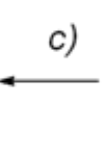

13a: $Y_{1}=Y_{2}=Y_{3}=\mathrm{OH}$

13b: $Y_{1}=Y_{3}=\mathrm{OH}, Y_{2}=\mathrm{H}$

13c: $Y_{1}=Y_{3}=\mathrm{H}, Y_{2}=\mathrm{OH}$

G11.4: $Y_{1}=Y_{3}=H, Y_{2}=\mathrm{COOH}$

Scheme S5. Synthesis of penta-substituted glycosides. a) 5, 6, 7, or 10 (5 eq.), DCC (5 eq.), DMAP (5 eq.), $\mathrm{CH}_{2} \mathrm{Cl}_{2}$, reflux, $24 \mathrm{hrs}, 75 \%$. b) $\mathrm{H}_{2}$ (g) (50 psi), $\mathrm{Pd}(\mathrm{OH})_{2} / \mathrm{C}(20 \%)$, $\mathrm{CH}_{3} \mathrm{OH} / \mathrm{THF}, \mathrm{rt}, 6 \mathrm{hrs}, 95 \%$. c) $\mathrm{SO}_{3}-\mathrm{N}\left(\mathrm{CH}_{3}\right)_{3}\left(5\right.$ eq./OH), $\mathrm{CH}_{3} \mathrm{CN}(2 \mathrm{~mL}), \mathrm{MW}$, $90{ }^{\circ} \mathrm{C}, 8 \mathrm{hrs}, 55-70 \%$. 


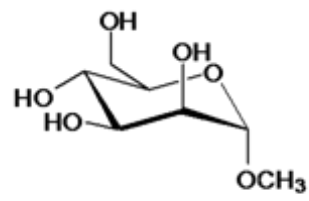

a)

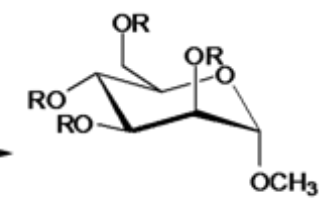

$R=\overbrace{O B n}^{O B n}$

15 b)

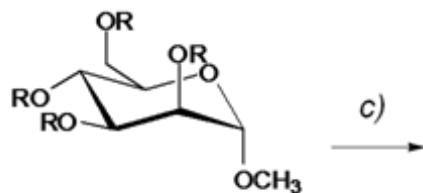<smiles>[R]=CC(=O)c1cc(O)cc(O)c1</smiles>

16

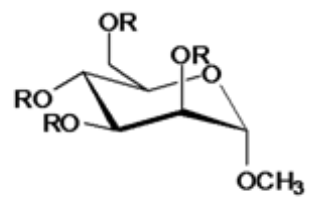

$\mathrm{R}=\overbrace{\mathrm{OSO}_{3}^{-}}^{\mathrm{OSO}_{3}^{-}}$

G11.5

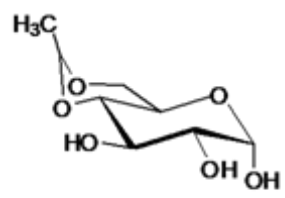

17 a)

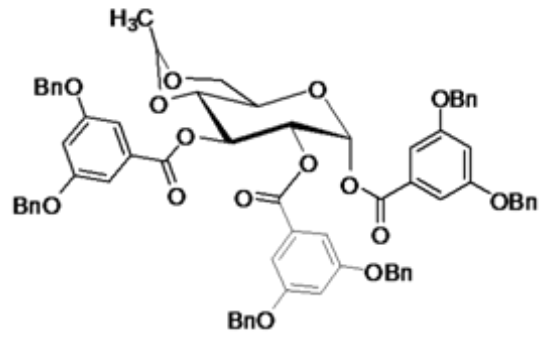

18

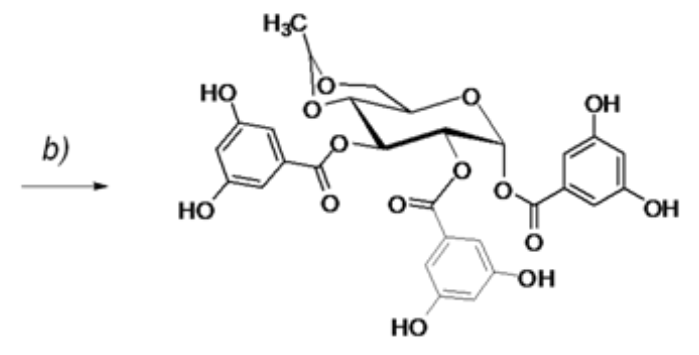

19

c)

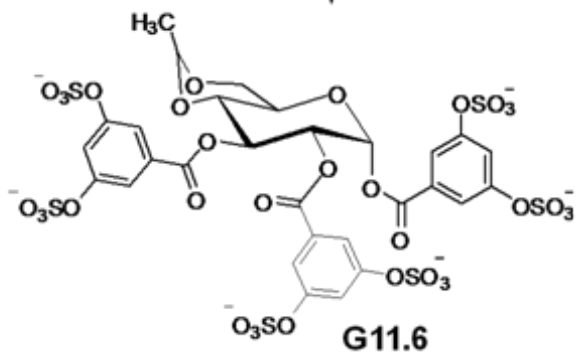

Scheme S6. Synthesis of tetra and tri-substituted glycosides. a) 5 (3-4 eq.), DCC (3-4 eq.), DMAP (3-4 eq.), $\mathrm{CH}_{2} \mathrm{Cl}_{2}$, reflux, $24 \mathrm{hrs}, 80-85 \%$. b) $\mathrm{H}_{2}$ (g) (50 psi), $\mathrm{Pd}(\mathrm{OH})_{2} / \mathrm{C}$ (20\%), $\mathrm{CH}_{3} \mathrm{OH} / \mathrm{THF}, \mathrm{rt}, 6 \mathrm{hrs}, 90 \%$. c) $\mathrm{SO}_{3}-\mathrm{N}\left(\mathrm{CH}_{3}\right)_{3}$ (5 eq./OH), $\mathrm{CH}_{3} \mathrm{CN}(2 \mathrm{~mL})$, $\mathrm{MW}, 90{ }^{\circ} \mathrm{C}, 8 \mathrm{hrs}, 65-72 \%$. 


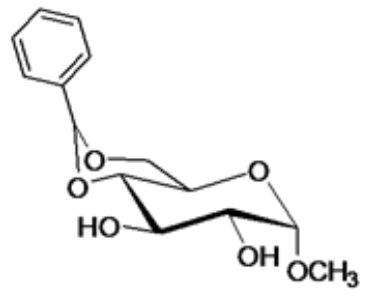

20 a)

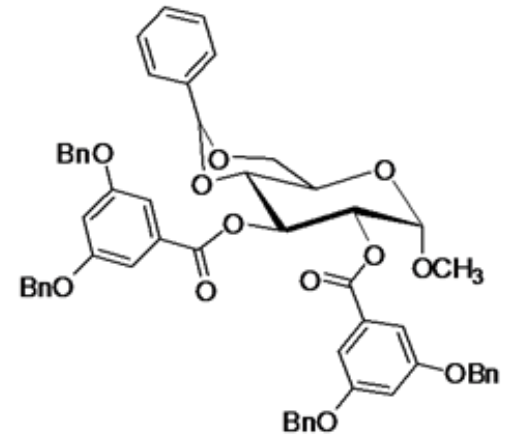

21

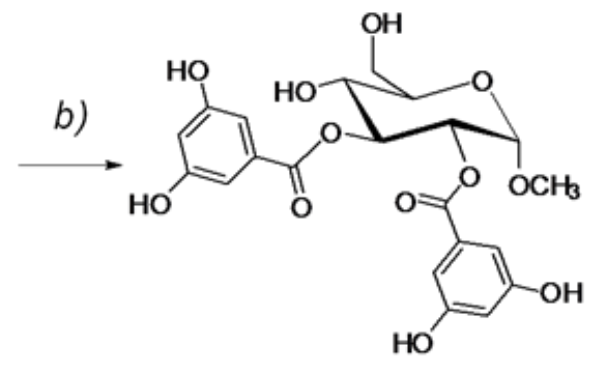

22

c)

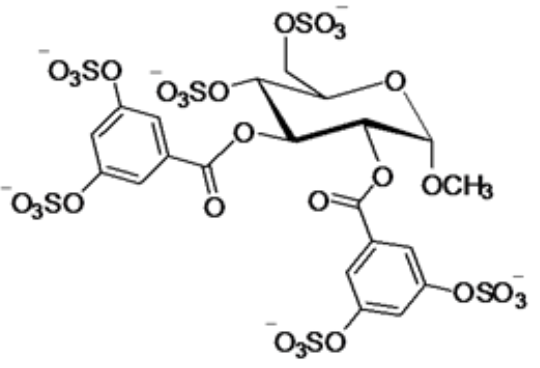

G11.7

Scheme S7. Synthesis of $d i$-substituted glycosides. a) 5 (2 eq.), DCC (2 eq.), DMAP (2 eq.), $\mathrm{CH}_{2} \mathrm{Cl}_{2}$, reflux, $24 \mathrm{hrs}, 91 \%$. b) $\mathrm{H}_{2}$ (g) (50 psi), $\mathrm{Pd}(\mathrm{OH})_{2} / \mathrm{C}(20 \%), \mathrm{CH}_{3} \mathrm{OH} / \mathrm{THF}$, rt, 8 hrs, $83 \%$. c) $\mathrm{SO}_{3}-\mathrm{N}\left(\mathrm{CH}_{3}\right)_{3}(5$ eq. $/ \mathrm{OH}), \mathrm{CH}_{3} \mathrm{CN}(2 \mathrm{~mL}), \mathrm{MW}, 90{ }^{\circ} \mathrm{C}, 8 \mathrm{hrs}$, $65 \%$. 


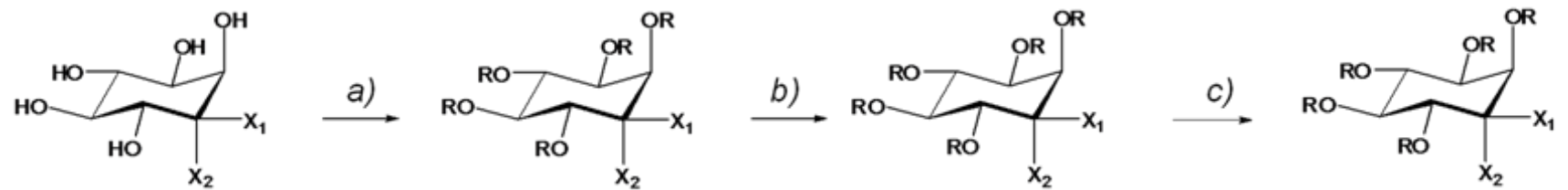

23: $\mathrm{X}_{1}=\mathrm{OH}, \mathrm{X}_{2}=\mathrm{H}$

24: $X_{1}=H, X_{2}=O H$

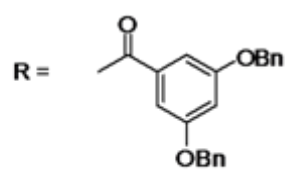

25: $X_{1}=\mathrm{OH}, \mathrm{X}_{2}=\mathrm{H}$

26: $X_{1}=\mathrm{H}, X_{2}=\mathrm{OH}$

c)

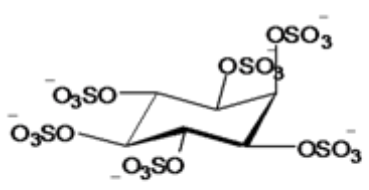

G12.3

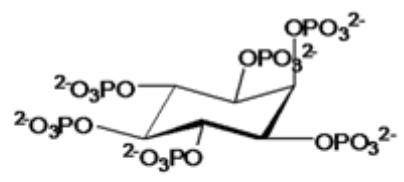

G12.4<smiles>CC(=O)c1cc(O)cc(O)c1</smiles>

27: $X_{1}=\mathrm{OH}, \mathrm{X}_{2}=\mathrm{H}$

28: $X_{1}=H, X_{2}=O H$

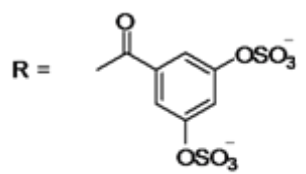

G12.1: $X_{1}=O H, X_{2}=H$

G12.2: $X_{1}=H, X_{2}=O H$

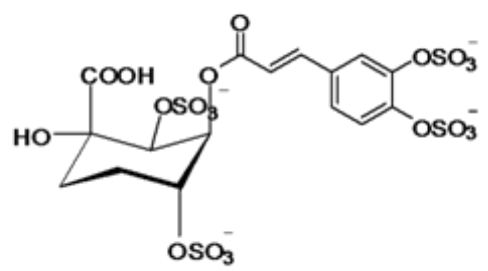

G12.5

Scheme S8. Structures and synthesis of substituted inositol derivatives. a) 5 (6 eq.), DCC (6 eq.), DMAP (6 eq.), $\mathrm{CH}_{2} \mathrm{Cl}_{2}$, reflux, $24 \mathrm{hrs}, 70 \%$. b) $\mathrm{H}_{2}$ (g) (50 psi), $\mathrm{Pd}(\mathrm{OH})_{2} / \mathrm{C}(20 \%)$, $\mathrm{CH}_{3} \mathrm{OH} / \mathrm{THF}, \mathrm{rt}, 6 \mathrm{hrs}, 90 \%$. c) $\mathrm{SO}_{3}-\mathrm{N}\left(\mathrm{CH}_{3}\right)_{3}\left(5\right.$ eq./OH), $\mathrm{CH}_{3} \mathrm{CN}(2 \mathrm{~mL}), \mathrm{MW}, 90{ }^{\circ} \mathrm{C}, 8 \mathrm{hrs}, 60-$ $65 \%$. 


\section{Synthesis of Sulfated Tetrahydroisoquinolines (THIQs) G10.1-G10.8, Sulfated Glycosides G11.1-G11.7, and Sulfated Inositols G12.1-G12.5.}

Polyphenolic 1,2,3,4-tetrahydroisoquinolines (THIQs) were chemically synthesized as reported

earlier. ${ }^{2,3}$ Briefly, synthesis of polyphenolic THIQ derivatives was achieved starting from the corresponding aldehydes by Horner-Wadsworth-Emmons reaction, followed by catalytic hydrogen and $N$-Boc deprotection. The resulting amino esters were subjected to formaldehyde/TFA-mediated PictetSpengler reaction, EDCI-mediated amidation, and $\mathrm{BBr}_{3}$-assisted deprotection to afford the desired polyphenolic derivatives as yellowish white solids in yield of $>75 \%$.

Polyphenolic glycosides $(\mathbf{1 3 a}-\mathbf{c}, \mathbf{1 6}, \mathbf{1 9}, \mathbf{2 2})$ and polyphenolic substituted inositols (27 and 28) were obtained in two steps, esterification and catalytic hydrogenation. In esterification step, a substituted benzoic acid (4-benzyloxy benzoic acid, 3,5-dibenzyloxy benzoic acid (5), 3,4,5tribenzyloxy benzoic acid (6), or 4-benzyloxycarbonyl benzoic acid (10)) was treated with DCC and DMAP in anhydrous $\mathrm{CH}_{2} \mathrm{Cl}_{2}$. The resulting activated acids were further treated with the desired polyalcohols $(\beta$ - $D$-glucopyranose, $\alpha, \beta$ - $D$-glucopyranose, 1 - $O$-methyl- $\alpha$ - $D$-mannopyranose, 4 , 6- $O$ ethylidene- $\alpha$ - $D$-glucopyranose, 4, 6- $O$-benzylidene-1- $O$-methyl- $\alpha$ - $D$-glucopyranoside, myo-inositol, and $D-(+)$-chiro-inositol) and refluxed $24 \mathrm{hrs}$ to afford the corresponding protected esters (12a-d, 15, 18, 21, 25, or 26) as white solids in yield of 70-91\%. In catalytic hydrogenation (deprotection of benzyl group), a solution of benzylated benzoyl derivatives in $\mathrm{CH}_{3} \mathrm{OH} / \mathrm{THF}$ solvent mixture was hydrogenated over $20 \%$ of $10 \% \mathrm{Pd}(\mathrm{OH})_{2} / \mathrm{C}$ with $\mathrm{H}_{2}$ (gas) (50 psi) at RT for 6-8 hrs. After purification, the desired polyphenolic intermediates were obtained as yellow-white solids in yield of 83-95\%. Importantly, the polyalcohols along with 4-benzyloxy benzoic acid used in the esterification step were commercially available whereas benzoic acid derivatives $(\mathbf{5}, \mathbf{6}$, and 10) were chemically synthesized. Briefly, benzyl bromide-mediated protection of methyl 3,5-dihydroxy benzoate and methyl 3,4,5-trihydroxy benzoate followed by $\mathrm{LiOH}$-promoted ester hydrolysis afforded intermediates $\mathbf{5}$ and $\mathbf{6}$, respectively, in overall yield of 61-65\%. Intermediate 10 was quantitatively obtained in overall yield of about $70 \%$ by benzyl bromide treating of 4-formyl benzoic acid in $\mathrm{CH}_{2} \mathrm{Cl}_{2}$ in presence of $\mathrm{K}_{2} \mathrm{CO}_{3}$ and catalytic amount of DMAP, followed by Oxone® oxidation in DMF (Scheme 1).

Sulfated molecules were synthesized by microwave-assisted synthesis followed by size exclusion and sodium exchange chromatographies. All sulfated molecules (penta-substituted glycosides: G11.1-G11.3 (Scheme 2), tetra-substituted glycoside G11.5 and tri-substituted glycoside G11.6 (Scheme 3), $d i$-substituted glycoside G11.7 (Scheme 4), and inositol derivatives G12.1-G12.3, and G12.5 (Scheme 5)) were quantitatively obtained in yield of 55-70\% as white fluffy powder. Briefly, the polyphenolic precursors $(13 a-c, 16,19,22)$ and trimethylamine-sulfur trioxide $(5$ equivalents/-OH group) were mixed in anhydrous $\mathrm{CH}_{3} \mathrm{CN}(2 \mathrm{~mL})$ under nitrogen in microwave tube. The reaction tube was sealed and microwaved for $2-8$ at $90-100{ }^{\circ} \mathrm{C}$. Sulfated chlorogenic acid (G12.5) was obtained by the same sulfation protocol for its commercially available polyphenolic precursor, chlorogenic acid. The only phosphorylated molecule in this series, sodium phytate (G12.4), was commercially available and was used in relation to sulfated myo-inositol (G12.3).

\section{Experimental Section}

General procedure for benzylation. To a stirring solution of methyl 3,5-dihydroxyl benzoate (1), methyl 3,4,5-trihydroxy benzoate (2), or 4-formyl benzoic acid (8) (1.0 mmol) in anhydrous $\mathrm{CH}_{2} \mathrm{Cl}_{2}(10 \mathrm{~mL}), \mathrm{K}_{2} \mathrm{CO}_{3}(1.5-4.0 \mathrm{mmol})$ and DMAP (cat.) were added at $0{ }^{\circ} \mathrm{C}$. The resulting mixture was kept stirring until it became clear solution. A solution of benzyl bromide (1.5-4.0 mmol) in $\mathrm{CH}_{2} \mathrm{Cl}_{2}$ was then added dropwise and temperature brought back to RT. The solution was kept stirring 
for 4-24 hrs and the reaction was then stopped as TLC indicated the completion of reaction. The organic phase was then diluted $(10 \mathrm{~mL})$, washed with $\mathrm{HCl}(1 \mathrm{~N}, 15 \mathrm{~mL})$ and brine solution $(15$ $\mathrm{mL}$ ). The organic phase was dried over anhydrous $\mathrm{Na}_{2} \mathrm{SO}_{4}$, concentrated in vacuo, and purified by flash chromatography using hexanes/EtOAc mobile phase as described above. $20 \mathrm{~mL}$ fractions containing the desired product $(\mathbf{3}, \mathbf{4}$, or $\mathbf{9})$ were pooled together and concentrated in vacuo to afford the desired products as colorless oil (87-92\%).

Methyl 3,5-(dibenzyloxy)benzoate (3). ${ }^{1} \mathrm{H}$ NMR $\left(\mathrm{CDCl}_{3}, 400 \mathrm{MHz}\right): 7.36-7.30(\mathrm{~m}, 7 \mathrm{H}), 7.27$ $(\mathrm{d}, 2 \mathrm{H}, J=6.68 \mathrm{~Hz}), 7.23(\mathrm{~s}, 2 \mathrm{H}), 6.73(\mathrm{~s}, 1 \mathrm{H}), 5.0(\mathrm{~s}, 4 \mathrm{H}), 3.83(\mathrm{~s}, 3 \mathrm{H}) .{ }^{13} \mathrm{C} \mathrm{NMR}\left(\mathrm{CDCl}_{3}, 100\right.$ MHz): 166.75, 159.85, 136.54, 132.13, 128.61, 128.09, 127.54, 108.50, 107.35, 70.35, 52.20. MS (ESI) calculated for $\mathrm{C}_{22} \mathrm{H}_{20} \mathrm{O}_{4},[\mathrm{M}+\mathrm{H}]^{+}, \mathrm{m} / \mathrm{z} 349.4$, found for $[\mathrm{M}+\mathrm{H}]^{+}, \mathrm{m} / \mathrm{z} 349.419$.

Methyl 3,4,5-(tribenzyloxy)benzoate (4). ${ }^{1} \mathrm{H} \mathrm{NMR}\left(\mathrm{CDCl}_{3}, 400 \mathrm{MHz}\right): 7.41-7.16(\mathrm{~m}, 17 \mathrm{H})$, $5.09(\mathrm{~s}, 1 \mathrm{H}), 5.08(\mathrm{~s}, 1 \mathrm{H}), 5.05(\mathrm{~s}, 3 \mathrm{H}), 5.03(\mathrm{~s}, 1 \mathrm{H}), 3.79(\mathrm{~s}, 3 \mathrm{H}) .{ }^{13} \mathrm{C} \mathrm{NMR}\left(\mathrm{CDCl}_{3}, 100 \mathrm{MHz}\right)$ : 166.62, 152.60, 151.12, 149.47, 142.52, 138.61, 137.49, 136.69, 136.36, 128.73, 128.68, 128.59, 128.54, 128.26, 128.18, 128.02, 127.93, 127.69, 127.55, 125.82, 125.25, 110.15, 109.19, 107.01, 75.46, 75.14, 71.29, 71.13, 52.20. MS (ESI) calculated for $\mathrm{C}_{29} \mathrm{H}_{26} \mathrm{O}_{5},[\mathrm{M}+\mathrm{H}]^{+}, \mathrm{m} / \mathrm{z} 455.52$, found for $[\mathrm{M}$ $+\mathrm{Na}]^{+}, \mathrm{m} / \mathrm{z} 477.210$.

Benzyl 4-formyl benzoate (9). ${ }^{1} \mathrm{H} \mathrm{NMR}\left(\mathrm{CDCl}_{3}, 400 \mathrm{MHz}\right): 10.02(\mathrm{~s}, 1 \mathrm{H}), 8.15(\mathrm{~d}, 2 \mathrm{H}, J=$ $8.24 \mathrm{~Hz}), 7.87(\mathrm{~d}, 2 \mathrm{H}, J=8.36 \mathrm{~Hz}), 7.39-7.28(\mathrm{~m}, 5 \mathrm{H}), 5.32(\mathrm{~s}, 2 \mathrm{H}) .{ }^{13} \mathrm{C} \mathrm{NMR}\left(\mathrm{CDCl}_{3}, 100 \mathrm{MHz}\right)$ : 191.50, 165.38, 139.26, 135.58, 135.14, 130.30, 129.48, 129.07, 128.68, 128.61, 128.49, 128.32, 67.31. MS (ESI) calculated for $\mathrm{C}_{15} \mathrm{H}_{12} \mathrm{O}_{3},[\mathrm{M}+\mathrm{H}]^{+}, \mathrm{m} / \mathrm{z} 241.26$, found for $[\mathrm{M}+\mathrm{Na}]^{+}, \mathrm{m} / \mathrm{z} 263.24$.

Methyl ester hydrolysis. To a stirred solution of methyl ester, methyl 3,4-(dibenzyloxy) benzoate (3) or methyl 3,4,5-(tribenzyloxy)benzoate (4), (1.0 mmol) in $\mathrm{CH}_{3} \mathrm{OH}: \mathrm{H}_{2} \mathrm{O}(18: 2 \mathrm{~mL})$ was added $\mathrm{LiOH}-\mathrm{H}_{2} \mathrm{O}(5.0 \mathrm{mmol})$ at $\mathrm{RT}$. Water $(5 \mathrm{~mL})$ was added after $8 \mathrm{hrs}$ to the reaction mixture which was kept stirring for further $30 \mathrm{~min}$. The reaction mixture was then concentrated in vacuo to about 10 $\mathrm{mL}$ and acidified by $\mathrm{HCl}(1 \mathrm{~N}, 5 \mathrm{~mL})$. The mixture was extracted with EtOAc $(2 \times 20 \mathrm{~mL})$. The organic extracts were combined, dried over anhydrous $\mathrm{Na}_{2} \mathrm{SO}_{4}$, filtered, and finally concentrated by rotary evaporation. The corresponding carboxylic acid derivative, 3,5-(dibenzyloxy)benzoic acid (5) or 3,4,5-(tribenzyloxy)benzoic acid (6), was obtained as yellowish white solid in $70 \%$ yield.

3,5-(dibenzyloxy)benzoic acid (5). ${ }^{1} \mathrm{H}$ NMR (acetone- $\left.d_{6}, 400 \mathrm{MHz}\right): 7.53$ (s, $\left.2 \mathrm{H}\right), 7.51$ (s, $2 \mathrm{H}$ ), 7.44-7.35 (m, $4 \mathrm{H}), 7.30(\mathrm{t}, 3 \mathrm{H}, J=1.36 \mathrm{~Hz}), 6.95(\mathrm{~s}, 1 \mathrm{H}), 5.20(\mathrm{~s}, 4 \mathrm{H}) .{ }^{13} \mathrm{C}$ NMR (acetone- $d_{6}, 100$ MHz): 171.48, 165.25, 142.34, 137.81, 133.62, 133.03, 132.76, 113.70, 111.94, 75.16. MS (ESI) calculated for $\mathrm{C}_{21} \mathrm{H}_{14} \mathrm{O}_{6},[\mathrm{M}+\mathrm{H}]^{+}, \mathrm{m} / \mathrm{z} 363.34$, found for $[\mathrm{M}+\mathrm{H}]^{+}, \mathrm{m} / \mathrm{z}$ 386.086.

3,4,5-(tribenzyloxy)benzoic acid (6). ${ }^{1} \mathrm{H}$ NMR (acetone- $\left.d_{6}, 400 \mathrm{MHz}\right): 7.56(\mathrm{~d}, 4 \mathrm{H}, J=7.28$ $\mathrm{Hz}), 7.48-7.36(\mathrm{~m}, 10 \mathrm{H}), 7.30-7.28(\mathrm{~m}, 3 \mathrm{H}), 5.25(\mathrm{~s}, 4 \mathrm{H}), 5.16(\mathrm{~s}, 2 \mathrm{H}), 2.84(\mathrm{~s}, \mathrm{br}, 1 \mathrm{H}) .{ }^{13} \mathrm{C}$ NMR (acetone- $\left.d_{6}, 100 \mathrm{MHz}\right)$ : 171.38, 157.86, 147.55, 143.18, 142.44, 133.59, 133.46, 133.22, 133.03, 132.90, 132.82, 130.89, 114.28, 79.82, 76.08. MS (ESI) calculated for $\mathrm{C}_{28} \mathrm{H}_{24} \mathrm{O}_{5},[\mathrm{M}+\mathrm{H}]^{+}, \mathrm{m} / \mathrm{z} 441.5$, found for $[\mathrm{M}+\mathrm{Na}]^{+}, \mathrm{m} / \mathrm{z} 463.236$.

Aldehyde oxidation. To a stirring solution of the aldehyde, benzyl-4-formyl benzoate (9), (1 $\mathrm{mmol})$ in DMF (10 mL), Oxone $®(2 \mathrm{mmol})$ was added in one portion and stirred at RT for 12 hrs. After the reaction completion (as indicated by TLC), diluted solution of $\mathrm{HCl}(1 \mathrm{~N}, 5 \mathrm{~mL}$ ) was used to dissolve the salts. The reaction mixture was then diluted with EtOAc (30 mL) and again washed with $\mathrm{HCl}(1 \mathrm{~N}, 2 \times 10 \mathrm{~mL})$ and brine solution. The organic phase was then dried over anhydrous $\mathrm{Na}_{2} \mathrm{SO}_{4}$ and EtOAc was removed under reduced pressure. The resulting organic residue was purified by flash 
chromatography using hexanes/EtOAc mobile phase as described above. $20 \mathrm{~mL}$ fractions containing the desired product, 4-benzyloxcabonyl benzoic acid (10), were pooled together and concentrated under reduced pressure to afford the desired product as white solid in $78 \%$ yield.

4-Benzyloxcabonyl benzoic acid (10). ${ }^{1} \mathrm{H}$ NMR (acetone- $\left.d_{6}, 400 \mathrm{MHz}\right): 8.03$ (s, $\left.4 \mathrm{H}\right), 7.39$ (d, 2 $\mathrm{H}, J=7.16 \mathrm{~Hz}) .7 .31-7.23(\mathrm{~m}, 3 \mathrm{H}) .{ }^{13} \mathrm{C} \mathrm{NMR}$ (acetone- $\left.d_{6}, 100 \mathrm{MHz}\right): 171.88,166.77,165.99,137.19$, 135.46, 134.93, 132.13, 130.59, 130.36, 129.42, 129.35, 129.08, 128.98, 67.59. MS (ESI) calculated for $\mathrm{C}_{15} \mathrm{H}_{12} \mathrm{O}_{4},[\mathrm{M}+\mathrm{H}]^{+}, \mathrm{m} / \mathrm{z} 257.26$, found for $[\mathrm{M}+\mathrm{Na}]^{+}, \mathrm{m} / \mathrm{z} 279.24$.

General procedure for Esterification of Polyalcohols. To a stirring solution of benzoic acid derivative $(\mathbf{5}, \mathbf{6}, \mathbf{7}$, or $\mathbf{1 0})(1.0 \mathrm{mmol} / \mathrm{OH}$ of polyalcohol $)$ and DMAP (1.0 mmol/OH of polyalcohol $)$ in anhydrous $\mathrm{CH}_{2} \mathrm{Cl}_{2}(20 \mathrm{~mL})$, DCC $(1.0 \mathrm{mmol} / \mathrm{OH}$ of polyalcohol) was added and the resulting mixture was stirred for $30 \mathrm{~min}$ at RT. A properly protected saccharide $(\mathbf{1 1}, \mathbf{1 4}, \mathbf{1 7}$, or $\mathbf{2 0})$ or psudosaccharide (23 or $\mathbf{2 4})$ (1.0 mmol) was then added and the resulting reaction mixture was refluxed $24 \mathrm{hrs}$. After that, the reaction was cooled to RT and filtered through a pad of Celite. The organic phase was then washed with $\mathrm{HCl}(1 \mathrm{M}, 15 \mathrm{~mL})$, brine solution $(15 \mathrm{~mL})$, and $\mathrm{H}_{2} \mathrm{O}(15 \mathrm{~mL})$. The organic phase was dried over anhydrous $\mathrm{Na}_{2} \mathrm{SO}_{4}$, concentrated in vacuo, and purified by flash chromatography using hexanes/EtOAc mobile phase as described above. $20 \mathrm{~mL}$ fractions containing the desired product (12ad, 15, 18, 21, 25, or 26) were pooled together and concentrated in vacuo to afford the desired products as white solid in yield of (70-91\%).

1, 2, 3, 4, 6-Penta-O-(3, 4, 5-tri-O-benzylgalloyl)- $\beta$-D-glucopyranose $(12 a) .{ }^{1} \mathrm{H} \mathrm{NMR}\left(\mathrm{CDCl}_{3}\right.$, $400 \mathrm{MHz}): 7.38-7.08(\mathrm{~m}, 85 \mathrm{H}), 6.15(\mathrm{~d}, 1 \mathrm{H}, J=8.12 \mathrm{~Hz}), 5.98(\mathrm{t}, 1 \mathrm{H}, J=9.68 \mathrm{~Hz}), 5.78-5.74(\mathrm{dd}, 1$ $\left.\mathrm{H}, J_{1}=9.80 \mathrm{~Hz}, J_{2}=8.20 \mathrm{~Hz}\right), 5.66(\mathrm{t}, 1 \mathrm{H}, J=9.64 \mathrm{~Hz}), 5.08-4.77(\mathrm{~m}, 30 \mathrm{H}), 4.71-4.68\left(\mathrm{dd}, 1 \mathrm{H}, J_{1}=\right.$ $\left.11.68 \mathrm{~Hz}, J_{2}=2.32 \mathrm{~Hz}\right), 4.39-4.35(\mathrm{~m}, 1 \mathrm{H}), 4.35-4.28\left(\mathrm{dd}, 1 \mathrm{H}, J_{1}=11.8 \mathrm{~Hz}, J_{2}=5.88 \mathrm{~Hz}\right) .{ }^{13} \mathrm{C}$ NMR $\left(\mathrm{CDCl}_{3}, 100 \mathrm{MHz}\right): 165.67,165.61,165.07,165.01,164.22,152.67,152.62,152.54,143.36$, $143.30,143.23,142.74,137.56,137.38,136.78,136.51,136.46,136.37,128.57,128.55,128.53$, $128.48,128.46,128.41,128.39,128.31,128.24,128.17,128.13,128.05,127.65,127.60,127.58$, 124.62, 123.75, 123.64, 123.40, 109.56, 109.51, 109.43, 109.31, 109.27, 106.51, 93.08, 75.14, 73.36, 73.30, 71.47, 71.34, 71.26, 71.16, 71.11, 69.88, 63.23. MS (ESI) calculated for $\mathrm{C}_{146} \mathrm{H}_{122} \mathrm{O}_{26},[\mathrm{M}+\mathrm{H}]^{+}$, $\mathrm{m} / \mathrm{z} 2293.53$, found for $\left[\mathrm{M}+\mathrm{H}-\mathrm{C}_{28} \mathrm{H}_{23} \mathrm{O}_{5}\right]^{+}, \mathrm{m} / \mathrm{z} 1852.975$.

1,2,3,4,6-Penta-O-(3, 5-di-O-benzyloxybenzoyl)- $\alpha, \boldsymbol{\beta}$-D-glucopyranose (12b). ${ }^{1} \mathrm{H} \mathrm{NMR}\left(\mathrm{CDCl}_{3}\right.$, $400 \mathrm{MHz}): 7.34-7.09(\mathrm{~m}, 60 \mathrm{H}), 6.78(\mathrm{~d}, 1 \mathrm{H}, J=3.6 \mathrm{~Hz}), 6.70-6.69(\mathrm{~m}, 1 \mathrm{H}), 6.66-6.64(\mathrm{~m}, 2 \mathrm{H})$, $6.63-6.62(\mathrm{~m}, 2 \mathrm{H}), 6.20(\mathrm{t}, 1 \mathrm{H}, J=9.92 \mathrm{~Hz}), 5.69(\mathrm{t}, 1 \mathrm{H}, J=10.12 \mathrm{~Hz}), 5.59-5.56\left(\mathrm{dd}, 1 \mathrm{H}, J_{1}=\right.$ $\left.10.16 \mathrm{~Hz}, J_{2}=3.76 \mathrm{~Hz}\right), 4.95-4.71(\mathrm{~m}, 20 \mathrm{H}), 4.63-4.59(\mathrm{~m}, 1 \mathrm{H}), 4.55-4.52(\mathrm{~m}, 1 \mathrm{H}), 4.37-4.33(\mathrm{dd}, 1$ $\left.\mathrm{H}, J_{1}=12.36 \mathrm{~Hz}, J_{2}=4.76 \mathrm{~Hz}\right) .{ }^{13} \mathrm{C} \mathrm{NMR}\left(\mathrm{CDCl}_{3}, 100 \mathrm{MHz}\right): 165.72,165.66,165.11,164.95,164.23$, $159.98,159.88,159.85,159.80,136.58,136.30,131.47,130.89,130.69,130.54,128.63,128.59$, 128.54, 128.14, 128.06, 127.64, 127.59, 127.55, 108.76, 108.71, 108.55, 108.39, 108.19, 107.96, 90.33, 70.91, 70.74, 70.56, 70.34, 70.30, 70.25, 70.17, 69.43, 62.86. MS (ESI) calculated for $\mathrm{C}_{111} \mathrm{H}_{92} \mathrm{O}_{21},[\mathrm{M}+$ $\mathrm{H}]^{+}, \mathrm{m} / \mathrm{z} 1761.91$, found for $[\mathrm{M}+\mathrm{Na}]^{+}, \mathrm{m} / \mathrm{z} 1784.975$.

1,2,3,4,6-Penta-O-(4-O-benzyloxybenzoyl)- $\boldsymbol{\alpha}, \boldsymbol{\beta}$-D-glucopyranose (12c). ${ }^{1} \mathrm{H} \mathrm{NMR}\left(\mathrm{CDCl}_{3}, 400\right.$ MHz): 7.99-7.96 (dd, $\left.4 \mathrm{H}, J_{1}=6.88 \mathrm{~Hz}, J_{2}=1.6 \mathrm{~Hz}\right), 7.87-7.64\left(\mathrm{dd}, 4 \mathrm{H}, J_{1}=8.84 \mathrm{~Hz}, J_{2}=3.88 \mathrm{~Hz}\right)$, $7.82(\mathrm{~d}, 2 \mathrm{H}, J=8.8 \mathrm{~Hz}), 7.41-7.32(\mathrm{~m}, 25 \mathrm{H}), 6.96(\mathrm{~s}, 2 \mathrm{H}), 6.94(\mathrm{~s}, 2 \mathrm{H}), 6.90-6.83(\mathrm{~m}, 6 \mathrm{H}), 6.22(\mathrm{~d}$, $1 \mathrm{H}, J=8.0 \mathrm{~Hz}), 5.94(\mathrm{t}, 1 \mathrm{H}, J=9.44 \mathrm{~Hz}), 5.78-5.71(\mathrm{~m}, 2 \mathrm{H}), 5.10(\mathrm{~s}, 2 \mathrm{H}), 5.09(\mathrm{~s}, 2 \mathrm{H}), 5.07(\mathrm{~s}, 2$ $\mathrm{H}), 5.04(\mathrm{~s}, 2 \mathrm{H}), 5.03(\mathrm{~s}, 2 \mathrm{H}), 4.62-4.59\left(\mathrm{dd}, 1 \mathrm{H}, J_{l}=12.32 \mathrm{~Hz}, J_{2}=2.84 \mathrm{~Hz}\right), 4.46-4.43\left(\mathrm{dd}, 1 \mathrm{H}, J_{1}\right.$ $\left.=7.36 \mathrm{~Hz}, J_{2}=4.88 \mathrm{~Hz}\right), 4.35-4.31(\mathrm{~m}, 1 \mathrm{H}) .{ }^{13} \mathrm{C} \mathrm{NMR}\left(\mathrm{CDCl}_{3}, 100 \mathrm{MHz}\right): 165.77,165.29,164.77$, $164.75,164.25,163.20,162.94,162.88,162.80,162.64,136.37,136.23,136.19,136.15,132.40$, 
132.02, 131.98, 131.92, 129.09, 128.66, 128.10, 127.47, 127.41, 127.34, 122.39, 121.54, 121.49, 121.22, 114.78, 114.68, 114.57, 114.54, 114.47, 92.69, 73.30, 72.72, 70.80, 70.15, 70.12, 69.07, 62.68. MS (ESI) calculated for $\mathrm{C}_{76} \mathrm{H}_{62} \mathrm{O}_{16},[\mathrm{M}+\mathrm{H}]^{+}, \mathrm{m} / \mathrm{z} 1232.30$, found for $[\mathrm{M}+\mathrm{Na}]^{+}, \mathrm{m} / \mathrm{z} 1254.484$.

\section{1,2,3,4,6-Penta-O-(4-O-benzyloxycarbonybenzoyl)- $\alpha, \beta$-D-glucopyranose $(12 d) .{ }^{1} \mathrm{H}$ NMR} $\left(\mathrm{CDCl}_{3}, 400 \mathrm{MHz}\right): 8.23-7.88(\mathrm{~m}, 20 \mathrm{H}), 7.59-7.29(\mathrm{~m}, 25 \mathrm{H}), 6.85(\mathrm{~d}, 1 \mathrm{H}, J=8.0 \mathrm{~Hz}), 6.26(\mathrm{t}, 1 \mathrm{H}, J$ $=8.84 \mathrm{~Hz}), 5.84(\mathrm{t}, 1 \mathrm{H}, J=10.04 \mathrm{~Hz}), 5.70-5.67(\mathrm{~m}, 1 \mathrm{H}), 5.42(\mathrm{~s}, 1 \mathrm{H}), 5.39(\mathrm{~s}, 3 \mathrm{H}), 5.35(\mathrm{~s}, 2 \mathrm{H})$, 5.32 (s, $4 \mathrm{H}), 4.67-4.63(\mathrm{~m}, 2 \mathrm{H}), 4.53-4.51(\mathrm{~m}, 1 \mathrm{H}) .{ }^{13} \mathrm{C} \mathrm{NMR}\left(\mathrm{CDCl}_{3}, 100 \mathrm{MHz}\right): 165.48,165.24$, $165.18,165.03,164.42,164.34,163.56,135.72$, 135.60, 135.09, 134.72, 134.66, 134.59, 134.30, 133.24, 132.49, 132.22, 132.17, 132.09, 131.90, 130.13, 129.95, 129.92, 129.74, 128.71, 128.66, 128.50, 128.41, 128.28, 128.24, 126.48, 90.29, 70.74, 70.58, 70.47, 68.97, 67.33, 67.14, 67.07. MS (ESI) calculated for $\mathrm{C}_{81} \mathrm{H}_{62} \mathrm{O}_{21},[\mathrm{M}+\mathrm{H}]^{+}, \mathrm{m} / \mathrm{z} 1371.35$, found for $[\mathrm{M}+\mathrm{Na}]^{+}, \mathrm{m} / \mathrm{z}$ 1394.529.

2,3,4,6-Tetra-O-(3, 5-di-O-benzyloxybenzoyl)-1-O-methyl- $\alpha$-D-mannopyranose (15). ${ }^{1} \mathrm{H}$ NMR $\left(\mathrm{CDCl}_{3}, 400 \mathrm{MHz}\right):{ }^{1} \mathrm{H} \mathrm{NMR}\left(\mathrm{CDCl}_{3}, 400 \mathrm{MHz}\right)$ : 7.26-7.02 (m, $\left.48 \mathrm{H}\right), 6.63-6.57(\mathrm{~m}, 4 \mathrm{H}), 5.88(\mathrm{dt}, 1$ $\left.\mathrm{H}, J_{1}=9.96 \mathrm{~Hz}, J_{2}=2.32 \mathrm{~Hz}\right), 5.80\left(\mathrm{dd}, 1 \mathrm{H}, J_{1}=10.04 \mathrm{~Hz}, J_{2}=2.44 \mathrm{~Hz}\right), 5.63(\mathrm{~d}, 1 \mathrm{H}, J=1.4 \mathrm{~Hz})$, 4.99-4.61 (m, $20 \mathrm{H}), 4.54-4.51(\mathrm{~m}, 2 \mathrm{H}), 4.39-4.37(\mathrm{~m}, 1 \mathrm{H}), 3.45(\mathrm{~s}, 3 \mathrm{H}) .{ }^{13} \mathrm{C} \mathrm{NMR}\left(\mathrm{CDCl}_{3}, 100\right.$ MHz): 165.83, 165.36, 165.10, 159.93, 159.85, 159.73, 136.51, 136.44, 136.39, 136.34, 131.63, $131.21,131.08,130.99,128.64,128.55,128.49,128.09,128.01,127.69,127.62,127.48,127.41$, 108.95, 108.62, 108.53, 108.40, 108.24, 108.05, 107.81, 107.62, 98.75, 70.85, 70.31, 70.13, 68.61, 68.08, 64.0, 55.50. MS (ESI) calculated for $\mathrm{C}_{91} \mathrm{H}_{78} \mathrm{O}_{18},[\mathrm{M}+\mathrm{H}]^{+}, \mathrm{m} / \mathrm{z} 1460.59$, found for $[\mathrm{M}+\mathrm{Na}]^{+}$, $\mathrm{m} / \mathrm{z} 1482.763$.

1,2,3-Tri-O-(3, 5-di-O-benzyloxybenzoyl)-4,6-O-ethylidene- $\alpha-D-g l u c o p y r a n o s e ~(18) . ~{ }^{1} \mathrm{H}$ NMR $\left(\mathrm{CDCl}_{3}, 400 \mathrm{MHz}\right): 7.34-7.19(\mathrm{~m}, 32 \mathrm{H}), 7.18-7.16(\mathrm{~m}, 2 \mathrm{H}), 7.08(\mathrm{~d}, 1 \mathrm{H}, J=2.28 \mathrm{~Hz}), 7.04(\mathrm{~d}, 1 \mathrm{H}, J$ $=2.28 \mathrm{~Hz}), 6.71-6.60(\mathrm{~m}, 3.5 \mathrm{H}), 6.03-5.41(\mathrm{~m}, 2.5 \mathrm{H}), 4.98-4.88(\mathrm{~m}, 8 \mathrm{H}), 4.84(\mathrm{~s}, 2 \mathrm{H}), 4.75-4.65$ $(\mathrm{m}, 3 \mathrm{H}), 4.26-3.69(\mathrm{~m}, 3 \mathrm{H}), 3.59-3.52(\mathrm{~m}, 1 \mathrm{H}), 1.30-1.26\left(\mathrm{dd}, 3 \mathrm{H}, J_{1}=13.28 \mathrm{~Hz}, J_{2}=4.96 \mathrm{~Hz}\right)$. ${ }^{13} \mathrm{C} \mathrm{NMR}\left(\mathrm{CDCl}_{3}, 100 \mathrm{MHz}\right): 165.39,165.28,165.10,164.31,159.93,159.89,159.84,159.81,159.77$, 136.42, 136.41, 136.37, 136.36, 136.31, 131.43, 131.28, 130.77, 130.69, 130.53, 130.36, 128.70, $128.61,128.57,128.53,128.13,128.10,128.08,127.69,127.61,127.44,127.30,108.75,108.62$, $108.49,108.31,108.21,107.88,107.53,107.43,100.08,99.98,93.32,90.68,78.32,78.15,72.14$, 71.83, 71.05, 70.35, 70.30, 70.14, 70.01, 68.09, 67.96, 67.48, 65.44, 20.29, 20.23. 1MS (ESI) calculated for $\mathrm{C}_{71} \mathrm{H}_{62} \mathrm{O}_{15},[\mathrm{M}+\mathrm{H}]^{+}, \mathrm{m} / \mathrm{z} 1155.24$, found for $[\mathrm{M}+\mathrm{Na}]^{+}, \mathrm{m} / \mathrm{z} 1178.652$.

2,3-Di-O-(3, 5-di-O-benzyloxybenzoyl)-4,6-O-benzylidene-1-O-methyl- $\alpha-D$-glucopyranoside (21). ${ }^{1} \mathrm{H} \mathrm{NMR}\left(\mathrm{CDCl}_{3}, 400 \mathrm{MHz}\right): 7.20-7.40$ (m, $\left.29 \mathrm{H}\right), 6.67$ (s, $\left.1 \mathrm{H}\right), 6.64$ (s, $\left.1 \mathrm{H}\right), 5.96$ (t, $1 \mathrm{H}, \mathrm{J}=9.8$ $\mathrm{Hz}), 5.48(\mathrm{~s}, 1 \mathrm{H}), 5.15(\mathrm{~d}, 1 \mathrm{H}, J=3.64 \mathrm{~Hz}), 5.05\left(\mathrm{dd}, 1 \mathrm{H}, J_{l}=9.88 \mathrm{~Hz}, J_{2}=3.64 \mathrm{H}\right), 5.05-4.8(\mathrm{~m}, 8$ $\mathrm{H}), 4.29\left(\mathrm{dd}, 1 \mathrm{H}, J_{1}=10.24 \mathrm{~Hz}, J_{2}=4.8 \mathrm{~Hz}\right), 4.02-3.96(\mathrm{~m}, 1 \mathrm{H}), 3.79\left(\mathrm{dd}, 2 \mathrm{H}, J_{1}=20.08 \mathrm{~Hz}, J_{2}=\right.$ $9.72 \mathrm{~Hz}), 3.36$ (s, $3 \mathrm{H}) .{ }^{13} \mathrm{C} \mathrm{NMR}\left(\mathrm{CDCl}_{3}, 100 \mathrm{MHz}\right): 165.76,165.43,159.86,159.82,136.97,136.48$, 136.40, 131.68, 131.03, 129.03, 128.61,128.57, 128.19, 128.1, 127.66, 127.6, 126.25, 126.20, 108.70, 108.58, 108.30, 107.24, 101.69, 97.85, 79.27, 73.13, 70.32, 69.87, 68.97, 62.65, 55.59. MS (ESI) calculated for $\mathrm{C}_{56} \mathrm{H}_{50} \mathrm{O}_{16},[\mathrm{M}+\mathrm{H}]^{+}, \mathrm{m} / \mathrm{z}$ 916.0, found for $[\mathrm{M}+\mathrm{Na}]^{+}, \mathrm{m} / \mathrm{z} 937.401$.

1,2,3,4,5,6-Hexa-O-(3,5-di-O-benzyloxybenzoyl)-myo-inositol (25). ${ }^{1} \mathrm{H} \mathrm{NMR}\left(\mathrm{CDCl}_{3}, 400\right.$ MHz): 7.39 (d, $2 \mathrm{H}, J=1.84 \mathrm{~Hz}), 7.30-7.13(\mathrm{~m}, 62 \mathrm{H}), 7.09$ (d, $4 \mathrm{H}, J=2 \mathrm{~Hz}), 7.07$ (d, $4 \mathrm{H}, J=2 \mathrm{~Hz})$, 6.66-6.59 (m, $6 \mathrm{H}), 6.35$ (t, $2 \mathrm{H}, J=10.28 \mathrm{~Hz}), 6.28(\mathrm{t}, 1 \mathrm{H}, J=2.24 \mathrm{~Hz}), 5.97(\mathrm{t}, 1 \mathrm{H}, J=10.12 \mathrm{~Hz})$, $5.78(\mathrm{t}, 1 \mathrm{H}, J=2.12 \mathrm{~Hz}), 5.75(\mathrm{t}, 1 \mathrm{H}, J=2.24 \mathrm{~Hz}), 4.95(\mathrm{~s}, 2 \mathrm{H}), 4.90(\mathrm{~s}, 4 \mathrm{H}), 4.82(\mathrm{~s}, 7 \mathrm{H}), 4.76(\mathrm{~s}, 4$ $\mathrm{H}), 4.73\left(\mathrm{dd}, 7 \mathrm{H}, J_{1}=16.92 \mathrm{~Hz}, J_{2}=11.4 \mathrm{~Hz}\right) .{ }^{13} \mathrm{C} \mathrm{NMR}\left(\mathrm{CDCl}_{3}, 100 \mathrm{MHz}\right): 165.61,165.4,164.91$, $160.07,159.87,159.84,159.80,136.50,136.43$, 136.36, 131.06, 130.81, 130.79, 130.57, 128.65, 
$128.60,128.58,128.53,128.13,128.1,128.06,127.69,127.63,127.60,127.44,108.68,108.64,108.57$, 108.41, 108.12, 108.09, 70.61, 70.32, 70.28, 70.19, 70.13, 69.90. MS (ESI) calculated for $\mathrm{C}_{132} \mathrm{H}_{108} \mathrm{O}_{24}$, $[\mathrm{M}+\mathrm{H}]^{+}, \mathrm{m} / \mathrm{z}$ 2079.26, found for $\left[\mathrm{M}+\mathrm{H}-\mathrm{C}_{21} \mathrm{H}_{17} \mathrm{O}_{4}\right]^{+}, \mathrm{m} / \mathrm{z} 1744.999$.

1,2,3,4,5,6-Hexa-O-(3,5-di-O-benzyloxybenzoyl)-D-(+)-chiro-inositol (26). ${ }^{1} \mathrm{H} \mathrm{NMR}\left(\mathrm{CDCl}_{3}\right.$, $400 \mathrm{MHz}$ ): 7.35 \&7.32 (s \& s, $12 \mathrm{H}), 7.26-7.07$ (m, $60 \mathrm{H}), 6.70$ (s, $2 \mathrm{H}), 6.60$ (t, $4 \mathrm{H}, \mathrm{J}=1 \mathrm{~Hz}), 6.27$ $(\mathrm{d}, 2 \mathrm{H}, J=6.48 \mathrm{~Hz}), 6.03(\mathrm{~s}, 2 \mathrm{H}), 5.95(\mathrm{~d}, 2 \mathrm{H}, J=7.44 \mathrm{~Hz}), 4.97$ (s, $8 \mathrm{H}), 4.78(\mathrm{~s}, 8 \mathrm{H}), 4.74-4.67$ $\left(\mathrm{dd}, 8 \mathrm{H}, J_{1}=19.8 \mathrm{~Hz}, J_{2}=11.32 \mathrm{~Hz}\right) .{ }^{13} \mathrm{C} \mathrm{NMR}\left(\mathrm{CDCl}_{3}, 100 \mathrm{MHz}\right): 165.61,164.92,164.79,160.05$, 159.86, 159.82, 136.43, 136.33, 130.95, 130.73, 128.67, 128.55, 128.38, 128.33, 128.15, 128.08, $127.89,127.83,127.70,127.64,127.45,108.81,108.56,108.52,108.34,107.98,105.62,70.53,70.51$, 70.39, 70.30, 70.15, 68.91. MS (ESI) calculated for $\mathrm{C}_{132} \mathrm{H}_{108} \mathrm{O}_{24},[\mathrm{M}+\mathrm{H}]^{+}, \mathrm{m} / \mathrm{z} 2079.26$, found for [M $\left.+\mathrm{H}-\mathrm{C}_{21} \mathrm{H}_{17} \mathrm{O}_{4}\right]^{+}, \mathrm{m} / \mathrm{z} 1744.740$.

General Procedure for Catalytic Hydrogenation (Debenzylation). A solution of benzylated benzoyl derivatives of saccharides and pseudosaccharides $(\mathbf{1 2 a}-\mathbf{d}, \mathbf{1 5}, \mathbf{1 8}, \mathbf{2 1}, \mathbf{2 5}$, or 26) in

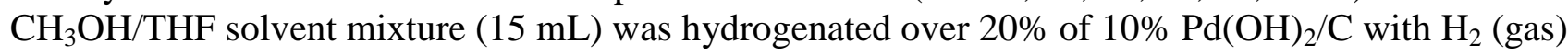
(50 psi) at RT for 6- $8 \mathrm{hrs}$. The $\mathrm{Pd}(\mathrm{OH})_{2} / \mathrm{C}$ catalyst was then removed by filtration over Celite and the resulting filtrate was dried over anhydrous $\mathrm{Na}_{2} \mathrm{SO} 4$ and concentrated in vacuo. A flash chromatography using hexanes/EtOAc mixture as a mobile phase was utilized to purify the reaction crude to afford the desired polyphenolic intermediates $(\mathbf{1 3 a}-\mathbf{c}, \mathbf{1 6}, \mathbf{1 9}, \mathbf{2 2}, \mathbf{2 7}$, or 28) and carboxylated final product (G11.4) as yellow-white solid in yield of (83-95\%).

1,2,3,4,6-O-Pentagalloyl-p-D-glucopyranose (13a). ${ }^{1} \mathrm{H}$ NMR (acetone- $d_{6}, 400 \mathrm{MHz}$ ): 8.32-7.98 (m, br, $15 \mathrm{H}$, phenolic-OH), 7.18 (s, $2 \mathrm{H}), 7.12$ (s, $2 \mathrm{H}), 7.06$ (s, $2 \mathrm{H}), 7.02$ (s, $2 \mathrm{H}), 6.97$ (s, $2 \mathrm{H}), 6.33$ $(\mathrm{d}, 1 \mathrm{H}, J=8.32 \mathrm{~Hz}), 6.01(\mathrm{t}, 1 \mathrm{H}, J=9.68 \mathrm{~Hz}), 5.68-5.59(\mathrm{~m}, 2 \mathrm{H}), 4.56-4.52(\mathrm{~m}, 2 \mathrm{H}), 4.43-4.39$ (dd, $\left.1 \mathrm{H}, J_{1}=12.68 \mathrm{~Hz}, J_{2}=4.68 \mathrm{~Hz}\right) .{ }^{13} \mathrm{C}$ NMR (acetone- $\left.d_{6}, 100 \mathrm{MHz}\right): 166.40,165.92,165.70,165.65$, 164.98, 146.18, 146.06, 146.02, 145.98, 145.90, 139.81, 139.32, 139.04, 121.52, 120.75, 120.65, $120.04,110.46,110.36,110.25,110.20,93.39,74.03,73.37,71.82,69.38,62.86$. MS (ESI) calculated for $\mathrm{C}_{41} \mathrm{H}_{32} \mathrm{O}_{26},[\mathrm{M}+\mathrm{H}]^{+}, \mathrm{m} / \mathrm{z}$ 941.69, found for $[\mathrm{M}+\mathrm{Na}]^{+}, \mathrm{m} / \mathrm{z} 963.157$.

1,2,3,4,6-Penta-O-(3, 5-dihydroxybenzoyl)- $\alpha, \boldsymbol{\beta}$-D-glucopyranose (13b). ${ }^{1} \mathrm{H}$ NMR (acetone- $d_{6}$, $400 \mathrm{MHz}$ ): 8.5 (s, br, $20 \mathrm{H}$, phenolic-OH), $7.03(\mathrm{~d}, 1 \mathrm{H}, J=2.08 \mathrm{~Hz}), 6.95(\mathrm{~d}, 1 \mathrm{H}, J=2.08 \mathrm{~Hz}), 6.94$ $(\mathrm{d}, 1 \mathrm{H}, J=2.16 \mathrm{~Hz}), 6.87(\mathrm{~d}, 1 \mathrm{H}, J=2.08 \mathrm{~Hz}), 6.82(\mathrm{~d}, 1 \mathrm{H}, J=2.12 \mathrm{~Hz}), 6.81(\mathrm{~d}, 1 \mathrm{H}, J=2.16 \mathrm{~Hz})$, 6.76-6.75 (m, $3 \mathrm{H}), 6.73(\mathrm{~d}, 1 \mathrm{H}, J=2.12 \mathrm{~Hz}), 6.69-6.29$ (d \& t \& t \& d, $2 \mathrm{H}, J=3.52 \mathrm{~Hz} \& J=1.88$ $\mathrm{Hz} \& J=2.08 \mathrm{~Hz} \& J=8.28 \mathrm{~Hz}), 6.47-6.44(\mathrm{~m}, 1 \mathrm{H}), 6.42(\mathrm{~s}, 1 \mathrm{H}), 6.37(\mathrm{~s}, 1 \mathrm{H}), 6.35(\mathrm{~d}, 1 \mathrm{H}, J=1.8$ $\mathrm{Hz}), 6.10 \& 5.97$ (t \& t, $1 \mathrm{H}, J=10.04 \mathrm{~Hz} \& J=9.68 \mathrm{~Hz}), 5.75$ (t \& m \& dd, $2 \mathrm{H}, J=10.04 \mathrm{~Hz} \& J_{l}=$ $\left.10.28 \mathrm{~Hz}, J_{2}=3.64 \mathrm{~Hz}\right), 4.66-4.51(\mathrm{~m}, 1 \mathrm{H}), 4.47-4.37(\mathrm{~m}, 2 \mathrm{H}) .{ }^{13} \mathrm{C}$ NMR (acetone- $\left.d_{6}, 100 \mathrm{MHz}\right)$ : 166.50, 166.30, 166.10, 166.03, 165.81, 165.75, 165.06, 159.75, 159.64, 159.49, 159.46, 159.42, $159.39,132.75,132.72,131.97,131.94,131.91,131.86,131.55,131.34,125.42,109.16,109.16$, 109.08, 109.0, 108.91, 108.86, 108.75, 108.66, 108.41, 93.51, 90.69, 73.89, 73.7, 72.07, 71.59, 71.57, 71.24, 69.62, 69.25, 63.06, 62.86. MS (ESI) calculated for $\mathrm{C}_{41} \mathrm{H}_{32} \mathrm{O}_{21},[\mathrm{M}+\mathrm{H}]^{+}, \mathrm{m} / \mathrm{z} 861.69$, found for $[\mathrm{M}+\mathrm{Na}]^{+}, \mathrm{m} / \mathrm{z} 883.225$.

1,2,3,4,6-Penta-O-(4-hydroxybenzoyl)- $\boldsymbol{\alpha}, \boldsymbol{\beta}$-D-glucopyranose $(\mathbf{1 3 c}) .{ }^{1} \mathrm{H}$ NMR (acetone- $d_{6}, 400$ MHz): 8.15-7.80 (m, $10 \mathrm{H}), 7.07-6.81(\mathrm{~m}, 10 \mathrm{H}), 6.51(\mathrm{~d}, 1 \mathrm{H}, J=8.08 \mathrm{~Hz}), 6.37 \& 5.95(\mathrm{t} \& \mathrm{t}, 1 \mathrm{H}, J$ $=10 \mathrm{~Hz} \& J=10.04 \mathrm{~Hz}), 6.20 \& 5.88(\mathrm{t} \& \mathrm{t}, 1 \mathrm{H}, J=9.48 \mathrm{~Hz}, J=9.64 \mathrm{~Hz}), 5.86-5.82 \& 5.74-5.71(\mathrm{dt}$ $\left.\& \mathrm{dd}, 1 \mathrm{H}, J_{1}=8.2 \mathrm{~Hz}, J_{2}=1.3 \mathrm{~Hz} \& J_{1}=10.24 \mathrm{~Hz}, J_{2}=3.76 \mathrm{~Hz}\right), 4.89-4.64(\mathrm{~m}, 2 \mathrm{H}), 4.56$ \& $4.55-$ $4.52\left(\mathrm{t} \& \mathrm{dd}, 1 \mathrm{H}, J=4.4 \mathrm{~Hz}, J_{l}=8.04 \mathrm{~Hz}, J_{2}=3.8 \mathrm{~Hz}\right){ }^{13} \mathrm{C}$ NMR (acetone- $d_{6}, 100 \mathrm{MHz}$ ): 166.42 , 166.0, 165.69, 164.96, 163.62, 163.56, 163.22, 163.19, 163.17, 163.13, 163.03, 163.02, 162.86, 133.16, 
$132.97,132.94,132.82,132.78,122.07,121.41,121.35,121.33,121.29,121.02,120.77,116.58$, $116.42,116.37,116.2,116.12,93.56,90.7,73.94,73.62,71.97,71.66,71.53,71.32,70.06,69.66$, 63.37, 63.24. MS (ESI) calculated for $\mathrm{C}_{41} \mathrm{H}_{32} \mathrm{O}_{16},[\mathrm{M}+\mathrm{H}]^{+}, \mathrm{m} / \mathrm{z} 781.69$, found for $[\mathrm{M}+\mathrm{Na}]^{+}, \mathrm{m} / \mathrm{z}$ 803.223.

1,2,3,4,6-Penta-O-(4-carboxybenzoyl)- $\alpha, \boldsymbol{\beta}$-D-glucopyranose (G11.4). ${ }^{1} \mathrm{H}$ NMR (acetone-d $400 \mathrm{MHz}): 8.29(\mathrm{~d}, 2 \mathrm{H}, J=8.36 \mathrm{~Hz}), 8.22(\mathrm{~d}, 2 \mathrm{H}, J=8.16 \mathrm{~Hz}), 8.10-7.92(\mathrm{~m}, 16 \mathrm{H}), 6.96(\mathrm{~d}, 1 \mathrm{H}, J=$ $3.68 \mathrm{~Hz}), 6.38(\mathrm{t}, 1 \mathrm{H}, J=9.84 \mathrm{~Hz}), 6.03(\mathrm{t}, 1 \mathrm{H}, J=9.84 \mathrm{~Hz}), 5.91\left(\mathrm{dd}, 1 \mathrm{H}, J_{1}=9.96 \mathrm{~Hz}, J_{2}=2.76\right.$ $\mathrm{Hz}), 4.95-4.89(\mathrm{~m}, 1 \mathrm{H}), 4.7-4.65(\mathrm{~m}, 2 \mathrm{H}) .{ }^{13} \mathrm{C}$ NMR (acetone-d $\left.d_{6}, 100 \mathrm{MHz}\right): 166.73,166.58,166.02$, 165.90, 165.29, 134.49, 133.53, 131.16, 131.03, 130.84, 130.80, 130.78, 130.72, 130.70, 130.66, 130.63, 91.84, 72.64, 72.21, 71.78, 70.61, 64.07. MS (ESI) calculated for $\mathrm{C}_{46} \mathrm{H}_{32} \mathrm{O}_{21},[\mathrm{M}+\mathrm{H}]^{+}, \mathrm{m} / \mathrm{z}$ 921.74, found for $[\mathrm{M}+\mathrm{Na}]^{+}, \mathrm{m} / \mathrm{z} 943.248$.

2,3,4,6-Tetra-O-(3, 5-dihydroxybenzoyl)-1-O-methyl- $\alpha$-D-mannopyranose (16). ${ }^{1} \mathrm{H}$ NMR (acetone- $\left.d_{6}, 400 \mathrm{MHz}\right): 8.51-8.40(\mathrm{br}, 8 \mathrm{H}$, phenolic-OH), $6.96(\mathrm{~d}, 2 \mathrm{H}, J=2.24 \mathrm{~Hz}), 6.94(\mathrm{~d}, 2 \mathrm{H}, J=$ $2.24 \mathrm{~Hz}), 6.84(\mathrm{~d}, 2 \mathrm{H}, J=2.24 \mathrm{~Hz}), 6.73(\mathrm{~d}, 2 \mathrm{H}, J=2.24 \mathrm{~Hz}), 6.49(\mathrm{t}, 1 \mathrm{H}, J=2.24 \mathrm{~Hz}), 6.47(\mathrm{t}, 1 \mathrm{H}$, $J=2.24 \mathrm{~Hz}), 6.40(\mathrm{t}, 1 \mathrm{H}, J=2.24 \mathrm{~Hz}), 6.34(\mathrm{t}, 1 \mathrm{H}, J=2.24 \mathrm{~Hz}), 5.66(\mathrm{t}, 1 \mathrm{H}, J=10.2 \mathrm{~Hz}), 5.63(\mathrm{dd}, 1$ $\left.\mathrm{H}, J_{1}=9.92 \mathrm{~Hz}, J_{2}=3.36 \mathrm{~Hz}\right), 5.51\left(\mathrm{dd}, 1 \mathrm{H}, J_{1}=2.8 \mathrm{~Hz}, J_{2}=1.8 \mathrm{~Hz}\right), 4.90(\mathrm{~d}, 1 \mathrm{H}, J=1.56 \mathrm{~Hz}), 4.39$ $\left(\mathrm{dd}, 1 \mathrm{H}, J_{1}=7.28 \mathrm{~Hz}, J_{2}=1.76 \mathrm{~Hz}\right), 4.36-4.33(\mathrm{~m}, 2 \mathrm{H}), 3.43(\mathrm{~s}, 3 \mathrm{H}) .{ }^{13} \mathrm{C}$ NMR (acetone- $d_{6}, 100$ MHz): 166.52, 166.06, 165.96, 165.79, 159.56, 159.47, 159.45, 159.38, 132.81, 132.24, 132.02, 131.97, 109.05, 108.97, 108.88, 108.83, 108.73, 108.63, 108.52, 108.33, 99.99.51, 71.09, 70.86, 69.68, 67.81, 64.44, 55.61. MS (ESI) calculated for $\mathrm{C}_{35} \mathrm{H}_{30} \mathrm{O}_{18},[\mathrm{M}+\mathrm{H}]^{+}, \mathrm{m} / \mathrm{z} 739.61$, found for $[\mathrm{M}+\mathrm{Na}]^{+}$, $\mathrm{m} / \mathrm{z} 761.077$.

\section{1,2,3-Tri-O-(3, 5-dihydroxybenzoyl)-4, 6-O-ethylidene- $\alpha$-D-glucopyranose (19). ${ }^{1} \mathrm{H}$ NMR} (acetone- $\left.d_{6}, 400 \mathrm{MHz}\right): 8.5(\mathrm{~s}, \mathrm{br}, 6 \mathrm{H}$, phenolic-OH), $6.99(\mathrm{~d}, 1 \mathrm{H}, J=2.28 \mathrm{~Hz}), 6.87(\mathrm{~d}, 1 \mathrm{H}, J=2.76$ $\mathrm{Hz}), 6.85(\mathrm{~d}, 1 \mathrm{H}, J=2.6 \mathrm{~Hz}), 6.83(\mathrm{~d}, 1 \mathrm{H}, J=2.84 \mathrm{~Hz}), 6.74(\mathrm{~d}, 1 \mathrm{H}, J=2.24 \mathrm{~Hz}), 6.72(\mathrm{~d}, 1 \mathrm{H}, J=$ $2.28 \mathrm{~Hz}), 6.55 \& 6.14(\mathrm{~d} \& \mathrm{~d}, 1 \mathrm{H}, J=3.76 \mathrm{~Hz} \& J=8.12 \mathrm{~Hz}), 6.52 \& 6.46(\mathrm{t} \& \mathrm{t}, 1 \mathrm{H}, J=2.28 \mathrm{~Hz} \& J$ $=2.28 \mathrm{~Hz}), 6.43\left(\mathrm{dd}, 1 \mathrm{H}, J_{1}=4.56 \mathrm{~Hz}, J_{2}=2.28 \mathrm{~Hz}\right), 6.36\left(\mathrm{dd}, 1 \mathrm{H}, J_{1}=4.60 \mathrm{~Hz}, J_{2}=2.28 \mathrm{~Hz}\right), 5.82$ \& $5.68(\mathrm{t} \& \mathrm{t}, 1 \mathrm{H}, J=9.88 \mathrm{~Hz} \& J=9.32 \mathrm{~Hz}), 5.46-5.33(\mathrm{~m}, 1 \mathrm{H}), 4.76-4.71(\mathrm{~m}, 1 \mathrm{H}), 4.10-4.01(\mathrm{~m}$, $1 \mathrm{H}), 3.95-3.88(\mathrm{~m}, 1 \mathrm{H}), 3.80-3.75(\mathrm{~m}, 1 \mathrm{H}), 3.57(\mathrm{~m}, 1 \mathrm{H}) .1 .13-1.10\left(\mathrm{dd}, 3 \mathrm{H}, J_{1}=6.92 \mathrm{~Hz}, J_{2}=\right.$ $5.08 \mathrm{~Hz}) .{ }^{13} \mathrm{C}$ NMR (acetone- $d_{6}, 100 \mathrm{MHz}$ ): 166.10, 165.97, 165.89, 165.71, 164.93, 164.88, 159.77, 159.60, 159.43, 132.44, 132.40, 131.92, 131.81, 131.51, 131.43, 109.03, 108.98, 108.92, 108.85, 108.73, 108.57, 108.42, 108.37, 100.51, 100.33, 93.75, 90.97, 78.80, 78.76, 72.79, 72.54, 71.84, 70.24, 68.44, 68.36, 67.94, 66.63, 20.83, 20.58. MS (ESI) calculated for $\mathrm{C}_{29} \mathrm{H}_{26} \mathrm{O}_{15},[\mathrm{M}+\mathrm{H}]^{+}, \mathrm{m} / \mathrm{z} 615.52$, found for $[\mathrm{M}+\mathrm{Na}]^{+}, \mathrm{m} / \mathrm{z} 637.128$.

2,3-Di-O-(3, 5-dihydroxybenzoyl)-1-O-methyl- $\alpha$-D-glucopyranoside (22). ${ }^{1} \mathrm{H}$ NMR (acetone$d_{6}, 400 \mathrm{MHz}$ ): 8.8-8.2 (s, br, $2 \mathrm{H}$, phenolic $\left.-\mathrm{OH}\right), 6.90\left(\mathrm{dd}, 4 \mathrm{H}, J_{1}=9.0 \mathrm{~Hz}, J_{2}=2.28 \mathrm{~Hz}\right), 6.57-6.54$ $(\mathrm{m}, 2 \mathrm{H}), 5.76(\mathrm{t}, 2 \mathrm{H}, J=9.2 \mathrm{~Hz}), 5.07\left(\mathrm{dd}, 1 \mathrm{H}, J_{1}=12.4 \mathrm{~Hz}, J_{2}=3.56 \mathrm{~Hz}\right), 3.97-3.68(\mathrm{~m}, 5 \mathrm{H}), 3.44$ $(\mathrm{s}, 3 \mathrm{H}) .{ }^{13} \mathrm{C}$ NMR (acetone- $\left.d_{6}, 100 \mathrm{MHz}\right): 166.45,166.29,159.35,159.31,159.22,133.14,132.26$, 108.91, 108.87, 108.37, 107.93, 97.91, 74.13, 73.33, 72.88, 69.60, 62.12, 55.39. MS (ESI) calculated for $\mathrm{C}_{21} \mathrm{H}_{22} \mathrm{O}_{12},[\mathrm{M}+\mathrm{H}]^{+}, \mathrm{m} / \mathrm{z} 467.4$, found for $[\mathrm{M}+\mathrm{Na}]^{+}, \mathrm{m} / \mathrm{z} 467.175$.

1,2,3,4,5,6-Hexa-O-(3,5-dihydroxybenzoyl)-myo-inositol (27). ${ }^{1} \mathrm{H}$ NMR (acetone-d 6 , $400 \mathrm{MHz}$ ): 8.75-8.40 (br, $12 \mathrm{H}$, phenolic-OH), $7.02(\mathrm{~d}, 2 \mathrm{H}, J=1.84 \mathrm{~Hz}), 6.79-6.74(\mathrm{~m}, 10 \mathrm{H}), 6.60(\mathrm{~s}, 1 \mathrm{H}), 6.41$ $(\mathrm{s}, 5 \mathrm{H}), 6.21(\mathrm{t}, 1 \mathrm{H}, J=2.72 \mathrm{~Hz}), 6.18-6.10(\mathrm{~m}, 3 \mathrm{H}), 5.92-5.89\left(\mathrm{dd}, 2 \mathrm{H}, J_{1}=9.32 \mathrm{~Hz}, J_{2}=1.72 \mathrm{~Hz}\right)$.

${ }^{13} \mathrm{C}$ NMR (acetone- $\left.d_{6}, 100 \mathrm{MHz}\right): 166.15,166.02,165.89,159.67,159.35,159.29,131.96,131.93$, 131.87, 131.66, 129.39, 129.33, 129.28, 128.77, 128.70, 128.61, 108.97, 108.84, 108.67, 108.55, 71.71, 
71.08, 70.88, 70.80, 70.63, 69.74. MS (ESI) calculated for $\mathrm{C}_{48} \mathrm{H}_{36} \mathrm{O}_{24},[\mathrm{M}+\mathrm{H}]^{+}, \mathrm{m} / \mathrm{z}$ 997.79, found for $[\mathrm{M}+\mathrm{H}]^{+}, \mathrm{m} / \mathrm{z} 1019.250$.

1,2,3,4,5,6-Hexa-O-(3,5-dihydroxybenzoyl)-D-(+)-chiro-inositol (28). ${ }^{1} \mathrm{H}$ NMR (acetone- $d_{6}$, $400 \mathrm{MHz}$ ): 8.73 (s, $4 \mathrm{H}$, phenolic-OH), 8.46 \& 8.44 (s \& s, $8 \mathrm{H}$, phenolic-OH), 7.21 (d, $4 \mathrm{H}, J=2.12$ $\mathrm{Hz}), 6.92(\mathrm{~d}, 4 \mathrm{H}, J=2.12 \mathrm{~Hz}), 6.88(\mathrm{~d}, 4 \mathrm{H}, J=2.12 \mathrm{~Hz}), 6.72(\mathrm{~d}, 2 \mathrm{H}, J=2.04 \mathrm{~Hz}), 6.52-6.50(\mathrm{~m}, 4$ $\mathrm{H}), 6.29-6.26(\mathrm{~m}, 2 \mathrm{H}), 6.09-6.08(\mathrm{~m}, 2 \mathrm{H}), 5.98-5.95$ (m, $2 \mathrm{H}) .{ }^{13} \mathrm{C}$ NMR (acetone- $\left.d_{6}, 100 \mathrm{MHz}\right)$ : 166.02, 165.94, 165.28, 159.78, 159.40, 131.87, 131.73, 1329.40, 129.32, 129.27, 128.77, 128.64, $128.59,109.14,109.06,108.87,108.71,108.60,71.20,70.75,69.18$. MS (ESI) calculated for $\mathrm{C}_{48} \mathrm{H}_{36} \mathrm{O}_{24},[\mathrm{M}+\mathrm{H}]^{+}, \mathrm{m} / \mathrm{z}$ 997.79, found for $[\mathrm{M}+\mathrm{Na}]^{+}, \mathrm{m} / \mathrm{z}$ 1019.259.

General Procedure for Microwave-Assisted Sulfation. To a stirring solution of polyphenolic intermediate $(\mathbf{1 3 a}-\mathbf{c}, \mathbf{1 6}, \mathbf{1 9}, \mathbf{2 2}, \mathbf{2 7}$, or 28$)(1.0 \mathrm{mmol})$ in anhydrous $\mathrm{CH}_{3} \mathrm{CN}(2 \mathrm{~mL})$, the sulfating reagent, $\mathrm{N}\left(\mathrm{CH}_{3}\right)_{3}-\mathrm{SO}_{3}$ complex $(5 \mathrm{mmol} / \mathrm{OH})$, was added. The resulting mixture was then microwaved at $90{ }^{\circ} \mathrm{C}$ for $8 \mathrm{hrs}$. The resulting crude product was cooled to RT and concentrated in vacuo at temperature less than $35^{\circ} \mathrm{C}$. All resulting polysulfated molecules were purified as described above using the size exclusion chromatography (G-10). The sodium salt form of the isolated white fluffy powder of sulfated species (G11.1-G11.3, G11.5-G11.7, G12.1-G12.3) was generated by the sodium exchange chromatography as described above in yield of (55-70\%).

Sodium 1,2,3,4,6-penta-O-(3, 5-di-O-sulfonato-benzoyl)- $\beta$-D-glucopyranose (G11.2). ${ }^{1} \mathrm{H}$ NMR $\left(\mathrm{D}_{2} \mathrm{O}, 400 \mathrm{MHz}\right): 7.38(\mathrm{~d}, 2 \mathrm{H}, J=1.92 \mathrm{~Hz}), 7.36(\mathrm{~d}, 2 \mathrm{H}, J=1.96 \mathrm{~Hz}), 7.32-7.27(\mathrm{~m}, 9 \mathrm{H}), 7.24(\mathrm{~d}, 2$ $\mathrm{H}, J=1.76 \mathrm{~Hz}), 6.45(\mathrm{~d}, 1 \mathrm{H}, J=7.88 \mathrm{~Hz}), 6.10(\mathrm{t}, 1 \mathrm{H}, J=9.28 \mathrm{~Hz}), 5.72(\mathrm{t}, 1 \mathrm{H}, J=8.52 \mathrm{~Hz}), 5.55$ $(\mathrm{t}, 1 \mathrm{H}, J=8.88 \mathrm{~Hz}), 4.68(\mathrm{~s}, \mathrm{br}, 1 \mathrm{H}), 4.32(\mathrm{~s}, \mathrm{br}, 2 \mathrm{H}) .{ }^{13} \mathrm{C} \mathrm{NMR}\left(\mathrm{D}_{2} \mathrm{O}, 100 \mathrm{MHz}\right): 166.19,165.45$, $165.14,165.01,164.43,152.29,152.0,131.35,130.48,130.32,120.98,120.61,120.54,120.42,120.21$, 120.11, 93.20, 73.84, 72.48, 71.97, 71.72, 70.09, 63.67. MS (ESI) calculated for $\mathrm{C}_{41} \mathrm{H}_{22} \mathrm{Na}_{11} \mathrm{O}_{51} \mathrm{~S}_{10}$ (sodium sulfates), $[\mathrm{M}+\mathrm{Na}]^{+1}, \mathrm{~m} / \mathrm{z} 1904.12$ and calculated for $\mathrm{C}_{113} \mathrm{H}_{214} \mathrm{~N}_{12} \mathrm{O}_{51} \mathrm{~S}_{10}$ (n-hexylammonium sulfates), $\left[\mathrm{M}+\left(\mathrm{CH}_{3}\left(\mathrm{CH}_{2}\right)_{5} \mathrm{NH}_{3}\right)_{12}\right]^{+2}, \mathrm{~m} / \mathrm{z}$ 1438.815, found for $\left[\mathrm{M}+\left(\mathrm{CH}_{3}\left(\mathrm{CH}_{2}\right)_{5} \mathrm{NH}_{3}\right)_{12}\right]^{+2}, \mathrm{~m} / \mathrm{z}$ 1438.707.

Sodium 1,2,3,4,6-penta-O-(4-O-sulfonato-benzoyl)- $\alpha$, $\beta$-D-glucopyranose (G11.3). ${ }^{1} \mathrm{H}$ NMR (DMSO- $\left.d_{6}, 400 \mathrm{MHz}\right): 7.91(\mathrm{~d}, 2 \mathrm{H}, J=8.72 \mathrm{~Hz}), 7.84(\mathrm{~d}, 2 \mathrm{H}, J=8.8 \mathrm{~Hz}), 7.81 \quad(\mathrm{~d}, 2 \mathrm{H}, J=8.76 \mathrm{~Hz})$, $7.75(\mathrm{~d}, 2 \mathrm{H}, J=8.68 \mathrm{~Hz}), 7.70(\mathrm{~d}, 2 \mathrm{H}, J=8.68 \mathrm{~Hz}), 7.29(\mathrm{~d}, 2 \mathrm{H}, J=8.64 \mathrm{~Hz}), 7.26(\mathrm{~d}, 2 \mathrm{H}, J=8.88$ $\mathrm{Hz}), 7.22(\mathrm{~d}, 2 \mathrm{H}, J=8.8 \mathrm{~Hz}), 7.18(\mathrm{~d}, 2 \mathrm{H}, J=8.56 \mathrm{~Hz}), 7.15(\mathrm{~d}, 2 \mathrm{H}, J=7.76 \mathrm{~Hz}), 6.71 \& 6.48(2 \times \mathrm{d}$, $1 \mathrm{H}, J=8.88 \mathrm{~Hz} \& J=8.04 \mathrm{~Hz}), 6.13(\mathrm{~d}, 1 \mathrm{H}, J=9.56 \mathrm{~Hz}), 5.65(\mathrm{t}, 2 \mathrm{H}, J=9.4 \mathrm{~Hz}), 4.71(\mathrm{~d}, 1 \mathrm{H}, J=$ $5.36 \mathrm{~Hz}), 4.49-4.40(\mathrm{~m}, \mathrm{br}, 2 \mathrm{H}) .{ }^{13} \mathrm{C}$ NMR $\left(\mathrm{D}_{2} \mathrm{O}, 100 \mathrm{MHz}\right): 167.12,166.46,166.17,165.65,165.32$, 156.0, 155.78, 155.45, 155.15, 132.55, 132.22, 131.67, 131.53, 131.25, 131.14, 125.71, 125.36, 124.38, 121.21, 121.08, 120.28, 120.10, 119.95, 93.44, 74.24, 72.07, 71.63, 69.37, 62.08. MS (ESI) calculated for $\mathrm{C}_{41} \mathrm{H}_{27} \mathrm{Na}_{6} \mathrm{O}_{31} \mathrm{~S}_{5}$ (sodium sulfates), $[\mathrm{M}+\mathrm{Na}]^{+1}, \mathrm{~m} / \mathrm{z} 1313.9$ and calculated for $\mathrm{C}_{83} \mathrm{H}_{139} \mathrm{~N}_{7} \mathrm{O}_{31} \mathrm{~S}_{5}(n-$ hexylammonium sulfates), $\left[\mathrm{M}+\left(\mathrm{CH}_{3}\left(\mathrm{CH}_{2}\right)_{5} \mathrm{NH}_{3}\right)_{7}\right]^{+1}, \mathrm{~m} / \mathrm{z} 1789.15$ found for $[\mathrm{M}$ $\left.+\left(\mathrm{CH}_{3}\left(\mathrm{CH}_{2}\right)_{5} \mathrm{NH}_{3}\right)_{7}\right]^{+1}, \mathrm{~m} / \mathrm{z} 1789.078$.

Sodium 2,3,4,6-tetra-O-(3,5-di-O-sulfonato-benzoyl)-1-O-methyl- $\alpha$-D-mannopyranose (G11.5). ${ }^{1} \mathrm{H}$ NMR ( $\left.\mathrm{D}_{2} \mathrm{O}, 400 \mathrm{MHz}\right): 7.91(\mathrm{~d}, 2 \mathrm{H}, J=1.52 \mathrm{~Hz}), 7.85(\mathrm{~d}, 2 \mathrm{H}, J=1.20 \mathrm{~Hz}), 7.81(\mathrm{~d}, 2 \mathrm{H}$, $J=1.60 \mathrm{~Hz}$ ), 7.65-7.63 (m, 3 H), 7.55-7.51 (m, 3 H), 5.97-5.85 (m, $3 \mathrm{H}), 5.21$ (br s, $1 \mathrm{H}), 4.81-4.75$ $(\mathrm{m}, 3 \mathrm{H}), 3.64(\mathrm{~s}, 3 \mathrm{H}) .{ }^{13} \mathrm{C} \mathrm{NMR}\left(\mathrm{D}_{2} \mathrm{O}, 100 \mathrm{MHz}\right): 166.32,165.98,165.42,152.53,152.38,152.20$, 152.09, 152.04, 151.90, 130.91, 130.80, 130.75, 130.49, 120.74, 120.59, 120.45, 120.34, 120.24, 120.18, 120.07, 119.94, 98.41, 71.38, 70.61, 68.71, 68.20, 64.79, 55.77. MS (ESI) calculated for $\mathrm{C}_{35} \mathrm{H}_{22} \mathrm{Na}_{9} \mathrm{O}_{42} \mathrm{~S}_{8}$ (sodium sulfates), $[\mathrm{M}+\mathrm{Na}]^{+1}, \mathrm{~m} / \mathrm{z} 1577.95$ and calculated for $\mathrm{C}_{95} \mathrm{H}_{182} \mathrm{~N}_{10} \mathrm{O}_{42} \mathrm{~S}_{8}(n-$ 
hexylammonium sulfates), $\left[\mathrm{M}+\left(\mathrm{CH}_{3}\left(\mathrm{CH}_{2}\right)_{5} \mathrm{NH}_{3}\right)_{10}\right]^{+2}, \mathrm{~m} / \mathrm{z} 1196.51$, found for $\left[\mathrm{M}+\left(\mathrm{CH}_{3}\left(\mathrm{CH}_{2}\right)_{5}\right.\right.$ $\left.\left.\mathrm{NH}_{3}\right)_{10}\right]^{+2}, \mathrm{~m} / \mathrm{z} 1196.004$.

\section{Sodium 1,2,3-tri-O-(3,5-di-O-sulfonato-benzoyl)-4,6-O-ethylidene- $\alpha-D$-glucopyranose}

(G11.6). ${ }^{1} \mathrm{H}$ NMR ( $\left.\mathrm{D}_{2} \mathrm{O}, 400 \mathrm{MHz}\right): 7.97$ (s, $\left.1 \mathrm{H}\right), 7.84$ (s, $\left.1 \mathrm{H}\right), 7.82$ (s, $\left.1 \mathrm{H}\right), 7.80$ (s, $\left.1 \mathrm{H}\right), 7.74$ (s, 1 $\mathrm{H}), 7.65 \& 7.53($ br $2 \times \mathrm{s}, 3 \mathrm{H}), 7.49 \& 7.46($ br $2 \times \mathrm{s}, 1 \mathrm{H}), 6.8 \& 6.42(\mathrm{~d} \& \mathrm{~d}, 1 \mathrm{H}, J=3.56 \mathrm{~Hz} \& J=$ $8.83 \mathrm{~Hz}), 6.05 \& 5.91(\mathrm{t} \& \mathrm{t}, 1 \mathrm{H}, J=9.24 \mathrm{~Hz} \& J=9.24 \mathrm{~Hz}), 5.84-5.5 .75(\mathrm{~m}, 1 \mathrm{H}), 5.0-4.99(\mathrm{t}, 1 \mathrm{H}, J$ $=5.4 \mathrm{~Hz}), 4.39-4.35(\mathrm{~m}, 1 \mathrm{H}), 4.32-4.21(\mathrm{~m}, 1 \mathrm{H}), 4.06-4.0(\mathrm{~m}, 1 \mathrm{H}), 3.85-3.80(\mathrm{~m}, 1 \mathrm{H}), 1.35(\mathrm{~d}, 3 \mathrm{H}$, $J=4.76 \mathrm{~Hz}) .{ }^{13} \mathrm{C}$ NMR $\left(\mathrm{D}_{2} \mathrm{O}, 100 \mathrm{MHz}\right): 165.72,165.61,165.18,164.94,164.68,164.35,152.22$, 152.12 , 152.02, 131.10, 130.93, 130.71, 130.50, 130.43, 130.30, 121.0, 120.48, 120.33, 120.21, 120.15, 120.09, 119.92, 100.43, 93.35, 91.26, 77.27, 77.19, 73.02, 72.89, 71.41, 70.92, 67.48, 67.37, 19.29. MS (ESI) calculated for $\mathrm{C}_{29} \mathrm{H}_{20} \mathrm{Na}_{7} \mathrm{O}_{33} \mathrm{~S}_{6}$ (sodium sulfates), $[\mathrm{M}+\mathrm{Na}]^{+1}, \mathrm{~m} / \mathrm{z} 1249.77$ and calculated for $\mathrm{C}_{71} \mathrm{H}_{132} \mathrm{~N}_{7} \mathrm{O}_{33} \mathrm{~S}_{6}$ (n-hexylammonium sulfates), $\left[\mathrm{M}+\left(\mathrm{CH}_{3}\left(\mathrm{CH}_{2}\right)_{5} \mathrm{NH}_{3}\right)_{7}\right]^{+1}, \mathrm{~m} / \mathrm{z}$ 1804.22, found for $\left[\mathrm{M}+\left(\mathrm{CH}_{3}\left(\mathrm{CH}_{2}\right)_{5} \mathrm{NH}_{3}\right)_{7}\right]^{+}, \mathrm{m} / \mathrm{z} 1804.234$.

Sodium 2,3-Di-O-(3,5-di-O-sulfonato-benzoyl)-1-O-methyl-4,6-di-O-sulfonato- $\alpha-D$ glucopyranoside (G11.7). ${ }^{1} \mathrm{H}$ NMR $\left(\mathrm{D}_{2} \mathrm{O}, 400 \mathrm{MHz}\right): 7.90(\mathrm{~d}, 2 \mathrm{H}, J=2.04 \mathrm{~Hz}), 7.81(\mathrm{~d}, 2 \mathrm{H}, J=1.84$ $\mathrm{Hz}), 7.62(\mathrm{~s}, 1 \mathrm{H}), 7.60(\mathrm{~s}, 1 \mathrm{H}), 6.0(\mathrm{t}, 1 \mathrm{H}, J=9.76 \mathrm{~Hz}), 5.61-5.59\left(\mathrm{dd}, 1 \mathrm{H}, J_{1}=3.64 \mathrm{~Hz}, J_{2}=10.24\right.$ $\mathrm{Hz}), 5.39(\mathrm{~d}, 1 \mathrm{H}, J=3.56 \mathrm{~Hz}), 4.84(\mathrm{t}, 1 \mathrm{H}, J=9.24 \mathrm{~Hz}), 4.66(\mathrm{~d}, 1 \mathrm{H}, J=9.68 \mathrm{~Hz}), 4.42-4.39(\mathrm{~m}, 2$ $\mathrm{H}), 3.87$ (s, $3 \mathrm{H}) .{ }^{13} \mathrm{C}$ NMR $\left(\mathrm{D}_{2} \mathrm{O}, 100 \mathrm{MHz}\right): 166.06,165.42,152.39,152.31,152.11,152.0,131.50$, $130.84,120.64,120.52,120.32,120.18,96.52,74.20,72.17,71.87,68.39,67.09,55.89$. MS (ESI) calculated for $\mathrm{C}_{21} \mathrm{H}_{16} \mathrm{Na}_{7} \mathrm{O}_{30} \mathrm{~S}_{6}$ (sodium sulfates), $[\mathrm{M}+\mathrm{Na}]^{+}, \mathrm{m} / \mathrm{z} 1101.65$ and calculated for $\mathrm{C}_{63} \mathrm{H}_{128} \mathrm{~N}_{7} \mathrm{O}_{30} \mathrm{~S}_{6}$ (n-hexylammonium sulfates), $\left[\mathrm{M}+\left(\mathrm{CH}_{3}\left(\mathrm{CH}_{2}\right)_{5} \mathrm{NH}_{3}\right)_{7}\right]^{+1}, \mathrm{~m} / \mathrm{z} 1656.11$, found for $\left[\mathrm{M}+\left(\mathrm{CH}_{3}\left(\mathrm{CH}_{2}\right)_{5} \mathrm{NH}_{3}\right)_{7}\right]^{+1}, \mathrm{~m} / \mathrm{z} 1656.12$.

Sodium 1,2,3,4,5,6-Hexa-O-(3,5-di-O-sulfonato-benzoyl)-myo-inositol (G12.1). ${ }^{1} \mathrm{H}$ NMR $\left(\mathrm{D}_{2} \mathrm{O}\right.$, $400 \mathrm{MHz}$ ): 7.93 (d, $2 \mathrm{H}, J=2.12 \mathrm{~Hz}), 7.64$ (d, $4 \mathrm{H}, J=2.08 \mathrm{~Hz}), 7.62$ (d, $1 \mathrm{H}, J=2.16 \mathrm{~Hz}), 7.57$ (d, 5 $\mathrm{H}, J=2.2 \mathrm{~Hz}), 7.40(\mathrm{t}, 6 \mathrm{H}, J=1.88 \mathrm{~Hz}), 6.41-6.36(\mathrm{~m}, 3 \mathrm{H}), 6.25(\mathrm{t}, 1 \mathrm{H}, J=9.8 \mathrm{~Hz}), 6.11-6.08$ (dd, $\left.2 \mathrm{H}, J_{1}=10.16 \mathrm{~Hz}, J_{2}=2.6 \mathrm{~Hz}\right) .{ }^{13} \mathrm{C} \mathrm{NMR}\left(\mathrm{D}_{2} \mathrm{O}, 100 \mathrm{MHz}\right): 165.71,165.29,165.15,164.94,152.28$, $151.95,151.88,130.33,130.31,130.25,130.19,120.75,120.48,120.35,120.07,119.91,71.75,71.28$, 70.44, 69.89. MS (ESI) calculated for $\mathrm{C}_{48} \mathrm{H}_{24} \mathrm{Na}_{12} \mathrm{O}_{60} \mathrm{~S}_{12}$ (sodium sulfates), $[\mathrm{M}+\mathrm{Na}]^{+1}, \mathrm{~m} / \mathrm{z} 2244.32$ and calculated for $\mathrm{C}_{132} \mathrm{H}_{248} \mathrm{~N}_{14} \mathrm{O}_{60} \mathrm{~S}_{12}$ (n-hexylammonium sulfates), $\left[\mathrm{M}+\left(\mathrm{CH}_{3}\left(\mathrm{CH}_{2}\right)_{5} \mathrm{NH}_{3}\right)_{14}\right]^{+2}, \mathrm{~m} / \mathrm{z}$ 1688.11, found for $\left[\mathrm{M}+\left(\mathrm{CH}_{3}\left(\mathrm{CH}_{2}\right)_{5} \mathrm{NH}_{3}\right)_{14}\right]^{+2}, \mathrm{~m} / \mathrm{z} 1688.13$.

Sodium 1,2,3,4,5,6-Hexa-O-(3,5-di-O-sulfonato-benzoyl)-D-(+)-chiro-inositol $\left(\right.$ G12.2). ${ }^{1} \mathrm{H}$ $\operatorname{NMR}\left(\mathrm{D}_{2} \mathrm{O}, 400 \mathrm{MHz}\right): 8.04(\mathrm{~d}, 4 \mathrm{H}, J=2.08 \mathrm{~Hz}), 7.74(\mathrm{~d}, 5 \mathrm{H}, J=2.16 \mathrm{~Hz}), 7.69(\mathrm{~d}, 5 \mathrm{H}, J=2.16$ $\mathrm{Hz}) 7.51(\mathrm{~d}, 4 \mathrm{H}, \mathrm{J}=2.44 \mathrm{~Hz}), 6.43(\mathrm{~d}, 2 \mathrm{H}, J=7.12 \mathrm{~Hz}), 6.29-6.27(\mathrm{~d}, \mathrm{br}, 4 \mathrm{H}, J=6.32 \mathrm{~Hz}) .{ }^{13} \mathrm{C}$ NMR ( $\left.\mathrm{D}_{2} \mathrm{O}, 100 \mathrm{MHz}\right)$ : 166.02, 165.48, 165.15, 165.05, 152.27, 152.07, 151.98, 130.59, 130.52, 130.45, 130.26, 129.0, 128.91, 128.64, 128.55, 128.06, 127.81, 120.71, 120.64, 120.58, 120.20, 120.04, 71.17, 71.10, 69.03. MS (ESI) calculated for $\mathrm{C}_{48} \mathrm{H}_{24} \mathrm{Na}_{12} \mathrm{O}_{60} \mathrm{~S}_{12}$ (sodium sulfates), $[\mathrm{M}+\mathrm{Na}]^{+1}, \mathrm{~m} / \mathrm{z}$ 2244.32 and calculated for $\mathrm{C}_{132} \mathrm{H}_{248} \mathrm{~N}_{14} \mathrm{O}_{60} \mathrm{~S}_{12}$ (n-hexylammonium sulfates), $\left[\mathrm{M}+\left(\mathrm{CH}_{3}\left(\mathrm{CH}_{2}\right)_{5} \mathrm{NH}_{3}\right)_{14}\right]^{+2}$, $\mathrm{m} / \mathrm{z} 1688.11$, found for $\left[\mathrm{M}+\left(\mathrm{CH}_{3}\left(\mathrm{CH}_{2}\right)_{5} \mathrm{NH}_{3}\right)_{14}\right]^{+2}, \mathrm{~m} / \mathrm{z} 1688.125$.

Sodium 1,2,3,4,5,6-Hexa-O-sulfonato-myo-inositol (G12.3). ${ }^{1} \mathrm{H}$ NMR (DMSO- $d_{6}, 400 \mathrm{MHz}$ ): 5.0 (br s, $2 \mathrm{H}$ ), 4.77 (br s, $2 \mathrm{H}), 4.59$ (br s, $1 \mathrm{H}$ ), 4.50 (br s, $1 \mathrm{H}) .{ }^{13} \mathrm{C} \mathrm{NMR}\left(\mathrm{D}_{2} \mathrm{O}, 100 \mathrm{MHz}\right)$ : 74.71, 73.74. MS (ESI) calculated for $\mathrm{C}_{6} \mathrm{H}_{6} \mathrm{Na}_{7} \mathrm{O}_{24} \mathrm{~S}_{6}$ (sodium sulfates), $[\mathrm{M}+\mathrm{Na}]^{+1}, \mathrm{~m} / \mathrm{z} 815.42$ and calculated for $\mathrm{C}_{48} \mathrm{H}_{118} \mathrm{~N}_{7} \mathrm{O}_{24} \mathrm{~S}_{6}$ (n-hexylammonium sulfates), $\left[\mathrm{M}+\left(\mathrm{CH}_{3}\left(\mathrm{CH}_{2}\right)_{5} \mathrm{NH}_{3}\right)_{7}\right]^{+1}, \mathrm{~m} / \mathrm{z} 1368.66$, found for $\left[\mathrm{M}+\left(\mathrm{CH}_{3}\left(\mathrm{CH}_{2}\right)_{5} \mathrm{NH}_{3}\right)_{7}\right]^{+1}, \mathrm{~m} / \mathrm{z} 1368.767$. 


\section{LEGENDS for SUPPLEMENTARY FIGURES S3 - S10}

Figure S3. Flow cytometric analysis for LGR5 expression in HT-29 colon cancer cells grown as monolayer and spheroid.

Figure S4. Primary screening studies with 53 NSGMs belonging to 12 structurally distinct scaffolds. Initial screening revealed differential growth in CSC enriched spheroid, measured by average number of spheres/100 plated cells at $120 \mathrm{~h}(\mathbf{A})$ vs. monolayer condition, measured by MTT assay (values derived as OD@490nM wavelength) at 72 h (B), by several NSGMs in HT-29 colon cancer cells. Data is presented as percent of control. Only two NSGMs from the G6 scaffold, (G6.1 and G6.9) demonstrated 50\% inhibition in monolayer but not in spheroid condition. In contrast, several compounds (12/53) belonging to four different scaffolds (G2, G4, G11 and G12, especially G2.2, G2.6, G11.1, G11.4 and G11.6) showed $\geq 50 \%$ inhibition of spheroid growth without having any effect on growth in monolayer condition. All 53 NSGMs were screened at 100 $\mu \mathrm{M}$ concentration.

Figure S5. Dose response profile of $\mathrm{G} 2.2$ treatment $(0 \rightarrow 500 \mu \mathrm{M})$ on the growth in spheroid and monolayer conditions.

Figure S6. Effect of $100 \mu \mathrm{M}$ G2.2 on primary spheroid growth in additional cancer cell lines. G2.2 treatment caused similar growth inhibition in HCT-116 p53-/- (p53 null) and Panc-1 (pancreatic cancer, K-RAS and p53 mutant) spheroids to that observed with HCT-116 and HT-29 colon cancer cell lines (A). Photomicrograph of Panc-1 spheroids at day 5 treated with vehicle or G2.2 taken at $10 \mathrm{X}$ resolution $(\mathbf{B}) .{ }^{*} \mathrm{p}<0.005$.

Figure S7. Flow cytometric analysis of DCLK1. Flow cytometric analysis of spheroids treated with G2.2 (100 $\mu \mathrm{M})$ showing robust inhibition in DCLK1 expression. Vehicle or G1.4 (100 $\mu \mathrm{M})$ treated cells do not show this inhibition. 


\section{LGR5 Expression in Monolayer and Spheroid Culture of HT-29 Colon Cancer Cells}
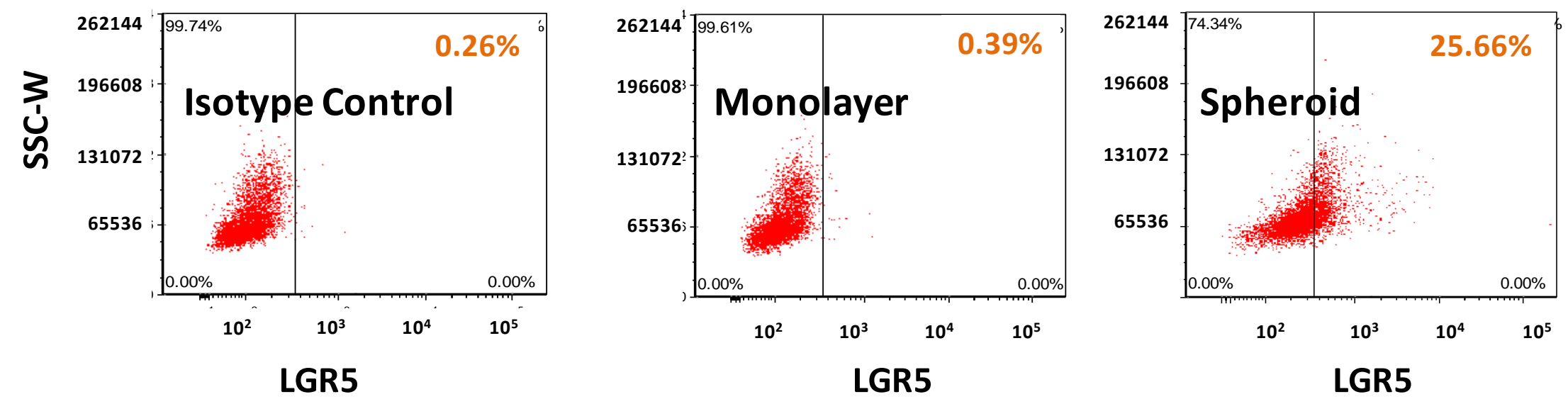

Figure S3 


\section{Differential Targeting of Monolayer and Spheres by NSGMs}

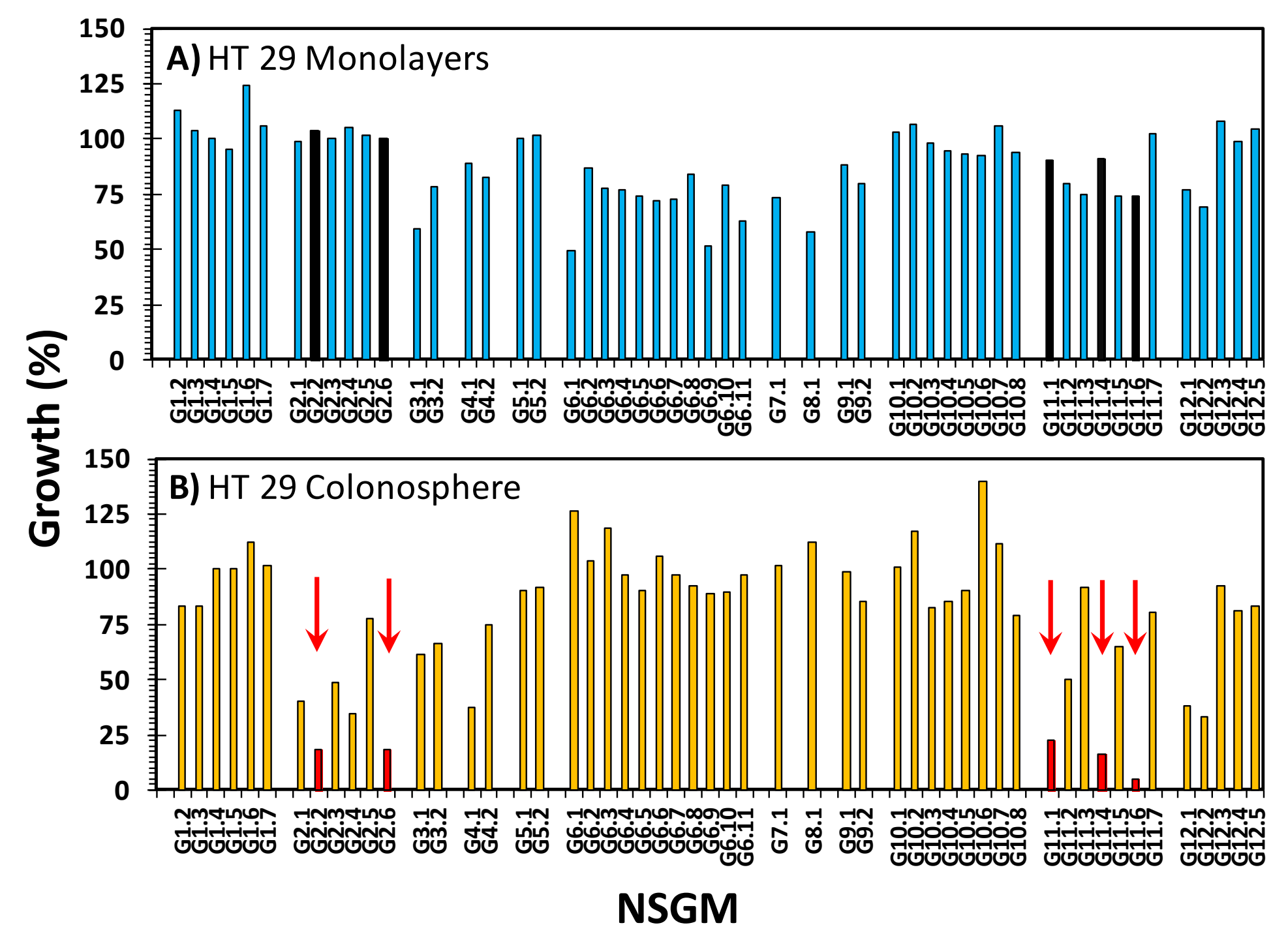

Figure S4 
G2.2 Dose-Response Curve- Monolayer vs. Spheroid Growth

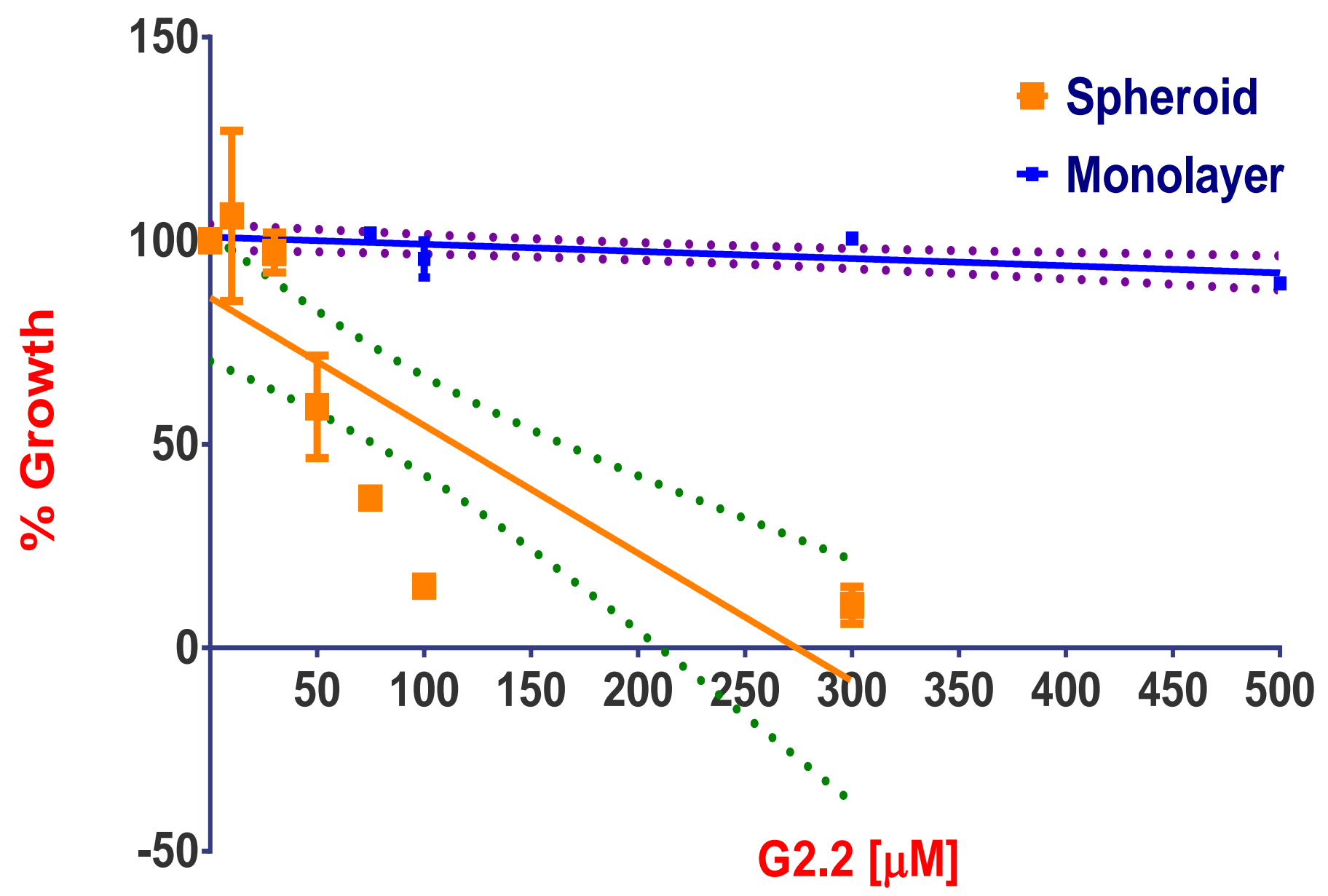

Figure S5 
G2.2 Inhibition of Growth of Two Other Colon Cancer Cell Lines

A

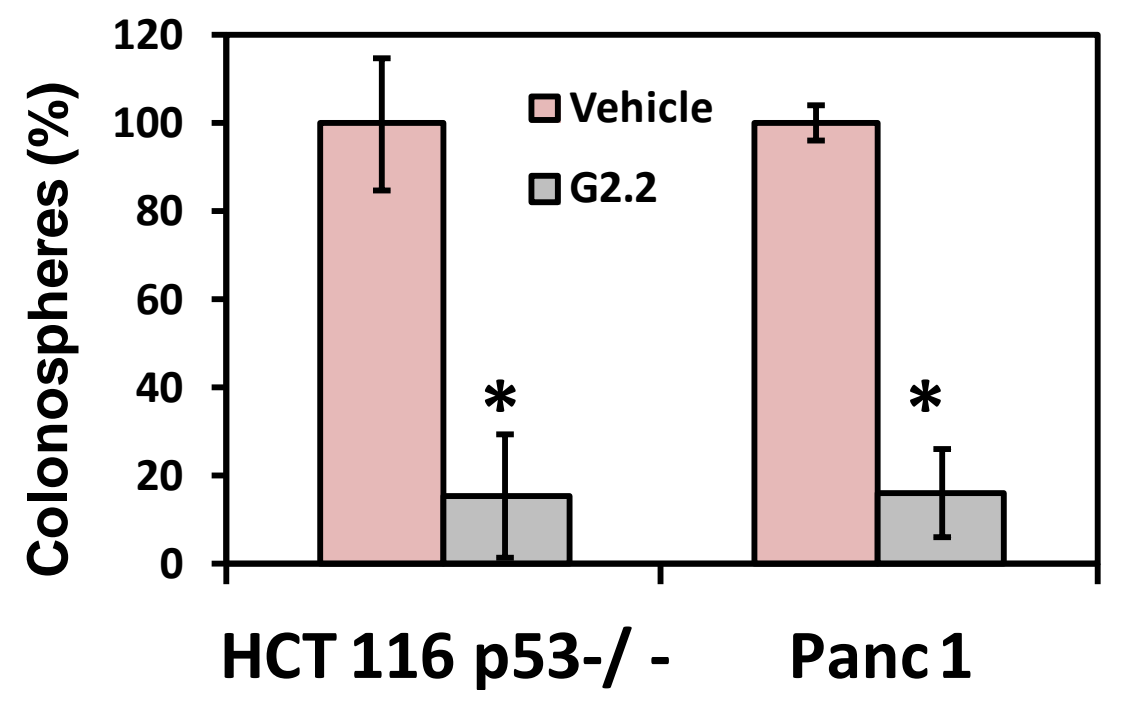

B Inhibition of Panc 1 colonospheres by G2.2

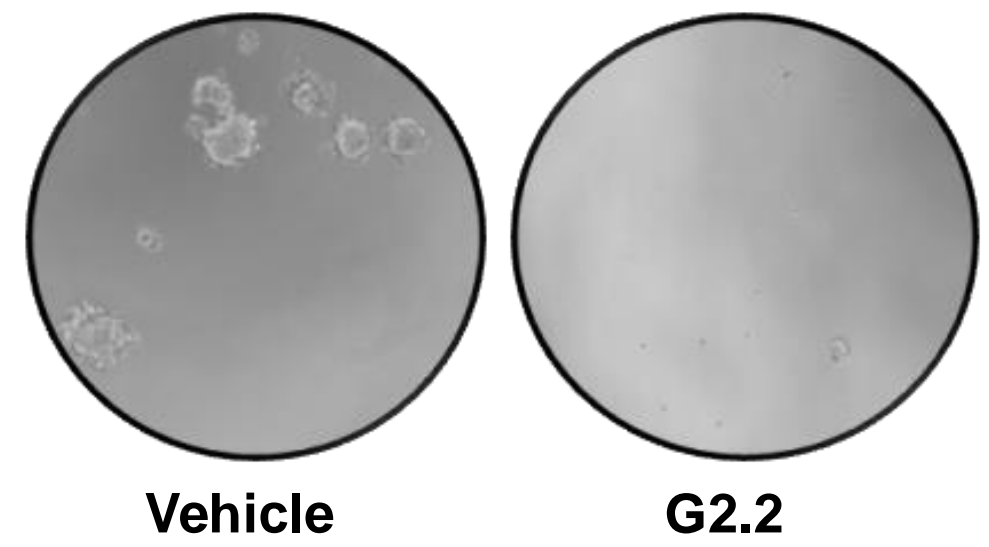

Figure S6 
Flow cytometric analysis shows inhibition of DCLK1 by G2.2, but not by G1.4
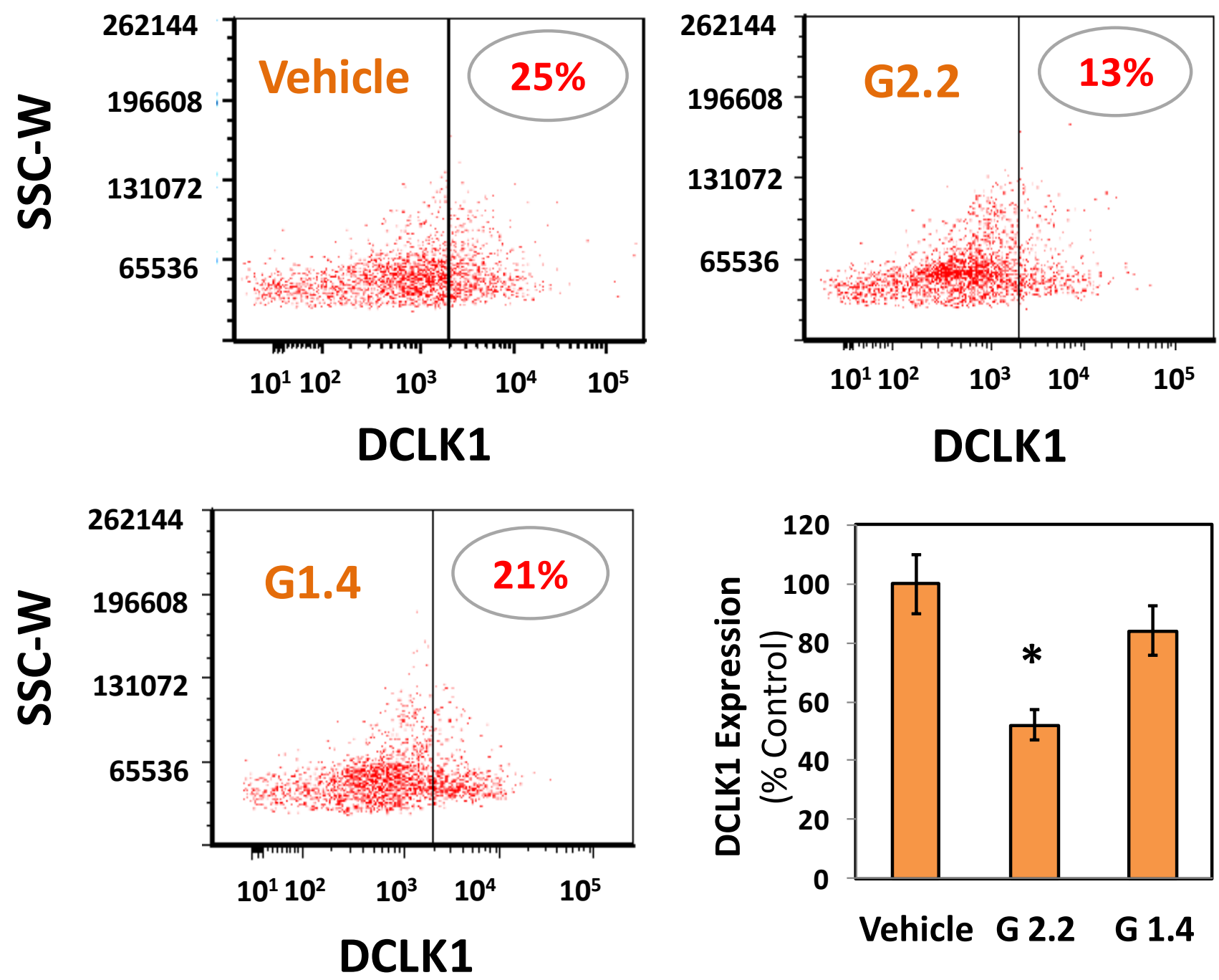

Figure S7 